\title{
Credit Migration and Covered Interest Rate Parity*
}

\author{
Gordon Y. Liao \\ First Draft: March 2016 \\ This Draft: September 2019
}

\begin{abstract}
This paper examines the joint determination of deviations in long-term covered interest rate parity and differences in the credit spread of bonds of similar risk but different currency denomination. These two pricing anomalies are highly aligned in both the time series and the cross-section of currencies. The sum of these two pricing deviations - the corporate basis - represents the currency-hedged borrowing cost difference between currency regions and explains up to a third of the variation in the aggregate corporate debt issuance flow. I show that arbitrage aimed at exploiting one type of security anomaly can give rise to the other.
\end{abstract}

Keywords: Covered interest rate parity, Credit spread, Debt issuance, Dollar convenience yield, Foreign exchange rate hedging, Corporate arbitrage, Limits of arbitrage JEL Classifications: E44, F3, F55, G12, G15, G23, G28, G32

${ }^{*}$ I am indebted to Robin Greenwood, Sam Hanson, Andrei Shleifer, and Jeremy Stein for their guidance and support. I am also grateful for comments and suggestions from Malcolm Baker, Robert Barro, Harjoat Bhamra, Vitaly Bord, John Campbell, Xavier Gabaix, Grace Gu, Victoria Ivashina, Arvind Krishnamurthy, David Lando, Yueran Ma, David Scharfstein, Jesse Schreger, Adi Sunderam, Luis Viceira, Dimitri Vayanos, and Zhenyu Wang. I thank seminar and workshop participants at Harvard, LSE, Oxford Saïd, UCLA, UC Davis, Bank of International Settlements, Federal Reserve Board, IMF, International Macro Finance Conference, Midwest Finance Conference, Stanford Institute for Theoretical Economics, SAFE Asset Pricing Workshop, Young Scholars Finance Consortium, and West Coast International Finance Workshop. I thank Vickie Chang for excellent research assistance. I am grateful for financial support from the Bradley Foundation Fellowship and Harvard Business School. The views in this paper are solely the responsibility of the author and should not be interpreted as reflecting the views of the Board of Governors of the Federal Reserve System or any other person associated with the Federal Reserve System. E-mail address: gliao@post.harvard.edu 


\section{Introduction}

Deviations from covered interest rate parity (CIP) have been persistently large since the global financial crisis (GFC) and have attracted the attention of a number of recent papers. ${ }^{1}$ While the anomaly is significant in size given the liquidity and volume of the foreign exchange rate (FX) market, research linking this pricing anomaly to the quantity of arbitrage capital and the behaviors of firms and households has been limited. This paper examines the spillover of pricing anomalies between the FX funding market and the corporate credit market as well as the impact on corporate debt issuance flow across currency regions. Using a data set covering $\$ 23$ trillion of corporate bonds, I find that variations in the relative FX-hedged borrowing costs predict firms' decision on the currency denomination of their debt. FX-hedged debt issuance flow, in turn, exerts price pressure on long-term cash CIP deviations and credit spread differentials, bundling together the two anomalies. I show, in this novel setting, that security anomaly in one market can arise as an equilibrium outcome of arbitrageur actions intended to correct anomaly in another market.

I relate my findings in three parts. First, I show large and persistent differences in the aggregated credit spreads of corporate bonds denominated in different currencies over their respective risk-free rates. These pricing differences cannot be explained by fundamentals or quanto adjustment that captures the covariance between exchange rate movement and credit default risk. Instead, the pricing difference suggests that the credit market is segmented along currency lines. Relating to previous studies that find local supply and demand shocks as important determinants of credit spreads, ${ }^{2}$ this paper is the first, to my knowledge, to show a currency denomination pricing anomaly for the aggregate corporate bond market. To measure this pricing anomaly in the aggregate, I construct a residualized credit spread for each currency that controls for bond and borrower characteristics using a large panel of bond prices.

Second, I show that residualized credit spread differentials align in direction and size with deviations from long-term covered interest rate parity in the cash market such that the overall borrowing costs with FX-hedging are largely equilibrated across currencies. CIP is a textbook no-arbitrage condition asserting that the interest rate differential between two currencies in the cash market should equal the differential between the forward and spot exchange rates. Although the CIP condition held tightly before 2008, persistent deviations appeared in the aftermath of the financial crisis. This anomaly is large given the size of the FX swap and forward market, which has an average daily turnover of $\$ 3.1$ trillion and an outstanding notional of $\$ 58$ trillion $3^{3}$

Fig. 1 shows the time series of residualized credit spread differential and long-term CIP deviation between EUR and USD. Both of these deviations were close to zero before the GFC. Since 2008, however, these spreads have been large, even in tranquil market conditions. The residualized credit spread difference between EUR- and USD-denominated bonds had reached over 70 basis points in 2016 , which is equivalent to $\$ 25$ billion, or $84 \%$ of net (12\% of

\footnotetext{
${ }^{1} \mathrm{Du}$, Tepper, and Verdelhan (2018), Sushko et al. (2016), Avdjiev et al. (2019), Rime, Schrimpf, and Syrstad (2017), Ivashina, Scharfstein, and Stein (2015), among others.

${ }^{2}$ For instance, Collin-Dufresne, Goldstein, and Martin (2001) and Huang and Huang (2012).

${ }^{3}$ Bank of International Settlements, 2016. Triennial Central Bank Survey of foreign exchange and OTC derivatives
} 
Fig. 1 Credit spread differential and CIP deviation

This figure shows the residualized credit spread differential and five-year cash CIP deviations for EURUSD. The residualized credit spread is estimated in the following cross-sectional regression at each month:

$$
S_{i t}=\alpha_{c t}+\beta_{f t}+\gamma_{m t}+\delta_{r t}+\varepsilon_{i t},
$$

where $S_{i t}$ is the credit spread at time $t$ for bond $i$ that is issued in currency $c$, by firm $f$, with maturity $m$ and rating $r$. The residualized credit spread differential between euro and dollar debt is calculated as the currency fixed effect, $\alpha_{\text {eur,t }}-\alpha_{u s d, t}$. The sample of bonds has an average maturity of five years. Vertical gray bars represent the $95 \%$ confidence interval with firm-level clustering. CIP deviation measures the difference between the inter-bank funding rate and the FX-implied funding rate in EUR. The sample is monthly from 2004:1 to 2016:9. Details of the measures' construction are discussed in Section 3 .

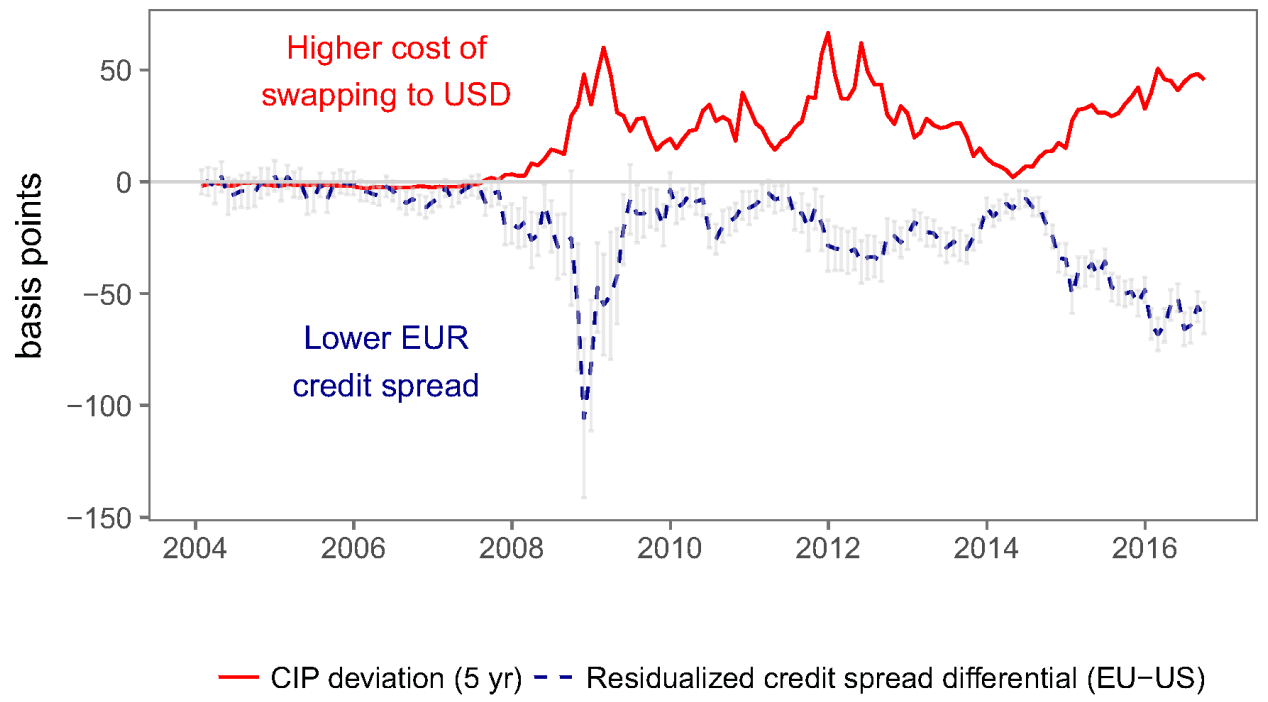

gross) annual issuance in the EUR corporate bond market. Periods in which the residualized credit spread is lower in EUR relative to USD (more negative dashed blue line) coincide with larger CIP violations in the direction of more expense to swap EUR to USD in the cash market (more positive red solid line). The two pricing disconnects share similar magnitudes and are highly correlated $(-75 \%)$. This comovement of pricing anomalies also appears in other developed country currencies (Japanese yen, JPY; UK sterling, GBP; Swiss franc, CHF; Canadian dollar, CAD; and Australian dollar, AUD).

Third, I show that debt issuance flow responds to and equilibrates the overall difference in FX-hedged borrowing cost. I refer to this FX-hedged corporate borrowing cost differential as the corporate basis, which is the sum of the CIP deviation and residualized credit spread differential. ${ }^{4}$ Fig. 2 shows that the corporate basis covaries with the aggregate debt issuance flow between the two currency regions for large global issuers. When the corporate basis is positive, the overall FX-hedged borrowing cost is cheaper in USD (red line), firms issue more in USD (blue bars) and vice versa. In equilibrium, the corporate basis is kept small by

\footnotetext{
${ }^{4}$ Section 2 presents this decomposition.
} 
Fig. 2 Corporate basis and issuance flow

This figure shows the corporate basis and the bilateral debt issuance flow between the European Monetary Union (EMU) and the US. The corporate basis is the FX-hedged borrowing cost differential estimated as the currency fixed effects in the cross-sectional regression $S_{i t}^{\text {FXhedged }}=$ $\alpha_{c t}+\beta_{f t}+\gamma_{m t}+\delta_{r t}+\varepsilon_{i t}$, where $S_{i t}^{F \text { Xhedged }}$ is the CIP-adjusted credit spread at time $t$ for bond $i$ that is issued in currency $c$, by firm $f$, with maturity $m$ and rating $r$. Issuance flow is defined as the amount of USD debt issued by EMU firms minus the amount of EUR debt issued by US firms scaled by the total amount of debt issuance each quarter. The sample is quarterly from 2004:Q1 to 2016:Q3. Details on the two measures are provided in Sections 4 and 6 .

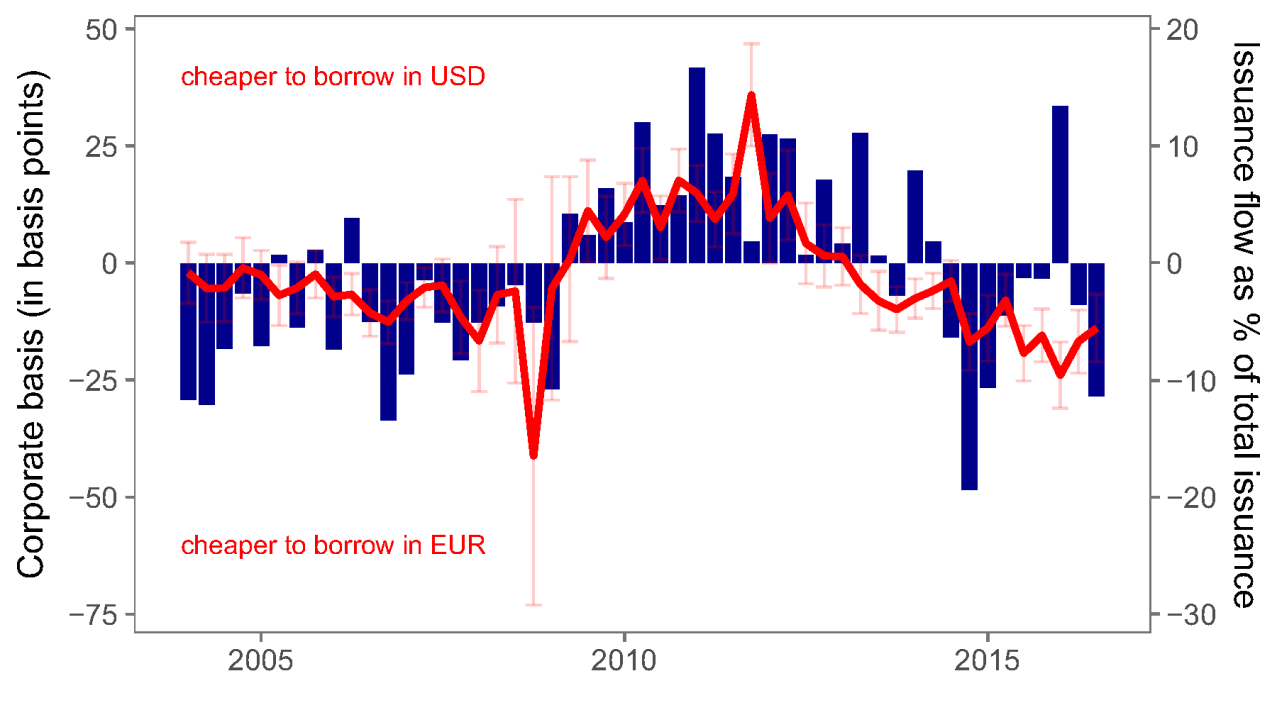

Issuance flow (EMU to US) - Corporate basis

large cross-currency issuance flow. A one standard deviation change in the corporate basis induces around a $4 \%$ shift in bilateral issuance flow (as a fraction of total issuance).

I develop a model of market segmentation to show that the reduction of either the credit spread differential or the CIP deviation necessitates arbitrageurs to engage in distorting the other. When markets are segmented, the price of risk in one market may be disconnected from those in other markets. Specialization of risk-taking contributes to market segmentation, as it has been studied in other contexts.5 The two pricing anomalies studied in this paper reflect distinct market segmentations along two dimensions - the credit market is segmented by the denomination currencies, and the CIP violation is a disconnect between the spot and forward exchange rates. The arbitrageur is risk-averse and thus desires to isolate the arbitrage spread while avoiding other risks. However, each of the two deviations serves as a short-sale constraint on the other. To take advantage of the credit spread differential, the arbitrageur needs to hedge FX risk through trading forwards or swaps. To arbitrage the cash CIP deviation, she needs to borrow and lend in different currencies using assets with

\footnotetext{
${ }^{5}$ For instance, in mortgage-backed securities (Gabaix, Krishnamurthy, and Vigneron, 2007), options (Gârleanu, Pedersen, and Poteshman, 2009), and bonds (Greenwood and Vayanos, 2014).
} 
the same fundamental risks.

Global debt issuers and investors are natural cross-market arbitrageurs, as their activities straddle the credit and FX markets. I focus on issuers for three main reasons. First, firms issue a substantial amount of cross-currency debt with FX hedge. A textual analysis of 10K filings of S\&P 500 firms indicates that around $40 \%$ of the firms have issued FX-hedged foreign debt in recent years (Section 6.1 presents this analysis). Second, firms make borrowing currency choice to cater to investors that have a strong home-currency bias. Related to this finding, Maggiori, Neiman, and Schreger (2019) show that investors have home-currency bias to such an extent that each country holds the bulk of all foreign debt securities denominated in their home currency regardless of the nationality of the issuer. Third, firms are natural cross-market arbitrageurs that can overcome limits of arbitrage problems, as shown in previous studies under other settings. ${ }^{6}$

What might be drivers of the two deviations in the first place? Local credit market shocks could emanate from quantitative easing (such as European Central Bank (ECB) corporate bond purchase), liability-driven investments (e.g., pension fund benchmark changes),7, and credit sentiments. 8 FX hedging demand shocks unrelated to debt could arise from bank funding shocks, ${ }^{9}$ regulatory changes, ${ }^{10}$ and structured products. The model presented in this paper highlights that shocks to either the credit market or the FX-hedging market are transmitted from one to the other through currency-hedged debt flows.

Additional empirical analyses support the model predictions. First, a counterintuitive implication of the model, which also appears in the data, is that the corporate basis is small even when deviations in both CIP and credit are large individually. Second, cross-currency issuance flow covaries with the corporate basis in predictable directions at the aggregate and the firm level. Third, large cross-currency debt issuances have a direct price impact on CIP deviations. Fourth, exogenous increases in total bond issuance, instrumented by the rollover of maturing debt, serve as increases in arbitrage capital that align the two deviations closer and reduce the corporate basis.

Violations of the law of one price (LOOP) have been found in various corners of the financial market. The typical explanation involves limits of arbitrage arguments that follow from the seminal work of Shleifer and Vishny (1997). Many important papers have contributed to the understanding of LOOP violation and arbitrage constraints: Kyle and Xiong (2001), Gromb and Vayanos (2002, 2018), Brunnermeier and Pedersen (2009), Gârleanu and Pedersen (2011), and He and Krishnamurthy (2013). The act of arbitrage can also endogenously determine the equilibrium risk of financial assets and transform alphas into betas (Cho, 2019). This paper contributes to the study of arbitrage by showing that LOOP violations in one market can arise as an equilibrium outcome of arbitrageur actions intended to correct violations in another market.

\footnotetext{
${ }^{6}$ For example, Baker and Wurgler (2000), Baker, Foley, and Wurgler (2009), Greenwood, Hanson, and Stein (2010), and Ma (2019).

${ }^{7}$ Greenwood and Vayanos (2010) and Greenwood and Vissing-Jorgensen (2018)

${ }^{8}$ Studies on credit sentiments include López-Salido, Zakrajšek and Stein (2017), Bordalo, Gennaioli, and Shleifer (2018), Greenwood, Hanson, and Jin (2019), and Greenwood and Hanson (2013).

${ }^{9}$ Ivashina, Scharfstein, and Stein (2015) show wholesale dollar funding shocks that led to European banks to substitution wholesale funding with FX-swapped funding during 2011-2012.

${ }^{10}$ Such as the US money market fund reform (Anderson, Du, and Schlusche, 2019).
} 
This study relates to papers on international portfolio holdings, borrowings, and exchange rates. The findings of credit market segmentation and issuers reaching across currency boundaries to cater to investor demand echo the results of investor home-currency bias (Maggiori, Neiman, and Schreger, 2019; Burger, Warnock and Warnock, 2018). The influence of debt issuance flows on the CIP deviation resonates with the theory of exchange rate determination that emphasizes capital flow in imperfect financial markets (Gabaix and Maggiori, 2015). Other works have examined local versus foreign currency borrowing by firms in different contexts, often without currency hedging (Bruno and Shin, 2014, 2017; Gozzi et al. 2015; Hale, Jones, and Spiegel, 2016). My result on corporate issuance flow being sensitive to the corporate basis at the aggregate level also expands upon the message by McBrady and Schill (2007), who find an opportunistic motive for foreign currency borrowing by sovereign government and agency issuers.

The CIP condition at the short and long maturities has been empirically validated in several early papers. ${ }^{11}$ A set of papers also examined short-term CIP violations during the financial crisis. ${ }^{12}$ The general conclusion from earlier work is that any CIP violations were short-lived before and during the financial crisis. My finding of FX-hedged corporate bond pricing differences parallels studies that examine sovereign bond pricing differences in currencies of different denominations ${ }^{13}$ The result that the corporate basis is relatively small in comparison to CIP deviation based on interbank funding rates accords with the findings of Rime, Schrimpf, and Syrstad (2017) that CIP holds well for most potential arbitrageurs when applying their marginal funding rates.

More closely related to this paper are Ivashina, Scharfstein, and Stein (2015), Du, Tepper, and Verdelhan (2018), and Sushko et al. (2016). Ivashina, Scharfstein, and Stein (2015) examine USD funding and lending behaviors of European banks during the eurozone sovereign crisis and explore how the shrinkage of wholesale USD funding compelled banks to swap their EUR funding into USD, which in turn generated CIP violations and affected lending. ${ }^{14}$ Du, Tepper, and Verdelhan (2018) study persistent deviations from CIP in recent periods and propose an explanation relating to bank regulatory costs that lead to large quarterend spikes in deviations. Sushko et al. (2016) examine the role of hedging demands and costly balance sheets in the determination of CIP violations. Relative to these papers, this study contributes in explaining the joint determination of both long-term CIP violations and credit spread disconnect in different denomination currencies - the two deviations need to be considered jointly in formulating an explanation for the equilibrium prices and debt capital flows.

This paper also contributes to the understanding of the US Treasury basis or "conve-

\footnotetext{
${ }^{11}$ Frenkel and Levich (1975, 1977), Dooley and Isard (1980), Popper (1993), and Fletcher and Taylor (1996).

${ }^{12}$ Baba, Packer, and Nagano (2008), Coffey, Hrung, and Sarkar (2009), Griffoli and Ranaldo (2011) and Levich (2012).

${ }^{13}$ Buraschi, Sener, and Menguturk (2015) explore the relative pricing of emerging market sovereign bonds issued in USD and EUR during the 2007-2008 financial crisis. Du and Schreger (2016) study emerging market sovereign credit risk by synthetically creating local currency risk-free rates using currency swaps. Corradin and Rodriguez-Moreno (2016) compare a small matched sample of European sovereign bonds issued in both EUR and USD and study the effect of ECB collateral and liquidity factors.

${ }^{14}$ Bräuning and Ivashina (2016) further explore the role of monetary policy in affecting funding sources of global banks and the use of FX hedges.
} 
nience yield" over other sovereign yields examined in recent studies 15 Using bonds from the same issuer but denominated in multiple currencies, this paper disentangles the currency effect from the entity effect in comparing currency-hedged yield differentials. The analysis suggests that most of the US government borrowing cost advantage relative to other developed countries is attributed to the specialness of the US dollar rather than the specialness of US Treasurys. The borrowing cost advantage in the dollar relative to other currencies is the largest for bonds that are high-grade and short-maturity, characteristics that resemble safeness.

\section{Credit spread, CIP deviation, and corporate basis}

To facilitate discussions, I define the corporate basis in relation to the credit spread differential and the CIP deviation based on the risk-free rates. Let $y_{t}^{€}$ and $y_{t}^{\$}$ be risky bond yields in the respective currencies and $f_{t}$ and $s_{t}$ be the forward and spot (log) exchange rate quoted in dollar per euro. For simplicity, we work with short-term interest rates and suppress terms indicating maturity. Corporate basis $\Psi_{t}$ is the FX-hedged bond yield difference between bonds denominated in the EUR and the USD:

$$
\Psi_{t} \equiv \underbrace{\left(y_{t}^{€}-y_{t}^{\$}\right)}_{\text {risky yield diff. }}+\underbrace{\left(f_{t}-s_{t}\right)}_{\text {forward premium }}
$$

Adding and subtracting the risk-free rates, $r_{t}^{€}$ and $r_{t}^{\$}, \Psi_{t}$ can be rewritten as

$$
\Psi_{t}=\underbrace{\left[\left(y_{t}^{€}-r_{t}^{€}\right)-\left(y_{t}^{\$}-r_{t}^{\$}\right)\right]}_{\begin{array}{c}
\kappa_{t}, \text { credit spread differential } \\
\text { over the respective risk-free rate }
\end{array}}+\underbrace{\left[r_{t}^{€}-r_{t}^{\$}+\left(f_{t}-s_{t}\right)\right]}_{\begin{array}{c}
x_{t}, \text { CIP deviation for } \\
\text { risk-free rates }
\end{array}} .
$$

Therefore, corporate basis $\Psi_{t}$ can be decomposed into credit spread differential $\kappa_{t}$ and cash CIP deviation based on risk-free rates $x_{t} . \Psi_{t}$ can also be loosely interpreted as CIP deviation on corporate yields.

If the global credit market is relatively efficient in equalizing the FX-hedged bond yields (if $\left|\Psi_{t}\right|$ is small), shocks to $x_{t}$ would be offset by movements in $\kappa_{t}$ and vice versa. This intuition is examined throughout this paper, which proceeds as follows. Section 3 measures $\kappa_{t}$ empirically, using bond yield spreads adjusted for differences in bond characteristics. This section also presents the stylized facts that $\kappa_{t}$ varies significantly across time and currencies and $\kappa_{t}$ and $x_{t}$ are highly aligned in offsetting each other. Section 4 studies the corporate basis $\Psi_{t}$, its heterogeneity across different bond characteristics, and its relation to the Treasury basis that recent literature has used to measure convenience yield. Section 5 provides a

\footnotetext{
${ }^{15} \mathrm{Du}, \mathrm{Im}$, and Schreger (2018) calculate a Treasury basis, also referred to as convenience yield, associated with holding US Treasurys over other developed country government bonds when swapped into dollars. Jiang, Krishnamurthy, and Lustig (2018) develop a model of safe asset demand that generates comovement between the convenience yield and the dollar exchange rate. Avdjiev et al. (2019) show that the dollar is a key barometer of risk-taking capacity that underpins the relationship between deviation from CIP and cross-border bank lending in the dollar. Jiang, Krishnamurthy, and Lustig (2019) rationalize the outsize impact of the dollar on the global financial cycle in the context of dollar safety demand.
} 
model that determines $\kappa_{t}$ and $x_{t}$ in equilibrium with cross-currency debt issuance flow. This is followed by a discussion of firms as arbitrageurs and further empirical tests of model predictions in Section 6 .

\section{$3 \quad$ Residualized credit spread differentials}

This section develops a measure of the aggregated credit spread differential for bonds denominated in different currencies. The ideal experiment is to find pairs of identical bonds (same issuer, maturity, etc.) that differ only in currency denomination. ${ }^{16}$ Since few bonds are perfectly alike, this approach would result in a small sample that might not be representative of the aggregate bond market. To study the aggregate difference in credit spread, I use a regression approach to estimate the currency effect while controlling for other bond characteristics.

\subsection{Data}

Yields on individual bonds are obtained from Bloomberg and bond attributes are from the Financial Securities Data Company (SDC) Platinum Global New Issues data set and Moody's Default and Recovery Database. The sample data contain more than 35,000 corporate bonds in seven major funding currencies (USD, EUR, GBP, JPY, AUD, CHF, and CAD) from 2004 to 2016. The selection of bonds is as exhaustive as possible and includes all fixed-coupon, noncallable, bullet corporate bonds with outstanding amounts of at least $\$ 50$ million and original maturities of at least one year. ${ }^{17}$ The total notional of the data set is $\$ 23$ trillion, and the outstanding notional as of June 2016 is $\$ 12$ trillion. These bonds were issued by more than 3,800 entities, including supranationals (such as the World Bank) and sovereign agencies (such as state-owned bank ${ }^{18}$ that are generally considered a part of the corporate bond market. I use the yield spread against the London Inter-bank Offered Rate (LIBOR) swap curve to measure credit spread. An alternate measure using the yield spread against the overnight index swap curve (e.g., swaps based on EONIA and effective federal funds rates) generates similar residualized credit spread differential (since the termed LIBOR-OIS spreads in different currencies are mostly netted out). Details of the data sample and a descriptive summary of the bond data are presented in the Appendix.

\footnotetext{
${ }^{16}$ As an example, AT\&T, the BBB-rated and US-based telecommunication giant, had a credit spread of 203 basis points on its 15-year US dollar-denominated bond in November 2014. At the same time, its eurodenominated bond of similar maturity had a credit spread of 129 basis points. The two bonds share the same rating, maturity, seniority, and jurisdiction.

${ }^{17}$ Securities with a remaining maturity of less than one year or $10 \%$ of original maturity are excluded from the sample, as liquidity tends to be poor and pricing observations are often missing. Excluding debt of less than one year also effectively rules out short-term funding instruments such as commercial paper.

${ }^{18}$ Mortgage-backed agency bonds are excluded.
} 


\subsection{Matrix pricing of corporate credit}

To assess the impact of denomination currency on the pricing of credit risk, I estimate the following cross-sectional regression separately at each date 19

$$
S_{i t}=\alpha_{c t}+\beta_{f t}+\gamma_{m t}+\delta_{r t}+\varepsilon_{i t},
$$

where $S_{i t}$ is the credit spread for bond $i$ traded in the secondary market at time $t . \alpha_{c t}, \beta_{f t}$, $\gamma_{m t}$, and $\delta_{r t}$ are fixed effect estimates for currency $c$, firm $f$, maturity bucket ${ }^{20} m$, and rating bucket $r$, respectively, at date $t$. The firm fixed effect is particularly important because it controls for other bond characteristics that are present at the firm level. The data sample is limited only to bonds belonging to multicurrency issuers. The currency fixed effect $\alpha_{c t}$ thus measures the residualized credit spread for bonds denominated in currency $c$. This method of attribution is analogous to the standard industry practice of matrix pricing in which a bond with unknown prices is assessed against other bonds with similar maturity and rating. The residualized credit spread differential between currency $c$ and USD is denoted as $\kappa_{c, t}$ and is estimated as $\kappa_{c, t}=\alpha_{c t}-\alpha_{U S D t} \cdot{ }^{21}$

Fig. 3 presents time series of $\kappa_{c, t}$ estimated at the end of each month for EUR, GBP, JPY, AUD, CAD, and CHF relative to USD. The currency fixed effect coefficients are estimated with relative precision given the large sample size (median number of observations each month: 5,504). The median firm-clustered standard error on the currency fixed effects is 3.6 basis points (mean: 4.8 basis points) ${ }^{22}$ The mean and median $R$-squared are both $82 \%$. This suggests that the regression specification captures most of the variation in bond pricing.

The credit spread differentials were small from 2004 to 2007 but increased significantly during the GFC. Foreign credit spreads tightened considerably relative to the dollar credit spread during the crisis period. In particular, EUR and JPY credit spread differentials reached deviations beyond negative 100 basis points during the peak of the crisis. The deviations briefly reversed after the crisis. However, since 2010, the credit spread differentials have widened again. In the cross-section, the spread differentials for each market have been persistent in both sign and relative magnitude. JPY credit (purple) has been the cheapest to borrow (negative spread differential) relative to USD credit, and AUD credit (red) has been the most expensive to borrow (positive differential). Against the backdrop of more aggressive

${ }^{19}$ The equivalent panel regression approach estimates the following

$$
S_{i t}=\gamma+\sum_{c \neq U S D} \alpha_{c} D_{c i}+\sum_{t} \tau_{t} D_{t i}+\sum_{c} \sum_{t} \delta_{c t}\left(D_{c i} D_{t i}\right)+\mathbf{X}_{\mathbf{i t}}^{\prime} \beta+\varepsilon_{i t},
$$

where $D_{c i}$ and $D_{t i}$ are dummies for currency $c$ and time $t$, respectively, $X_{i t}$ is a list of controls including firm, rating, maturity fixed effects, and the associated interaction terms with date. The residualized credit spread difference can be obtained by $\kappa_{c t}=E\left[S_{i t} \mid c, t, \mathbf{X}_{\mathbf{i t}}\right]-E\left[S_{i t} \mid c=\mathrm{USD}, t, \mathbf{X}_{\mathbf{i t}}\right]=\alpha_{c}+\tau_{t}+\delta_{c t}$. The large number of interactions, especially due to firm-time fixed effects, introduces computational challenges. The standard errors are improved in the panel regression.

${ }^{20}$ The maturity of the bond at each pricing date $t$ is categorized into four buckets (one to three years, three to seven years, seven to ten years, and beyond ten years). Alternative specification that includes maturity as a linear control is also tested and produces similar results.

${ }^{21}$ In the currency fixed effects, the dummy variable associated with the dollar is omitted. Therefore, the coefficient estimates on other currency dummies are directly interpreted as estimates of the differential.

${ }^{22}$ Confidence intervals constructed with firm-clustered standard errors are presented in Fig. 5 . 
Fig. 3 Residualized credit spread differential

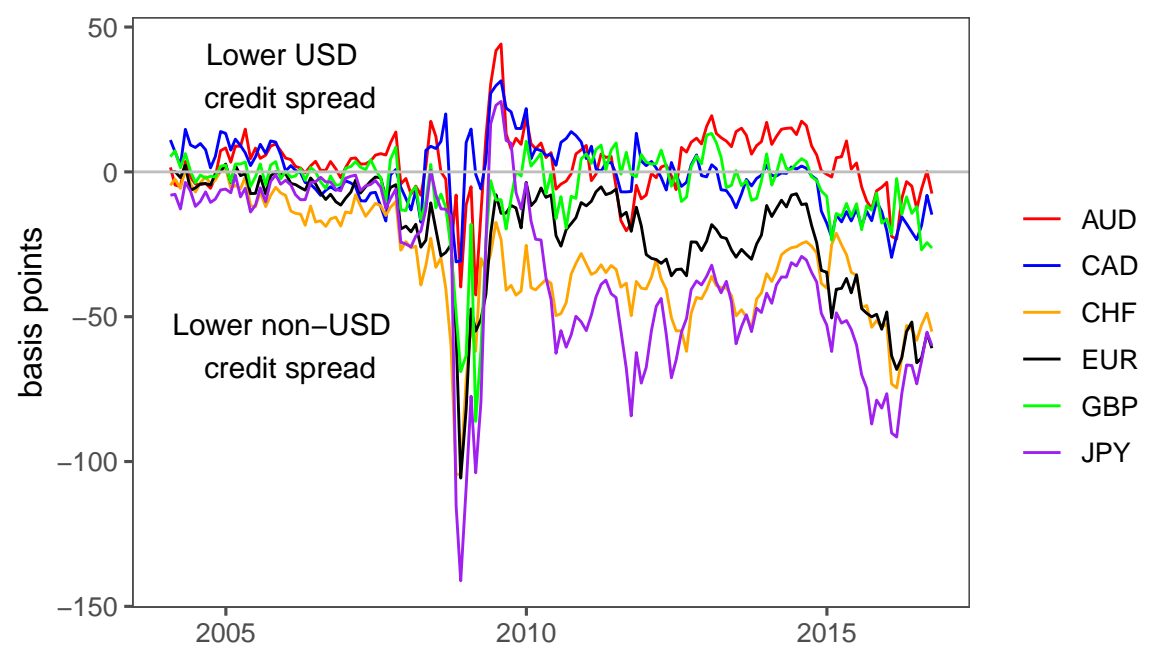

This figure presents the residualized credit spreads relative to the dollar credit spread $\kappa_{c, t}$ for $c \in\{A U D, C A D, C H F, E U R, G B P, J P Y\} . \kappa_{c, t}$ is estimated as $\alpha_{c, t}-\alpha_{U S D, t}$ from the following cross-sectional regression, $S_{i t}=\alpha_{c t}+\beta_{f t}+\gamma_{m t}+\delta_{r t}+\varepsilon_{i t}$, where $S_{i t}$ is the credit spread at time $t$ for bond $i$ that is issued in currency $c$, by firm $f$, with maturity $m$ and rating $r$. The sample is monthly from 2004:1 to 2016:9.

ECB QE, the EUR credit spread differential (black) trended more negatively starting in 2014 and had reached negative 70 basis points in 2016.

\subsection{Additional controls}

I conduct a number of robustness checks of the estimation of the residualized credit spread differential. In addition to the bond-level covariates and firm fixed effects in Eq. 3, I augment the regression specification with additional controls - amount outstanding, bond age relative to initial maturity, seniority, and governance law. The first two controls serve as liquidity proxies. Larger bond issuance size and newly issued bonds are known to be more liquid. On-the-run bonds, or newly issued bonds, have a premium when compared to off-the-run bonds of similar maturities (Krishnamurthy, 2002). To capture this effect, a control for bond age, defined as the ratio of remaining maturity to initial maturity, is also included. I also control for the governing law of bonds. Kim and Stulz (1988) find positive abnormal returns associated with issues in the Eurobond market, which refers to the offshore market that has less regulatory oversight (not to be confused with the currency denomination of the bond). Additionally, I control for bond seniority (e.g., senior secured, unsecured, subordinate, etc.), which I obtain from Moody's Default and Recovery Database.

These controls make little difference in the residualized credit spread differentials (comparison provided in the Appendix). This is unsurprising because other unobserved bond attributes should not affect the aggregate residualized credit spread differential, as they are likely idiosyncratic in nature. One notable piece of supportive evidence is that $\kappa_{c, t}$ were 
small before the GFC. It is unlikely that the bond-specific unobservables only begin to vary systematically across currencies after the GFC. Since many bonds have missing values for the additional controls (especially for bonds not denominated in USD and EUR), the baseline specification is used throughout the text to maintain the most comprehensive sample.

Another potential concern is that the aggregate credit rating varies significantly across different currency-segmented bond markets. That is, if all EUR-denominated bonds are triple-A rated while all USD-denominated bonds are single-A rated, then the currency and rating fixed effects would be multicollinear. Under this scenario, the residualized credit spread differential might pick up the difference between triple-A bonds and single-A bonds, rather than a difference due to currency denomination. This concern is addressed in two ways. First, the data sample on each date is limited to only to bonds that are issued by entities that have debt outstanding in at least one other currency. This filtering reduces the concern above since bonds issued by the same firm generally have similar credit ratings. Second, a further robustness check splits the sample for high- and low-grade bonds (presented in the Appendix). The residualized credit spread differential persists in the subsamples.

\subsection{Covariance of debt repayment and FX return}

One potential concern is that the covariance of debt default and currency depreciation can affect the residualized corporate credit spread differential. This default-deprecation covariance, sometimes referred to as the quanto adjustment, has been studied in the sovereign debt context by papers including Buraschi, Sener, and Menguturk (2015), Du and Schreger (2016), Augustin, Chernov, and Song (2018), and Lando and Nielsen (2018). ${ }^{23}$ In contrast to sovereign defaults that often indicate economic malaise at the country level and thus coincide with local currency depreciation, corporate defaults are mostly idiosyncratic in nature. This section formalizes the effect of a default-depreciation covariance, and along with analysis presented in the appendix, it shows that the residualized corporate credit spread differential cannot be explained by this covariance.

Let $M_{t+1}$ and $M_{t+1}^{*}$ denote the domestic (dollar) and the foreign (euro) stochastic discount factors (SDFs). Foreign association is denoted with $*$. In a complete market, the two SDFs

are related by $M_{t+1}^{*}=M_{t+1} \frac{Q_{t+1}}{Q_{t}}$, where $Q_{t}$ is the exchange rate quoted in dollar per euro (Campbell 2017). An increase in $Q_{t}$ corresponds to an appreciation of the euro. Let $L_{t+1}$ be a random variable that denotes the default loss as a fraction of the bond face value at time $t+1$ when the bond matures. The price of a risky dollar bond is $P_{t}=\mathbb{E}\left[M_{t+1}\left(1-L_{t+1}\right)\right]$, and the price of a risky foreign bond is $P_{t}^{*}=\mathbb{E}\left[M_{t+1}^{*}\left(1-L_{t+1}^{*}\right)\right]$. Substituting in the relation between the two SDFs, the foreign bond price is

$$
P_{t}^{*}=\mathbb{E}\left[M_{t+1} \frac{Q_{t+1}}{Q_{t}}\left(1-L_{t+1}^{*}\right)\right],
$$

${ }^{23}$ These previous studies present mixed results on the effect of quanto risk on sovereign debt. Buraschi, Sener, and Menguturk (2015) conclude that the quanto effect is minimum for a set of emerging market countries in their sample from 2005 to 2010. Du and Schreger (2016) show that the quanto adjustment can explain the large persistent level differences between the local currency and foreign currency credit spreads of emerging market sovereign bonds. Augustin, Chernov, and Song (2018) find that the quanto adjustments of eurozone sovereigns were substantial during the 2011-2012 European sovereign crisis due to the risk of simultaneous EUR depreciation and bond default. 
or, equivalently,

$$
P_{t}^{*}=\mathbb{E}\left[\left(1-L_{t+1}^{*}\right)\right] \mathbb{E}\left[M_{t+1} \frac{Q_{t+1}}{Q_{t}}\right]+\operatorname{Cov}\left(\left(1-L_{t+1}^{*}\right), M_{t+1} \frac{Q_{t+1}}{Q_{t}}\right) .
$$

Thus, a positive covariance of debt repayment (default) and foreign currency appreciation (depreciation) leads to a higher foreign bond price, or a lower bond yield.

The impact of this covariance term on residualized credit spread is assessed in two ways. First, I test if systematic covariance between default risk and currency returns are priced in the currency cross-section of $\kappa_{c, t}$. The intuition is that corporate bonds in currencies with positive depreciation-default covariance should have lower credit spreads in a complete market setting as demonstrated above. Empirically, the data show the contrary, as can be observed in Fig. 3. Safe-haven currencies such as JPY and CHF typically have corporate bonds with lower credit spreads. Second, I use quanto credit default swap (CDS) contracts with payout in multiple currencies to obtain forward-looking market pricings of the defaultdepreciation covariance. This methodology has been used by a number of recent papers. ${ }^{24}$ The CDS-implied currency depreciations from corporate bonds are much smaller than those of sovereign bonds, indicating that individual firm defaults mostly reflect idiosyncratic risk unlike sovereigns. These two sets of analyses, detailed in the Appendix, show that the covariance term contributes minimally to the credit spread differential.

\subsection{Alignment of the credit spread differential and CIP deviation}

This section presents empirical evidence on the linkage between the residualized credit spread differentials and CIP deviations. The two deviations are related and potentially act as shortsale constraints on each other - distortions in the FX forward market can affect the pricing of credit risk in local currencies, and vice versa.

CIP deviation is empirically measured using a LIBOR-based cross-currency basis swap, consistent with other papers. ${ }^{25}$ A cross-currency basis swap is a bilateral market instrument that allows the market participant to simultaneously borrow in one currency and lend in another currency at the respective floating interest rates. The counterparty of the swap agrees to take on the reverse position. The currency basis is a market-determined adjustment to the reference floating cash funding rates - by convention, LIBOR. As defined in Eq. 2, $x_{t} \equiv r_{t}^{€}-r_{t}^{\$}+\left(f_{t}-s_{t}\right) . x_{t}$ is the CIP deviation, with a positive sign indicating expensiveness of swapping to the dollar, and is measured as the level of cross-currency basis swap multiplied by negative one. ${ }^{26}$

Alternatively, using overnight index swap (OIS) rates with reference to transactional short rates, such as the effective federal funds rate and the EONIA rate, produces generally similar bases. The Appendix provides a comparison. Calculating CIP deviations using FX forward and spot rates also produces similar results. Since the LIBOR-based cross-currency basis swap is the most liquid FX-hedging instrument for maturities greater than a year and

\footnotetext{
${ }^{24}$ Mano (2013), Buraschi, Sener, and Menguturk (2015), Della Corte et al. (2018), Du and Schreger (2016), Augustin, Chernov, and Song (2018), and Lando and Nielsen (2018).

${ }^{25}$ Du, Tepper, and Verdelhan, (2018); Sushko, et al. (2016); Iida, Kimura, and Sudo, (2016).

${ }^{26}$ The market convention is to quote the swap as a basis to the nondollar cash funding rate.
} 
has the most comprehensive data across maturities and currencies, I focus on this measure in the main analysis. Details of the cross-currency basis swap, its relation with forwards, and CIP violation at different maturities are discussed in the Appendix. ${ }^{27}$

Fig. 4 shows deviations from CIP at the five-year horizon for AUD, CAD, CHF, EUR, GBP, and JPY relative to the USD. The CIP condition held tightly before 2008. However, large deviations from the CIP relation appeared in the aftermath of the financial crisis and persisted through 2016. For most of the post-GFC period, it was relatively expensive to swap EUR, JPY, CHF, and GBP to USD (to buy the foreign currency against selling USD in the forward market). In contrast, AUD and CAD CIP deviations have had the opposite sign, reflecting that it was expensive to swap from USD to these currencies. Du, Tepper, and Verdelhan (2018) provide a detailed exposition of post-crisis CIP violation and show a strong quarter-end effect in short-term CIP deviation that indicates regulatory window dressing. Here, I examine CIP deviations at longer maturities that match the bond maturities.

Fig. 4 Long-term covered interest rate parity deviations

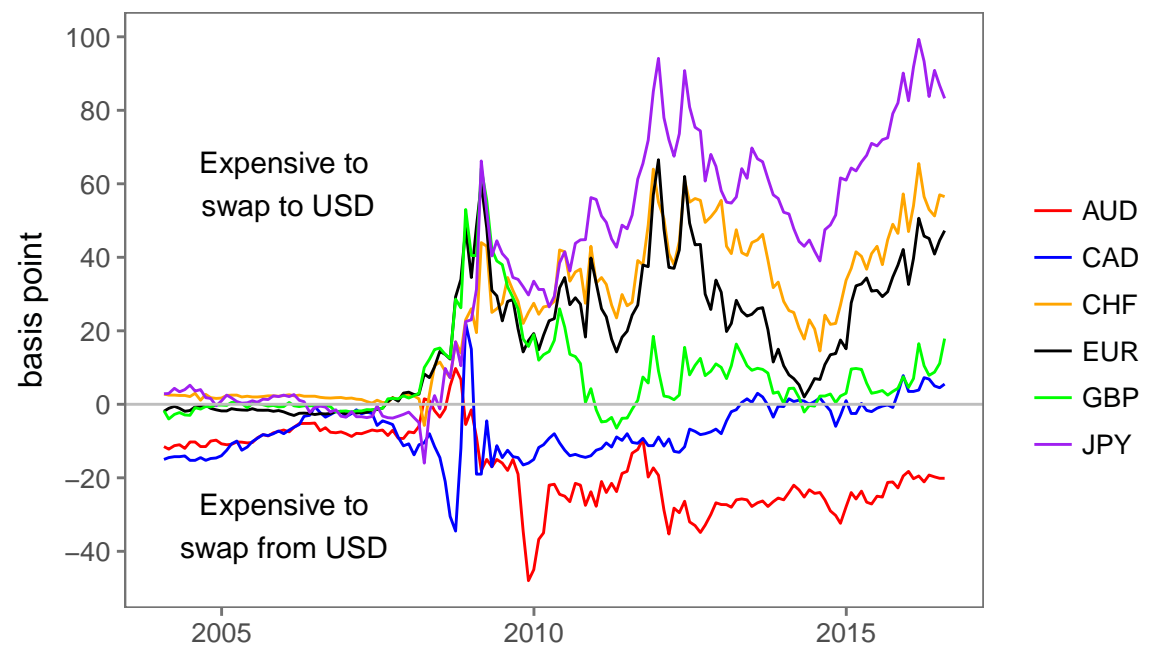

This figure presents covered interest rate parity deviations, $x_{c, t}$, at the five-year maturity for $c=\{A U D, C A D, C H F, E U R, G B P, J P Y\}$ relative to the USD. The deviations are measured using cross-currency basis swap levels and are expressed as the difference between local currency inter-bank funding rate and the FX-implied funding rate. The sample is monthly from 2004:1 to 2016:9.

CIP violations and the residualized credit spread differentials are highly aligned in the time series and the cross-section. Fig. 5 graphs the time series of credit spread differential and CIP deviations at the five-year horizon (matching the average bond maturity) for six major funding currencies relative to the USD. The time series of the two deviations match closely in magnitude and direction for each currency, especially outside of the crisis period. The correlation in the cross-section is also high. Pooling the observations across time and

\footnotetext{
${ }^{27}$ In the Appendix, I show that $T$-horizon CIP deviation $x_{t, T}$ is related to cross-currency basis swap rate $B_{T}$ by the following approximation: $x_{t, T} \approx-B_{T}\left[\sum_{\tau=1}^{T}\left(1+Z_{\tau}^{*}\right)^{-t}\right] \frac{1+Z_{T}^{*}}{T}$, where $Z_{\tau}^{*}$ denotes the foreign zero-coupon rate with maturity $\tau$.
} 
currency, the two violations have a correlation of $-81 \%$.

Fig. 5 Credit spread differential and CIP violation relative to the USD
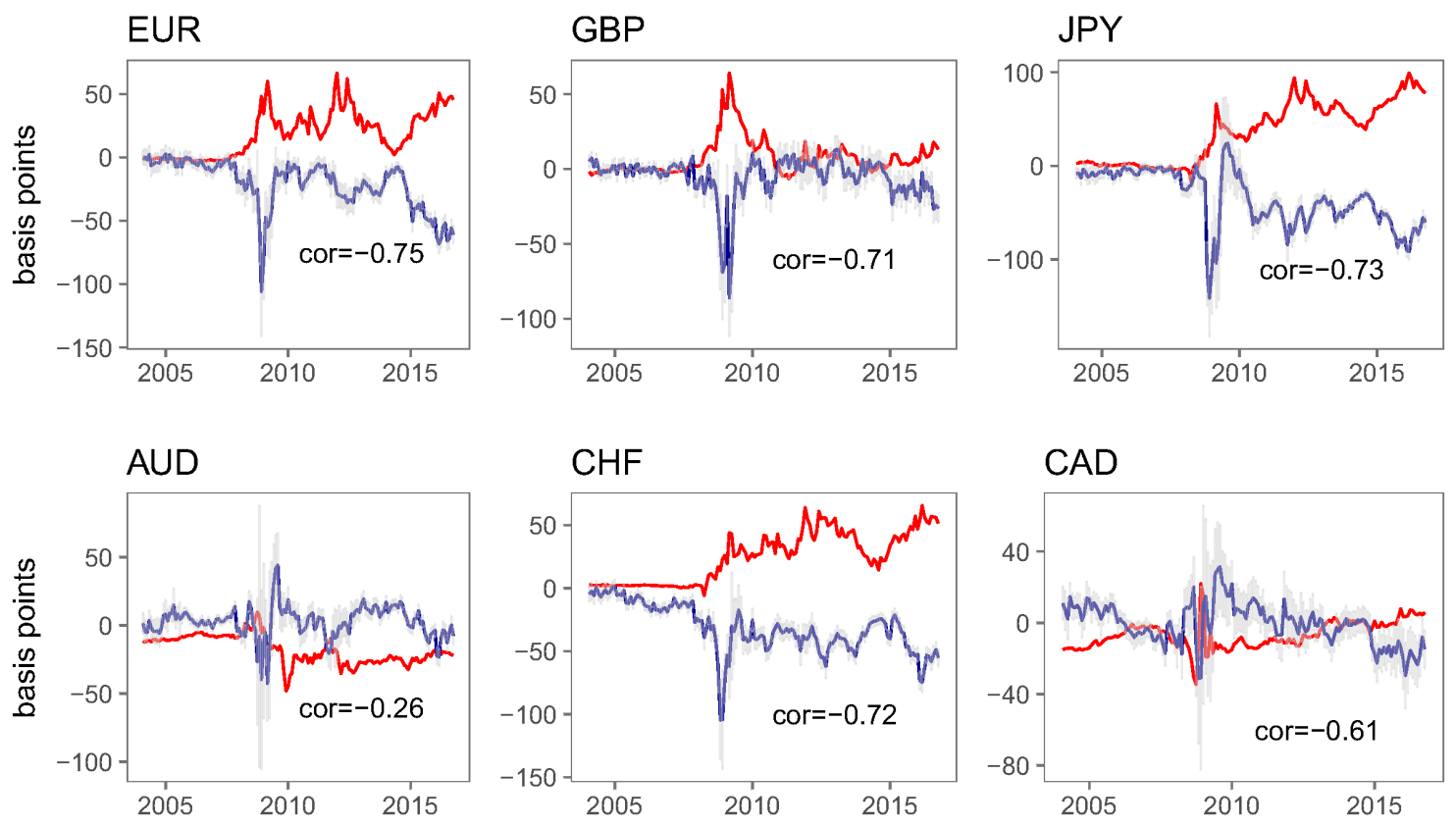

- CIP deviation (5 yr) - Residualized credit spread differential

This figure presents the residualized credit spread differentials, $\kappa_{c, t}$, and five-year CIP deviations $\left(x_{c, t}\right)$ relative to the USD for six major funding currencies

$c=\{E U R, G B P, J P Y, A U D, C H F, C A D\}$. The CIP deviations are in solid red, with positive sign indicating expensiveness to swap to USD. Credit spread differentials (foreign currency minus the US dollar) are in dashed blue. Vertical bars (gray) represent the $95 \%$ confidence interval for the estimated credit spread differentials constructed using robust standard errors clustered at the firm level. The sample is monthly from 2004:1 to 2016:9.

Fig. 6 shows a scatter plot with credit spread differential on the horizontal axis and deviation from CIP on the vertical axis. This figure highlights both the cross-sectional and time-serial correlation between the two deviations. The high correlation and high persistence in the two pricing discrepancies are striking. Japan (purple), mostly plotted in the upper left quadrant, has had positive CIP deviation and negative credit spread relative to the dollar. Australia (red), on the other hand, mostly in the bottom right, has had higher credit spread relative to the USD and negative CIP deviation - indicating cheapness to swap to USD.

Descriptive regressions further validate the statistical significance of the relationship above. Table 1 presents the relationship between the two pricing anomalies in panel and individual regressions. Most coefficients range from 0.7 to close to 1 and are highly significant. Columns 2 and 3 present regressions controlling for time and currency fixed effects. While these regressions cannot be interpreted as causal, they nonetheless demonstrate the close alignment of the two anomalies. Among the individual currencies, AUD and CAD have the weakest relation (columns 7 and 9). This fact might reflect the degree of substitutability between debt market and it is discussed later in the context of cross-currency debt issuance. 


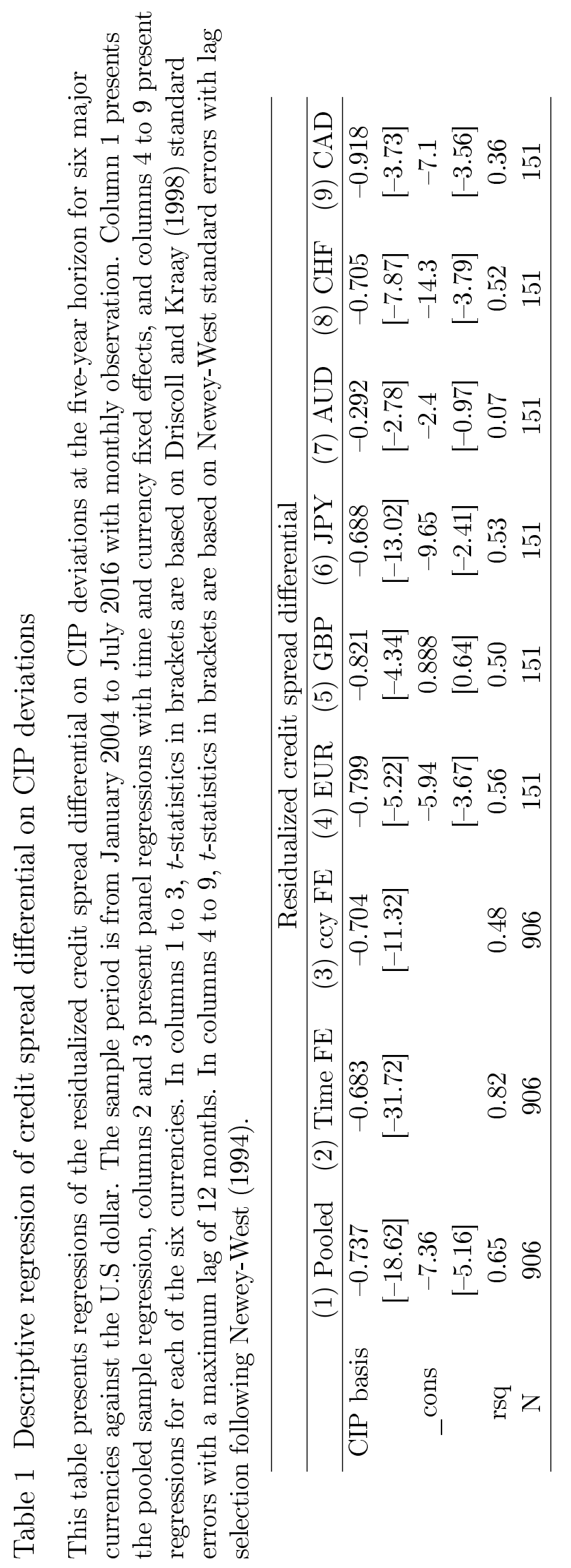


Fig. 6 Credit spread differential and CIP violation

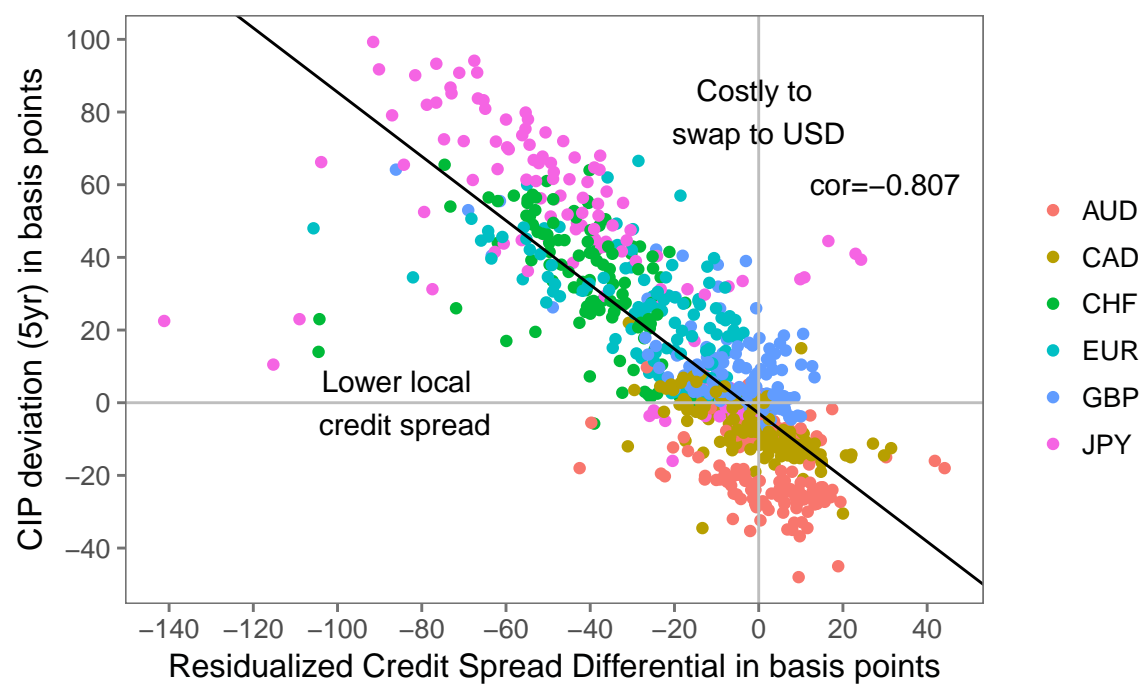

This figure presents the residualized credit spread differential $\kappa_{c, t}$ (horizontal axis) and five-year CIP deviations $x_{c, t}$ (vertical axis) for $c=\{E U R, G B P, J P Y, A U D, C H F, C A D\}$ relative to USD. Each point is an observation at the currency-month level. The sample is monthly from 2004:1 to 2016:9.

This close alignment between the two anomalies does not arise mechanically from changes in the risk-free rates. Naively taking partial derivatives on credit spread differential $\kappa$ and CIP basis $x$ with respect to the foreign funding rate $r^{*}$ would yield $\frac{\partial \kappa}{\partial r^{*}}<0$ and $\frac{\partial x}{\partial r^{*}}>0$. This is, however, not true in the data. Event studies using intraday prices around ECB policy announcements shown by Du, Tepper, and Verdelhan (2018) suggest that $x_{E U R}$ decreases when there is a positive shock to the EUR interest rate. The Appendix presents further evidence ruling out mechanical effects.

\section{Corporate bases}

To understand the overall currency-hedged yield difference between similar bonds denominated in different currencies, I examine the combined measure of the residualized credit spread differential $\kappa_{c, t}$ and the risk-free CIP deviation $x_{c, t}$. As defined earlier in Eq. 2, this combined measure is the corporate basis, $\Psi_{c, t} \equiv \kappa_{c, t}+x_{c, t}$. The corporate basis measures the incentives for firms to borrow and investors to invest in one currency relative to another. These decisions ultimately aggregate into predictable flows of debt issuance across currency boundaries, a topic that is examined in later sections.

Since the maturity of each bond is different, I calculate the corporate basis from maturitymatched $k_{c, t}$ and $x_{c, t}$ using the following procedure. I first adjust the nondollar yield curves by the corresponding CIP deviations at each maturity. I calculate each bond's CIP-adjusted

credit spreads, $S_{i t}^{F X \text { Hedged }}$, as the difference between the bond yield and the CIP-adjusted risk-free yield curve linearly interpolated to each bond's maturity. Last, I estimate a crosssectional regression similar to Eq. 3 but with $S_{i t}^{F X \text { Hedged }}$ as the dependent variable: 


$$
S_{i t}^{F X \text { Hedged }}=\alpha_{c t}+\beta_{f t}+\gamma_{m t}+\delta_{r t}+\varepsilon_{i t} .
$$

As in the case of $\kappa_{c, t}$ before, I take the currency fixed effects as estimates of the corporate bases: $\Psi_{c, t}=\alpha_{c t}-\alpha_{U S D, t}$. Empirically, the estimated $\Psi_{c, t}$ from this procedure is similar to a measure that directly subtracts the five-year CIP deviations from the residualized credit spread differentials because the average maturity of the bond portfolio is around five years.

Fig. 7 shows the corporate bases for the six currencies relative to the dollar. Corporate bases are, on average, smaller relative to the risk-free CIP deviations and credit spread differentials since $x_{c, t}$ and $k_{c, t}$ tend to offset one another. This indicates that the currencyhedged corporate bond yields are largely equalized across currencies. That is, the corporate CIP deviation available to arbitrage by firms and investors holds much better than the risk-free CIP deviation based on LIBOR or OIS rate, which might be inaccessible to many institutions.

The corporate bases were generally small except during the GFC when they were sharply negative, indicating that $\kappa_{c, t}$ had larger (more negative) spikes than $x_{c, t}$. These negative spikes potentially reflect the capping of CIP deviations when the Federal Reserve established swap lines with other central banks to alleviate strains in dollar liquidity (Goldberg, Kennedy, and Miu, 2010; McGuire and von Peter, 2012; Bahaj and Reis, 2018). In contrast, credit market distortions were exacerbated during this period by the lack of liquidity in the fixed income market. 
Fig. 7 Corporate bases
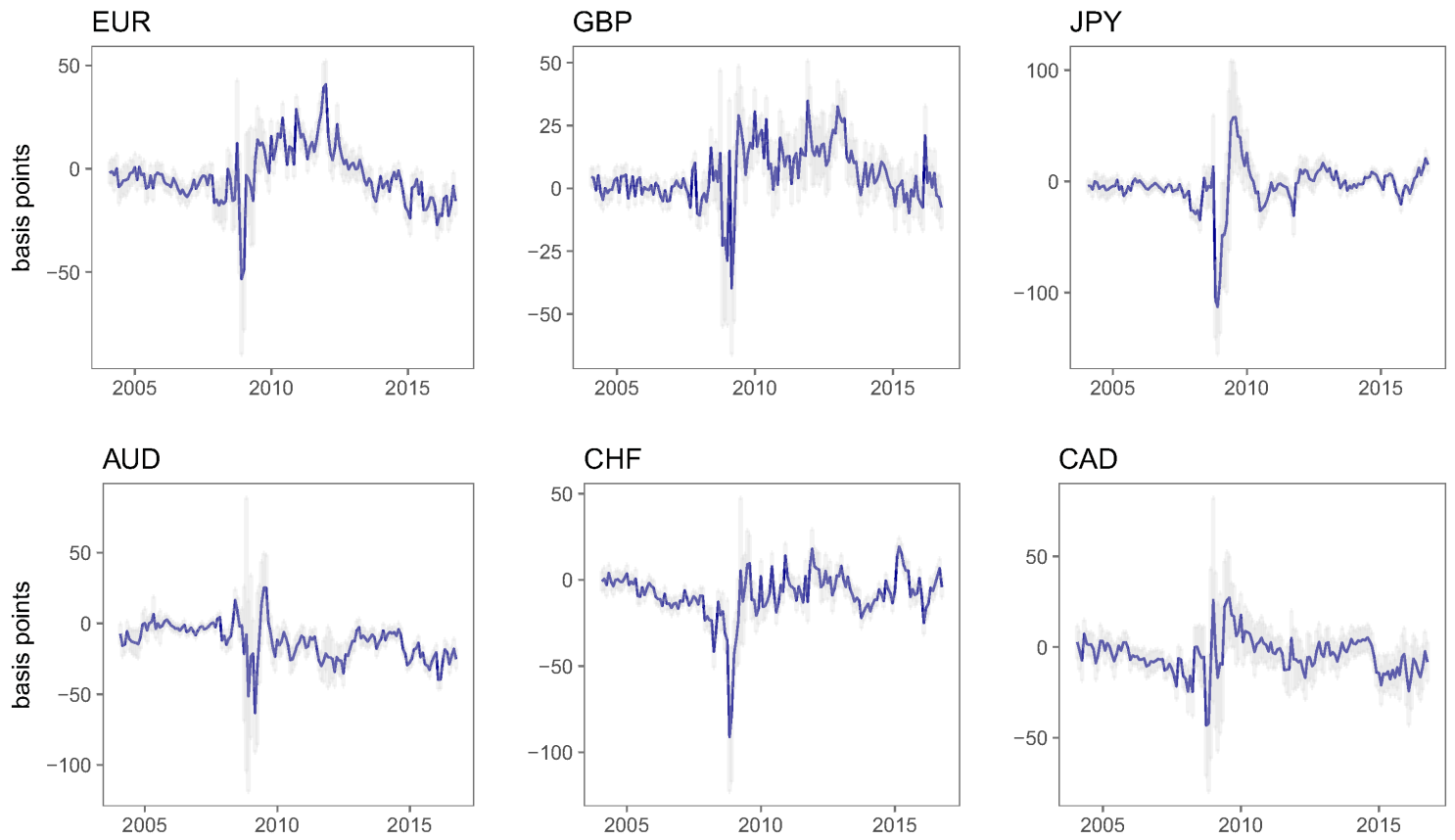

This figure presents the corporate basis $\Psi_{c, t}$ for EUR, GBP, JPY, AUD, CHF, and CAD relative to the USD. $\Psi_{c, t}$ is estimated as $\alpha_{c, t}-\alpha_{U S D, t}$ with the following cross-sectional regression, $S_{i t}^{F X \text { Hedged }}=\alpha_{c t}+\beta_{f t}+\gamma_{m t}+\delta_{r t}+\varepsilon_{i t}$, where $S_{i t}^{F X \text { Hedged }}$ is the credit spread adjusted for CIP deviation at time $t$ for bond $i$ that is issued in currency $c$, by firm $f$, with maturity $m$ and rating $r$. Vertical bars (gray) represent the $95 \%$ confidence interval with firm-level clustering. The sample is monthly from 2004:1 to $2016: 9$. 


\subsection{Heterogeneity in the subsamples}

The corporate bases in Fig. 7 are estimated on the entire sample of corporate bonds. Dissecting into different types of bonds or issuers can shed light on which segments of the market are more distorted and who might stand to benefit more from arbitrage. I limit this subsample exercise to the euro and the dollar bond markets since they are the largest in size.

Fig. 8 shows the comparison of corporate bases for different subsamples. Panel A shows the comparison of the corporate basis for financial versus nonfinancial issuers. Both types of issuers have similar magnitude and variation. This is somewhat surprising since one would expect financials to be more active in arbitraging their own borrowing cost differential and as a result might have a smaller basis. The similarity of the two sectors suggests that bonds from nonfinancials are equally well-arbitraged by either the issuers themselves or investors. Panel B compares bonds of US and non-US investors. The generally positive corporate basis for US issuers suggests that they enjoy cheaper dollar funding relative to euro funding swapped into the dollar. In contrast, non-US issuers face higher dollar funding costs - often more so than the cost of funding in euro and swapping into the dollar. This difference suggests that local issuers have home advantage in attracting local currency debt investors who might be more familiar with the issuers, and this advantage is particularly strong for the US issuers.

Panel $\mathrm{C}$ shows that high-grade bonds (AA- or better rated) typically have a positive corporate basis, translating into lower dollar yields relative to synthetic dollar yields. In comparison, low-grade bonds generally have a lower and more volatile basis. Panel D shows that bonds with shorter maturities (less than seven years) generally have a lower dollar yield relative to synthetic dollar yields. The last two comparisons combined suggest that bonds with high ratings and short maturities - two attributes commonly associated with safe assets - have a dollar funding premium (cheaper to directly borrow in the dollar).

\subsection{Comparison to Treasury basis}

The Treasury basis, calculated as the FX-hedged yield differential of developed country sovereign bonds relative to the US Treasury, has been referred to by recent studies as a measure of "convenience yield" or safety premium (Du, Im, and Schreger, 2018 and Jiang, Krishnamurthy, and Lustig, 2018). The premise for these characterizations is that excess demand for the US Treasury as a liquid, safe security causes the yields to be relatively low. Therefore, a positive Treasury basis, defined similarly as corporate basis $\Psi^{\text {sov }} \equiv k^{\text {sov }}+x$, indicates an "exorbitant privilege" of a lower borrowing cost for the US, echoing earlier papers that studied the return differentials between the US and the rest of the world (Gourinchas and Rey, 2007a,b). However, studies thus far have not separated the entity effect from the currency effect on the Treasury basis because developed market sovereigns typically only issue in their home currency. The advantage of the corporate basis is that the entity-specific effects are removed through the residualization of the bond prices of multicurrency issuers so that the corporate basis is due to currency denomination alone.

My result suggests that the treasury basis and the corporate basis share a large common component associated with dollar denomination and that the highest "convenience" appears in short-maturity, highly rated bonds. Fig. 9 presents a comparison of the treasury basis and the "safe"-high-rated, short-maturity - corporate basis. The Treasury basis is from Jiang, 
Fig. 8 Corporate bases comparisons

These figures compare corporate bases for EUR-USD in different bond subsamples. Panel A compares bonds of financial versus nonfinancial issuers. Panel $\mathrm{B}$ compares bonds of US vs non-US-based issuers. Panel $\mathrm{C}$ compares high-grade (AA- or better) versus low-grade bonds (worse than AA-). Panel D compares short-maturity (less than seven years) vs long-maturity bonds (seven years or greater). The bases are estimated following the regression method described in the text, with the adjustment that removes rating fixed effects in the regression for panel $\mathrm{C}$ and maturity fixed effects for panel D. The sample is monthly from 2004:1 to 2016:9.

A. financials vs nonfinancials

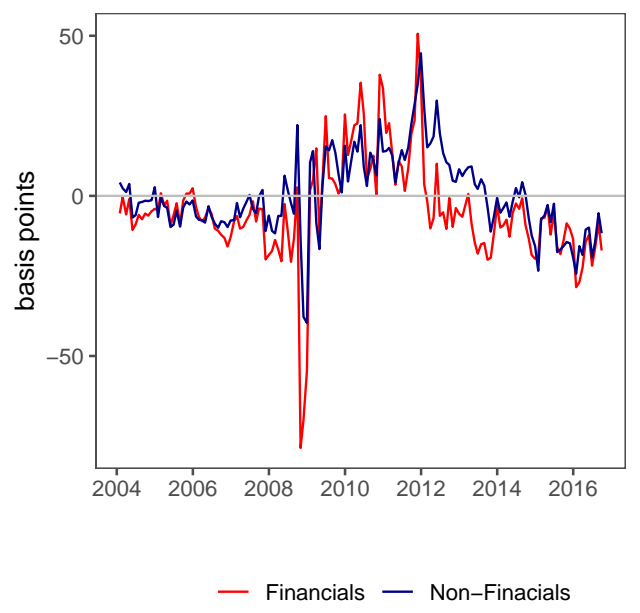

C. high vs low grade

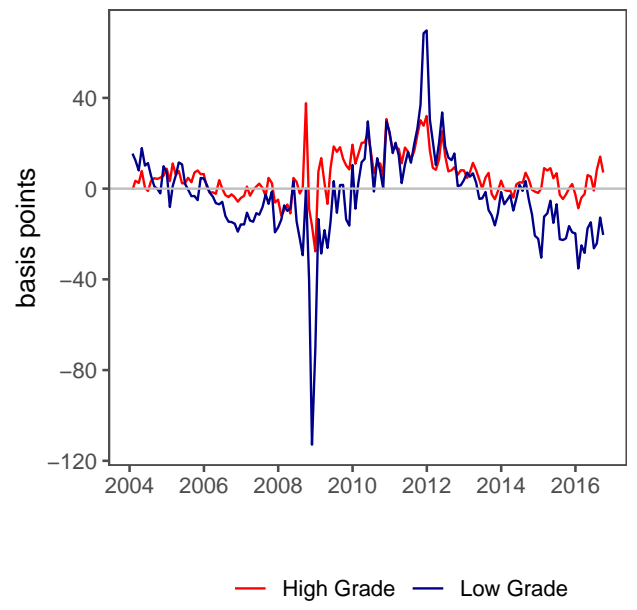

B. US vs non-US issuers

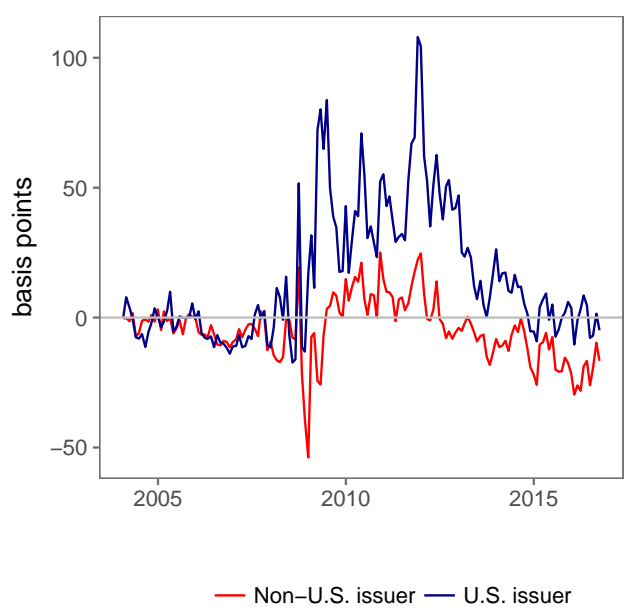

D. short vs long maturity

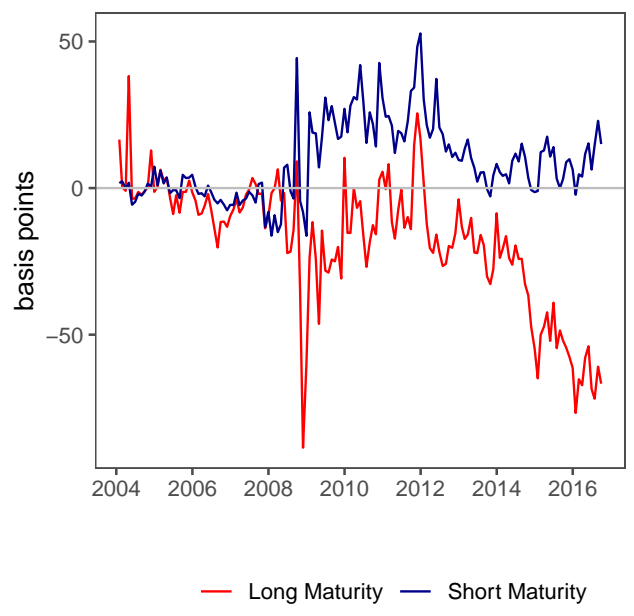


Krishnamurthy, and Lustig (2018) and is averaged across a sample of developed market sovereign bonds with a one-year constant maturity ${ }^{28}$ The corporate basis is estimated using the procedure discussed earlier on a sample of high-grade, short-maturity bonds pooling the estimation of the six currencies together relative to the dollar ${ }^{29}$ The two types of bases are highly correlated and positive throughout most of the sample period, indicating a relative cheapness of borrowing in the dollar. The gray shading plots the one-year LIBOR CIP deviation averaged over the six currencies. The CIP deviation appears to be a common component of both the Treasury and corporate bases in the post-GFC period. This is unsurprising since the definitions for both bases can be decomposed into a CIP deviation component $(x)$ and a credit risk component $\left(\kappa^{c o r p}\right.$ or $\left.\kappa^{s o v}\right)$. Yet, it is worth highlighting that the credit component is meaningful in generating heterogeneity in the Treasury and corporate bases.

The Treasury basis is, on average, higher than the corporate bases, which indicates relatively more safety or convenience under safe asset demand theories. Interestingly, the Treasury basis was also large and positive before the GFC, whereas the corporate bases were smaller; neither can be explained by CIP deviations that were close to zero and slightly negative. The 1-3Y corporate basis estimated with bonds with the highest credit ratings is on average the next highest and aligns well with the Treasury basis. The 1-7Y corporate basis estimated from a larger range of maturity and credit ratings shows a lower premium, on average. This result is in line with the finding from Du, Im, and Schreger (2018) that the term structure of the Treasury basis has been downward-sloping in recent years.

\footnotetext{
${ }^{28} \mathrm{Du}$, Im, and Schreger (2018) calculate equivalent convenience yields for a large number of countries at different maturities.

${ }^{29}$ Specifically, the estimate is of an indicator variable for dollar denomination with other currencies classified together as nondollar.
} 
Fig. 9 Treasury and corporate bases

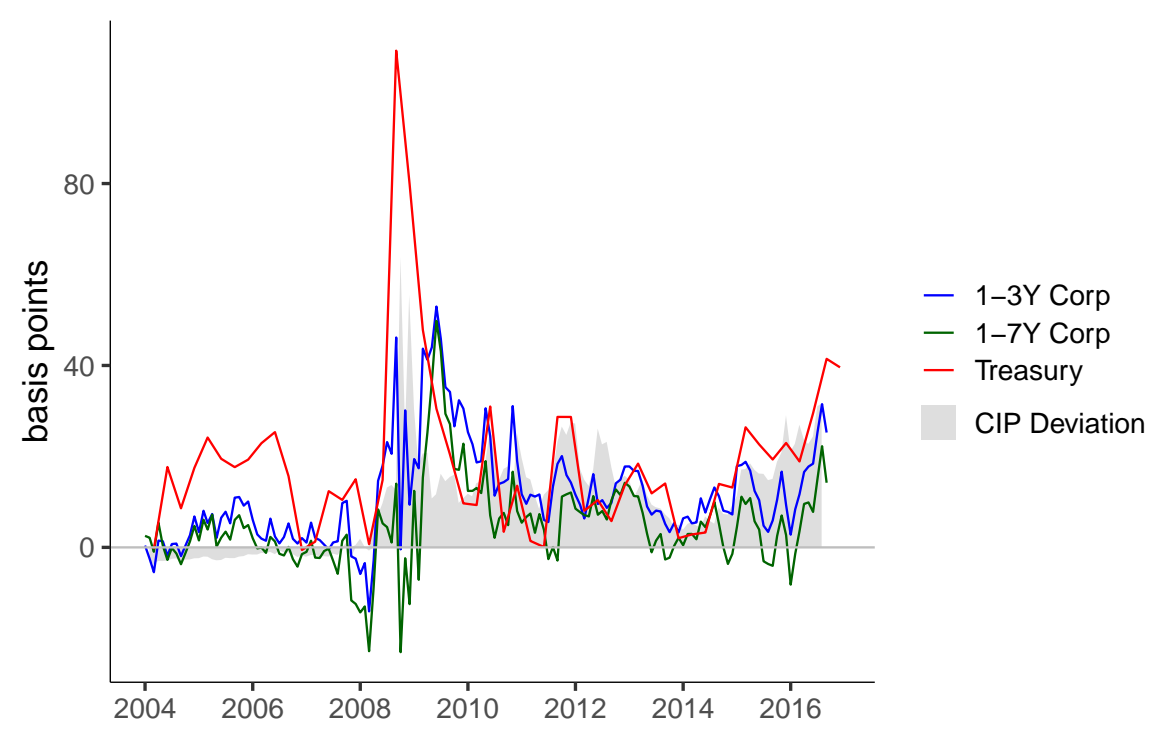

The Treasury basis is the spread between one-year foreign government bond yields swapped into dollars and US Treasury bonds. The 1-3Y corporate basis is estimated from bonds with credit ratings from AA- to AAA and maturities of 1 to 3 years. The 1-7Y corporate basis is estimated from bonds with credit ratings from BBB- to AAA and maturities from one to seven years. Foreign in both cases is a sample of developed economies. The LIBOR CIP deviation is of one-year maturity and is averaged over six currencies against the dollar. The sample is monthly from 2004:1 to 2016:9. 


\section{A model of aligned deviations in credit and FX markets}

The frictionless benchmark presented in Section 3.4 shows that in the absence of quanto risk, the same debt obligations in different currencies should have the same credit spread. The existence of a nonzero residualized credit spread differential $\kappa$ suggests that markets are incomplete. The empirical evidence also motivates a theory that links $\kappa$ to CIP deviation $x$.

In this section, I present a model that explains the high degree of alignment between $k$ and $x$, as well as their relation to cross-currency debt issuance flow. We take market segmentation as given in a setup similar to Gromb and Vayanos (2002). There are two risky assets - a bond denominated in the euro and a bond denominated in the dollar. The markets for these two assets are segmented in that EMU investors can only invest in the euro-denominated risky bond and riskless asset, and US investors can only invest in the dollar-denominated bond and riskless asset.

Additionally, there are cross-market arbitrageurs who can trade in both markets. The cross-market arbitrageur is an issuer that sells debt, although this arbitrageur can broadly be interpreted as a global investor (investors buy instead of sell bonds as if they are firms with negative issuance amounts). The issuer avoids currency mismatch by trading FX forward to hedge currency exposure. Therefore, the issuer is a cross-market arbitrageur in the sense of both connecting the euro and dollar debt markets and connecting the credit market with the FX forward market.

I use this model to illustrate the transmission of shocks across markets, the alignment of the two deviations, and the response and impact of issuance flow. The model also provides testable predictions that are examined in Section 6. An extended model in the Appendix relaxes many of the simplifying assumptions presented in the main text.

\section{$5.1 \quad$ Issuer}

In this static model, a representative price-taking firm needs to raise a fixed debt amount $D$ for dollar-based investments. The firm observes its dollar bond yield $Y_{\$}$, a credit spread differential between its EUR- and USD-denominated bonds $\kappa$, and a CIP deviation $x$. As presented earlier, CIP deviations reflect hedging costs beyond the risk-free rate differentials. The firm fully hedges FX exposure and eliminate currency mismatches between the asset and the liability side of its balance sheet ${ }^{30}$ The exchange rate is normalized to one as it does not enter into the decision. Therefore, the cost difference between borrowing in the two currencies is the corporate basis $\Psi$, which is expressed as the individual components $\kappa+x$, in order to focus on the interactions between $\kappa$ and $x$. The firm chooses dollar debt issuance share $\mu$ to minimize borrowing cost: $\min _{\mu}\left[Y_{\$}-(\kappa+x) \mu\right] D$. The issuer's currency decision is binary:

$$
\mu= \begin{cases}1 & \text { if } \kappa+x>0 \\ 0 & \text { otherwise }\end{cases}
$$

\footnotetext{
${ }^{30}$ We can relax the simplification that the firm only has dollar asset and must fully hedge FX risk. The Appendix shows an extension in which the firm has a desired dollar funding ratio $m ;(1-m)$ fraction of its asset is in EUR and serves as a natural hedge. The firm decides on the deviation from its optimal debt currency mix $(\mu-m)$ and a $\mathrm{FX}$ hedging ratio $h$.
} 
If the corporate basis is positive, $\kappa+x>0$, then the firm shifts its issuance entirely to USD. Otherwise, it issues in EUR. Thus, $\mu$ is loosely interpreted as debt issuance flow.

The extended model, shown in the Appendix, introduces capital structure friction, natural asset hedges, and partial FX hedging. With these extensions, the model also produces an interior solution. The main result and intuition carry through with these extensions.

\subsection{Credit markets}

To understand how deviation in one market spills over to the other market, we endogenize $\kappa$ and $x$. We start by endogenizing $\kappa$.

There are two risky bonds (EUR and USD bonds) each in zero net supply. The bonds represent two credit markets. The investor base is segmented. US active investors only invest in the investment of USD-denominated corporate bonds, and European active investors only invest in EUR-denominated bonds. The firm supplies debt in both USD and EUR.

Local active investors. Investors have a funding cost equal to the domestic short rate, $r_{i}$, and purchase bonds with a promised net yield of $Y_{i}$, where $i=€$ for EUR or $\$$ for USD. The two bonds have identical default probability $\pi$ and loss-given-default $L$. The payoff of bonds has a variance of $V$, which is treated as an exogenous constant in the model for tractability ${ }^{31}$ The investors have a mean-variance preference with identical risk tolerance $\tau$ and choose investment amount $X_{i}$ to solve $\max _{X_{i}}\left[X_{i}\left((1-\pi) Y_{i}-\pi L-r_{i}\right)-\frac{1}{2 \tau} X_{i}^{2} V\right]$. This has the solution $X_{i}=\frac{\tau}{V}\left((1-\pi) Y_{i}-\pi L-r_{i}\right)$.

Exogenous demand. In addition to the active local investors, there are exogenous bond demand shocks $\varepsilon_{i}$, for $i \in\{€, \$\}$. The source of these demand shocks can originate from quantitative easing (such as ECB corporate bond purchase program), changes to preferredhabitat investors (e.g. liability-driven investments, pension fund benchmark changes), and credit market sentiment.

Market-clearing. Combining investor demand with firm debt issuance supply, the marketclearing conditions for the two credit markets are $X_{\$}+\varepsilon_{\$}=\mu D$ and $X_{€}+\varepsilon_{€}=(1-\mu) D$.

The difference between the two promised bond yields can be expressed as a credit spread difference and interest rate difference: $Y_{€}-Y_{\$} \equiv \kappa+\left(r_{€}-r_{\$}\right)$. Solving for the credit spread differential using the market clearing conditions, we obtain $\kappa=\left(\frac{1}{1-\pi}\right) \frac{V}{\tau}\left((1-2 \mu) D-\varepsilon_{\kappa}\right)+$ $\left(\frac{\pi}{1-\pi}\right)\left(r_{€}-r_{\$}\right)$, where $\varepsilon_{\kappa} \equiv \varepsilon_{€}-\varepsilon_{\$}$ is defined as the relative excess EUR credit demand. The coefficient on the second term, $\frac{\pi}{1-\pi}$, is negligible given realistic default probabilities for large firms in developed countries. ${ }^{32}$ To focus on studying meaningful drivers in the variations of $\kappa$, we apply a first-order Taylor approximation for $\pi$ around zero and express credit spread

\footnotetext{
${ }^{31}$ A Bernoulli default distribution with probability $\pi$, loss given default $L$, and promised yield $Y$ implies that $V=\pi(1-\pi)(Y+L)^{2}$. The solution to the investors' problem would contain a quadratic root. To keep the model tractable, $V$ is assumed to be an exogenous constant and the same for both bonds.

${ }^{32}$ The annual default rate averages less than $0.1 \%$ for investment grade bonds and $4.1 \%$ for high yield bonds in the US from 1981 to 2016 (S\&P Global).
} 
differential as

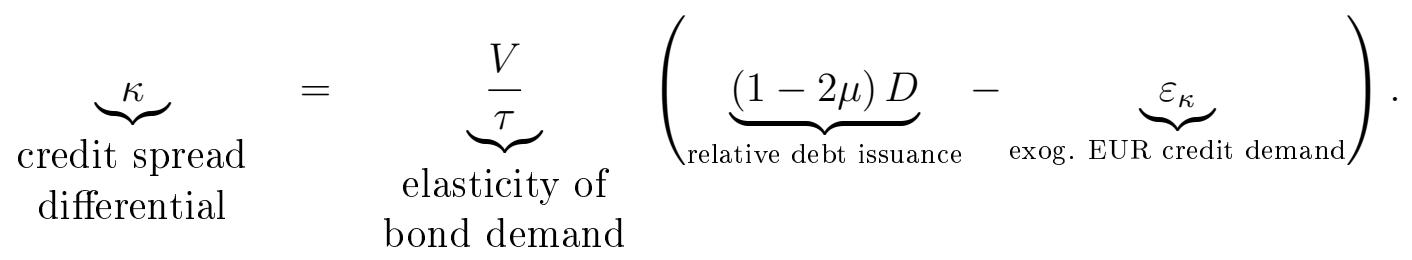

The intuition is that $\kappa$ is equal to the quantity of risk - the net supply and demand imbalances between the two markets - multiplied by the price of risk - the elasticity of bond demand. The cross-currency issuer can influence the relative credit spread through its choice of $\mu$, although this influence is limited by the size of the total debt issuance $D$.

\subsection{Currency swap market}

Next, I endogenize the CIP deviation $x$ and describe the dynamics of the currency swap market. The intuition here is similar to that of the credit market above, but instead of investor risk preference determining the slope of the demand curve, the FX trader's collateral and capital constraints limit arbitrage in CIP deviation. There are two main players in this market: issuers and currency swap traders.

Currency swap trader. The currency swap trader chooses the amount of capital to devote to either CIP deviations $x$ or to an alternative investment opportunity with a profit of $f(I)$, where $I$ is the amount of investment.

To arbitrage CIP violations, the trader must set aside a haircut $H$ when it enters the swap transaction. Following Gârleanu and Pedersen (2011), the haircut amount is assumed to be proportional to the size $s$ of the swap position: $H=\gamma|s|$. Therefore, the capital devoted to alternative investment is $I=W-\gamma|s|$. The swap trader has total wealth $W$ and solves $\max _{s} x s+f(W-\gamma|s|)$. The solution, $x=\operatorname{sign}[s] \gamma f^{\prime}(W-\gamma|s|)$, provides the intuition that the expected gain from conducting a unit of additional CIP arbitrage is equal to the marginal profitability of the alternative investment. A simple case is when the alternative investment activity is quadratic: $f(I)=\phi_{0} I-\frac{1}{2} \phi I^{2}$. In this case, $x=\operatorname{sign}[s] \gamma\left(\phi_{0}-\phi W+\gamma \phi|s|\right)$.

I make an additional simplifying assumption that while CIP deviation $x$ disappears when there is no net demand for swaps, as soon as there is net demand for swaps, $x$ becomes nonzero. This assumption is equivalent to stating that $\frac{\phi_{0}}{\phi}=W$, which means that the arbitrageur has just enough wealth $W$ to take advantage of all positive net present value (NPV) investment opportunities in the alternative project $f(I)$. Simplifying with this assumption and omitting the constant intercept term in the equation for $x$, we obtain that CIP deviation is proportional to the trader's position: $x=\phi \gamma^{2} s$. I further normalize $\phi$ to one for simplicity. This swap trader model is analogous to that of Ivashina, Scharfstein, and Stein (2015) that models the outside alternative activity of the trader with a log functional form instead of the quadratic form.

Exogenous demand. The representative firm from earlier in this paper uses the FX market to convert its EUR issuance proceeds, $D(1-\mu)$ to USD. Additionally, there are exogenous shocks to CIP basis $\varepsilon_{x}$ that represent other nondebt-related uses of FX swaps. The $\varepsilon_{x}$ shocks can emanate from banks' dollar funding through the FX market, regulatory- 
driven hedging demand, and structured note hedging, among others. The Appendix provides further discussions on sources of $\varepsilon_{x}$ shocks.

Market clearing. The market-clearing condition of the FX swap market implies that the equilibrium level of CIP deviation satisfies

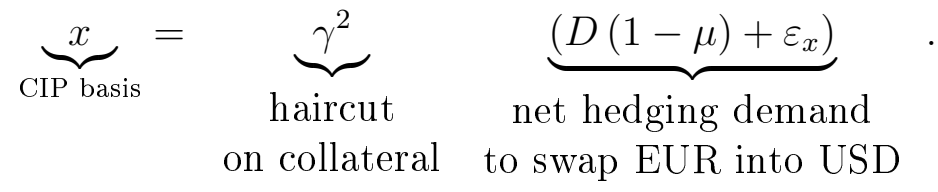

CIP deviation $x$ is proportional to net hedging demand (quantity of risk) multiplied by the collateral haircut (price of risk). A higher haircut $\gamma$ amplifies the impact of hedging demand, but without net hedging demand, $x$ is zero.

Debt-issuance-related hedging demand $D(1-\mu)$ can have a different sign from other hedging demand $\varepsilon_{x}$. In the case $\operatorname{sign}\left[\varepsilon_{x}\right] \neq \operatorname{sign}[D(1-\mu)]$ and $\left|\varepsilon_{x}\right|>|D(1-\mu)|$, the issuer provides (rather than demands) liquidity in the FX swap market and incurs an additional benefit (instead of cost) through hedging.

\subsection{Predictions}

The market clearing conditions in credit (Eq. 8) and FX hedging (Eq. 9) combined with issuer currency choice (Eq. 7) deliver the following propositions.

Proposition 1. (Spillover of deviations) If $\varepsilon_{\kappa} \uparrow$, then $\kappa \downarrow \Rightarrow \mu \downarrow \Rightarrow x \uparrow$. If $\varepsilon_{x} \uparrow$, then $x \uparrow \Rightarrow \mu \uparrow \Rightarrow \kappa \downarrow$. Shocks to one market are transmitted to the other through debt issuance flows. Credit spread differentials $\kappa$ and CIP deviations $x$ respond in the opposite direction to either credit demand shocks $\varepsilon_{\kappa}$ or FX swap demand shocks $\varepsilon_{x} .^{33}$

Proposition 1 clearly predicts that $\kappa$ and $x$ comove oppositely to each other, but the sign of $\mu$ is ambiguous without distinguishing whether the shock is $\varepsilon_{\kappa}$ or $\varepsilon_{x}$. Nonetheless, the relation between $\mu$ and the corporate bases $\kappa+x$ is unambiguous, leading to the following:

Proposition 2. (Corporate basis and issuance flow) $\kappa+x \uparrow \Longrightarrow \mu \uparrow$. Corporate basis comoves positively with issuance flow into the dollar.

Another related prediction that follows from the above is that increased cross-market arbitrage capital reduces the corporate basis and the two deviations are perfectly offset in the limit.

Proposition 3. (Arbitrage capital and corporate basis) $D \uparrow \Rightarrow|\kappa+x| \downarrow$ and $\lim _{D \rightarrow \infty} \kappa+x=0$. An increase in the total amount of debt issuance decreases the absolute value of the corporate basis. As the total amount of debt increases toward infinity, the corporate basis converges to zero.

\footnotetext{
${ }^{33}$ These transitions occur discretely at the boundary when $\kappa+x$ changes sign. A small amount of friction to the firm's capital structure would generate an interior solution, as shown in the Appendix.
} 


\subsection{Distinction from intermediary-based asset pricing}

The model developed above is also useful for assessing alternative explanations of the alignment between the two anomalies. One alternative hypothesis is based on intermediary-based asset pricing. Under this alternative, a financial intermediary with financing constraints trades in both the FX market and credit market ${ }^{34}$ Deviations might be correlated when there are fluctuations in the binding constraints for the common intermediary. A way of incorporating this alternative in the framework above is to define a common intermediary constraint $\lambda$ that captures the constraints faced by the FX trader and active credit investor, (i.e., $\lambda \equiv \gamma^{2}=c \frac{V}{\tau}$, where $c$ is a constant). In the presence of a shock to $\lambda$, both $\kappa$ and $x$ would be affected.

There are three reasons to falsify this alternative hypothesis in explaining the relationships among $\kappa, x$, and $\mu$. First, without net demand imbalances in each market, changes in $\lambda$ would not cause deviations to occur; it would only amplify the effect of demand imbalances. Second, while the absolute value of deviations would be correlated through intermediary capital (i.e., $\frac{\partial|x|}{\partial \lambda} \propto \frac{\partial|\kappa|}{\partial \lambda}$ ), changes in $\lambda$ would not explain the direction and magnitude of $x$ and $\kappa$ over time and across currencies. Last, changes in $\lambda$ do not speak to the comovement of the corporate basis $\kappa+x$ with issuance flow $\mu$. Therefore, the model above is distinct from one that focuses on fluctuations in $\lambda$.

\section{Tests of model predictions on issuance flow}

In this section, I provide further validation of the theoretical framework using data on bond issuance. I first discuss reasons to focus on debt issuance. I then present evidence on the interactions among issuance flows, credit spreads, and CIP deviations that support the model.

\subsection{Firms as natural cross-market arbitrageurs}

While both currency-hedged investors and issuers can exploit a nonzero corporate basis, I focus the analysis on firms, as their currency-hedged issuance is substantial and they are well-suited as arbitrageurs. In this section, I first present evidence of currency-hedged issuance. Second, I discuss reasons for why we observe firms opportunistically issuing in different currencies rather than investors providing sufficient arbitrage capital to equalize the borrowing cost difference.

Firms can issue debt denominated in different currencies for reasons unrelated to cheaper FX-hedged borrowing costs. Firms with global operations might raise debt denominated in a different currency to match currency exposure in their cash flows or local assets. Additionally, some firms might issue debt in a currency with a lower interest rate but bearing the currency risk, effectively engaging in a carry trade. Therefore, evidence of FX-hedged cross-currency issuance is important in establishing the arbitrage motives of firms.

\footnotetext{
${ }^{34}$ Examples of this type of model are Gromb and Vayanos (2002, 2017), Gârleanu and Pedersen (2011), and He and Krishnamurthy (2013). The insufficient dealer arbitrage of CIP violation is rationalized in the context of funding valuation adjustments by Andersen, Duffie, and Song (2019).
} 
I find evidence of firms engaged in FX-hedged debt issuance with a textual analysis of US Securities and Exchange Commission (SEC) filings by S\&P 500 firms. Fig. 10 graphs the fraction of $10 \mathrm{~K}$ filings with mentions of words relating to (1) "debt," (2) "exchange rate," (3) "hedging," and (4) "derivatives" in the same sentence. This restriction of having all four groups of words appear in a single sentence likely underestimates the actual disclosure of currency-hedged issuance since the disclosure is voluntary and could be noted in multiple sentences. While this proxy might be imperfect, it nonetheless indicates that a substantial fraction of S\&P 500 firms have engaged in currency-hedged issuance in recent years. The sharp rise in this proxy from 2007 to 2010 corresponds to the period when deviations in credit spreads and CIP first begin to emerge. This analysis attests to the pervasiveness of firms acting as cross-market arbitrageurs between the credit market and the FX market in recent years. 
Fig. 10 Textual analysis of FX-hedged foreign debt issuance for S\&P 500 firms

This exhibit presents a textual analysis of 10K filings by firms in the S\&P 500 index from 2004 to 2016. Panel A provides three examples of filings with mentions of currency hedged debt issuance. Panel B shows the percentage of firms that have words relating to (1) "debt," (2) "exchange rate," (3) "hedging," and (4) "derivatives" in the same sentence (separated by common punctuation or paragraph denotation) for $10 \mathrm{~K}$ filings in each year.

A. Examples of SEC filings with mentions of currency-hedged debt issuance

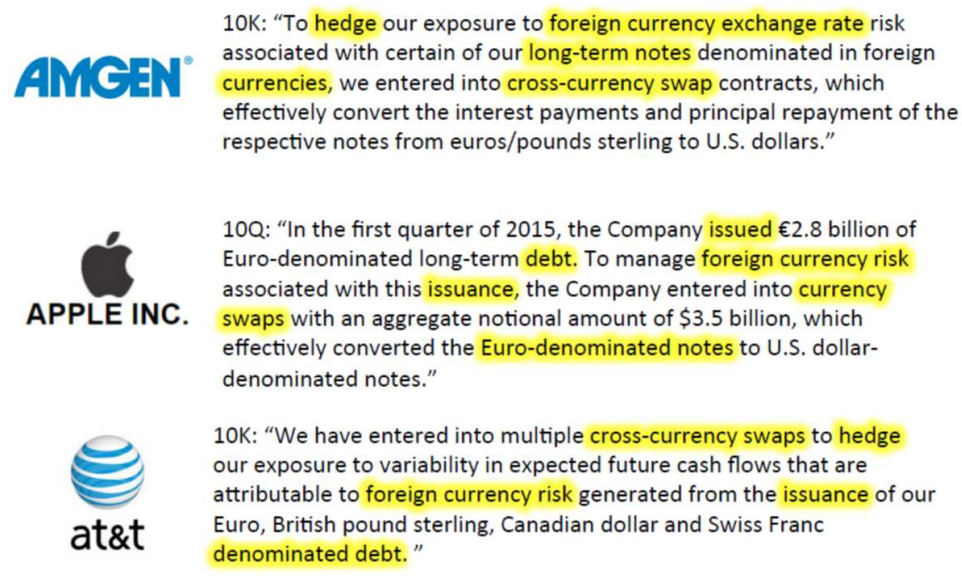

B. Percentage of $10 \mathrm{~K}$ filings with mentions of currency-hedged debt issuance

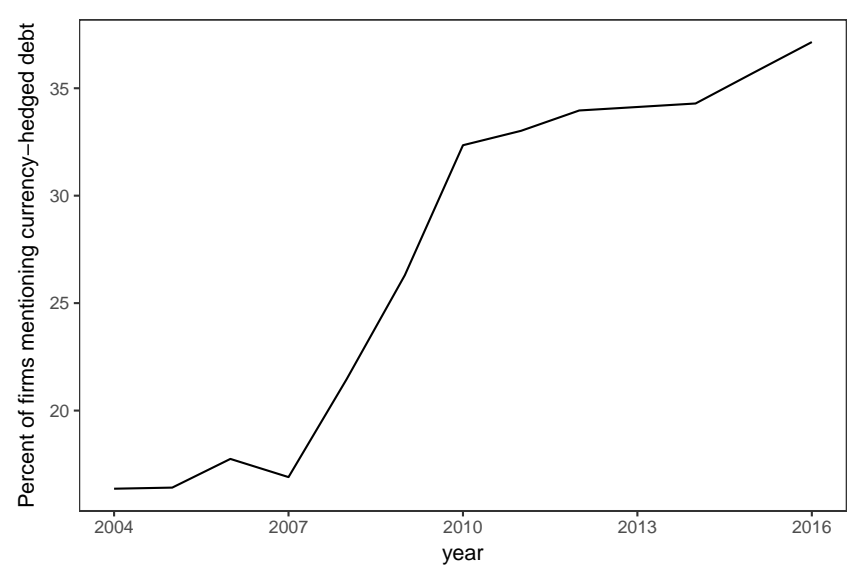


If firms' issuance flow are arbitrage capital, it must be the case that investors are not supplying sufficient arbitrage capital. Most institutional investors have rigid portfolio benchmarks and restrictions on derivatives use that might hinder their ability to exploit the corporate basis. In support of this view, Maggiori, Neiman, and Schreger (2019) show that investors have a strong bias in investing in their home currencies beyond the home-country bias. Hedge funds and dealers also face constraints due to balance sheet frictions ${ }^{35}$ transaction cost, ${ }^{36}$ and limits to arbitrage associated with delegated investment managers (Shleifer and Vishny, 1997).

Firms are natural arbitrageurs to exploit capital-intensive, slow-convergence arbitrage opportunities. They can bear noise-trader risk and endure long investment horizons. Previous papers have examined the role of corporate arbitrageurs in other contexts (Baker and Wurgler, 2000; Greenwood, Hanson, and Stein, 2010; and Ma, 2015). Because firms have stable cash flows and do not face redemption, a one-time issuance and hedging choice is equivalent to holding an arbitrage trade to maturity.

An additional reason to focus the empirical analysis on debt issuance is the availability and comprehensiveness of the data. Debt offerings are typically recorded in public filings and are broadly advertised to investors even for private issuance.

\subsection{Defining issuance flow $\mu$}

To test the model predictions on cross-currency issuance flow, I analyze the amount of corporate debt issued by public firms in the seven free-floating funding currencies analyzed earlier. Debt issuance amounts and other bond characteristics are obtained from the Thomson One SDC Platinum data set. I focus on bilateral issuance flows with the US since the US corporate bond market is the largest, with more than one-third of the global corporate debt issuance in the data sample. The issuance data sample is on fixed-rate, long-term (maturity of two years or greater) corporate bonds with ratings of B- or better. I define the monthly bilateral issuance flow between two currency regions as the amount of debt issuance by foreign firms in USD minus the amount of debt issuance by US firms in the corresponding foreign currency expressed as a percentage of total issuance. For example, the bilateral issuance flow between the EMU and the US is expressed as

$$
i s s P c t^{E M U \rightarrow U S}=\frac{\text { EMU firm issuance in USD - US firm issuance in EUR }}{\text { total issuance in USD \& EUR }} .
$$

This variable definition aims to capture the issuers' active behavior of reaching across currency boundaries to cater to investor demand. An alternative measure is the ratio of all debt issuance in a currency to total issuance. However, this alternative measure is less representative of the issuers' active currency denomination choice, as it is confounded by changes in overall financing needs in the currency regions.

\footnotetext{
${ }^{35} \mathrm{Du}$, Tepper, and Verdelhan (2018) show a strong quarter-end effect suggestive of bank balance sheet constraints. Andersen, Duffie, and Song (2019) show that funding valuation adjustments can be a cost for CIP arbitrage.

${ }^{36} \mathrm{~A}$ long-short strategy requires repo borrowing to fund bond purchase in one currency and reverse-repo lending to short the bond in the other currency while also hedging FX risk.
} 


\subsection{Issuance price impact}

I find evidence of a price impact on LIBOR-based CIP deviations from large issuances, a phenomenon consistent with the model of deviation alignment. Large cross-currency debt issuances are a recurrent source of FX-hedging demand and are a laboratory for studying price impact. Debt issuance is announced ahead of the actual issuance date and anticipated by market participants. Anecdotal accounts of FX traders front-running large cross-currency issuance and issuers' placement agents pre-hedging in advance of the actual debt offering date would suggest possible FX swap price movements prior to the issuance date. I conduct an event study that examines changes in CIP deviation around days with large cross-currency issuance.

The event dates are defined for each currency pair as dates on which there are large total issuances (greater than $\$ 500$ million) of dollar-denominated bonds by foreign firms (often referred to as Yankee bonds ${ }^{37}$ ) and dates on which there are large foreign currency bond issues by US firms (Reverse Yankee bonds). For instance, if the sum of USD-denominated bond issued by Australian firms is greater than $\$ 500$ million on a particular date, this date is categorized as a large Yankee bond issuance date for AUDUSD. Defining event dates using other issuance size cutoffs of significant size, (i.e. $\$ 250$ million, $\$ 1$ billion) yields similar results ${ }^{38}$ With an issuance size cutoff of $\$ 500$ million, $7.8 \%$ of the trading days qualify as large Yankee issuance events and $2.5 \%$ of the sample qualifies as large reverse Yankee issuance events averaged across the six currencies.

Fig. 11 presents the event study result. On the days before large dollar bond issuance by foreign firms, the price of swapping bond proceeds from USD to the foreign currency gradually increases until the event date (red line). The reverse price action can be observed for large nondollar issues of US firms (blue line).

Similar to the price impact on CIP deviations, new debt supply also has an impact on the credit spread at the individual firm and the aggregate level. For instance, Newman and Rierson (2004) show that the issuance of 15.5 billion euros of bonds by Deutsche Telekom had a sizable pricing impact on the entire European telecom debt sector. Since the residualized credit spread differential is estimated with a standard error, the event study approach on the residualized credit spreads cannot be as easily applied.

Another piece of evidence supporting the existence of spillovers between FX hedging and credit market comes from shocks to FX hedging costs. Bahaj and Reis (2018) find that lowering the cap on CIP deviations (by cutting the central bank swap line rate) impacts bond yields and holdings of currency-hedged debt in directions consistent with the model presented in this paper. During the eurozone sovereign crisis in November 2011, the Federal Reserve coordinated with five other central banks to cut the central bank swap line rate from OIS +100 basis points to OIS +50 basis points. The goal was to increase the take-up of

\footnotetext{
${ }^{37}$ Dollar debt issuance by foreign firms can occur both in the US bond market (Yankee bonds) or in the international Eurobond market. I emphasize on the currency denomination and therefore include bonds of both types.

${ }^{38}$ Alternatively, defining large cross-currency issuance event days by quantile for each of the currencies separately also produce similar results. For instance, I define event dates as the top $1 \%$ of days with large dollar bond issuance by firms originating in the EMU (the corresponding absolute cutoff size is $\$ 8$ billion). I also perform additional robustness checks by removing the impact of large outliers, defining event dates as ones that have cross-currency issuance of size between $\$ 500$ million and $\$ 3$ billion.
} 
Fig. 11 Impact of large cross-currency issuance on CIP deviation

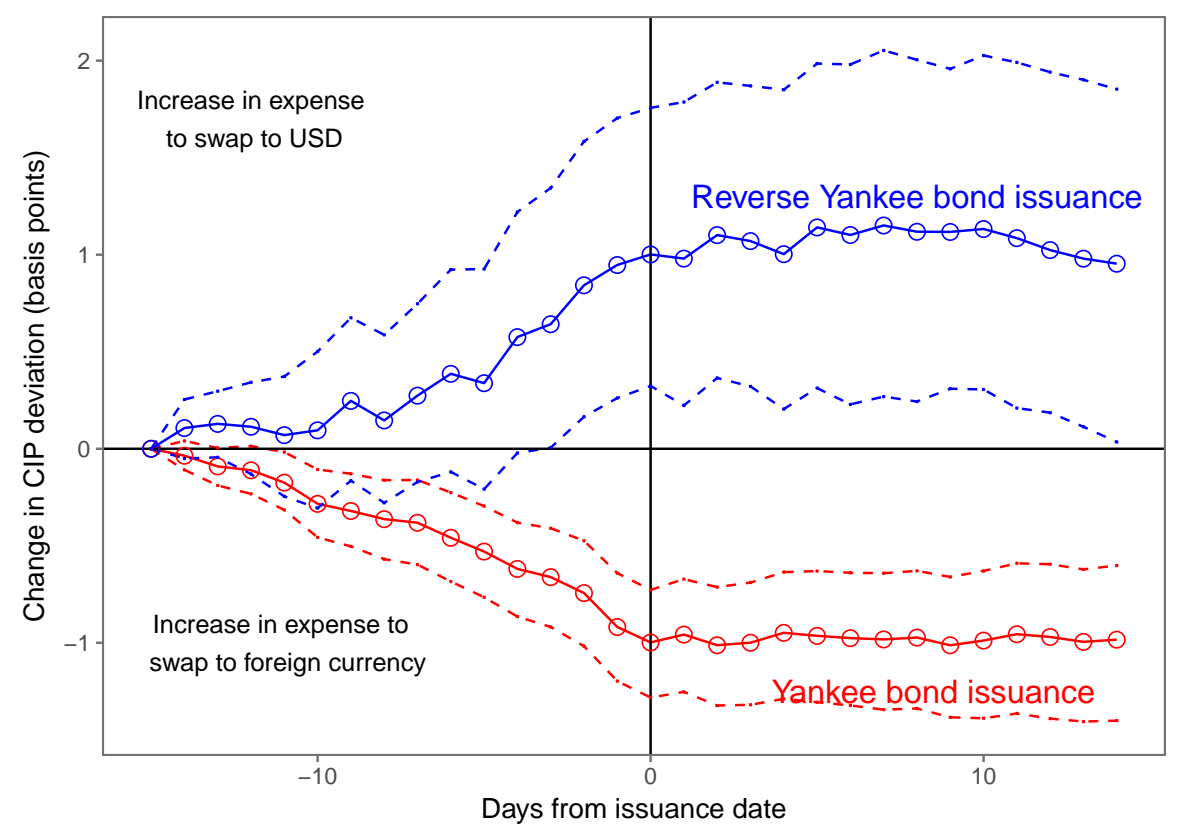

This figure graphs changes in five-year CIP deviation around dates with large cross-currency issuance for EUR, GBP, AUD, JPY, CHF, and CAD relative to USD. Yankee bond issuance refers to dollar denominated bond issuance by non-US firms, and reverse Yankee issuance refers to non-dollar denominated bond issuance by US firms. The dashed lines represent the $95 \%$ confidence interval from bootstrapping with 1,000 draws. 
central bank swap lines, which provided an alternative to traded FX swaps. ${ }^{39}$

Bahaj and Reis (2018) argue that the exact timing and size of the swap line rate cut had some exogeneity. They present evidence showing that the central bank swap line rate cut resulted in 1) a decline in CIP deviation (cheaper cost of hedging dollar asset by foreign entities), 2) an increase in dollar-denominated corporate bond purchases by European Economic Area (EEA) regulated banks, ${ }^{40}$ and 3) a reduction in dollar corporate bond yields as a result of the bond purchase price pressure. The one-week pass-through from the CIP shock to corporate bonds is around 40\%.41 Given the effect of slow-moving capital (Duffie 2010; Greenwood, Hanson, and Liao, 2018), the long-term spillovers could be much higher.

\subsection{Issuance flow and corporate basis}

Another prediction from the model is that issuance flow fluctuates with the corporate basis in predictable directions. As firms observe differences in the FX-hedged cost of borrowing, they shift issuance from the more expensive borrowing currency to the cheaper ones.

The reaction of issuance flow to the corporate basis can be tested using forecasting regressions. Table 2 presents regression results showing this relationship. To account for the gradualness in issuance response, I regress issuance flow averaged over six months following observations of the corporate basis at month $t$.

The coefficient on the corporate basis for EMU-US bilateral issuance flow in the first column is economically and statistically significant. For each basis point increase in the corporate basis (indicating more attractive borrowing costs in USD), firms tilt their borrowing toward USD-denominated debt by 0.285 percent of their total issuance. This corresponds to an increase of $4 \%$ in dollar borrowing for each standard deviation increase in the corporate basis. The $R$-squared in this univariate regression (column 1 ) is 0.34 , indicating that the corporate basis explains a sizable portion of issuance flow variation. The coefficients for GBP, JPY, and CHF (columns 2, 3, and 5) are also positive and suggest that issuance flow responds to the corporate basis, corroborating model prediction. The smaller size of the coefficients for these three currencies indicates a weaker bilateral flow responses and reflects smaller bond markets (as the issuance flow is scaled by the total size of issuance in USD and the alternate currency).

Columns 7 to 12 present the issuance response regression, controling for interest rate differential. The interest rate differential measures FX-unhedged (dis)advantage of issuing in one currency versus another. One interpretation of this variable is that it proxies carry trade motives. The interest rate differential coefficient is small and insignificant for EUR, GBP, and CHF (columns 7, 8, 11). This result suggests that issuance flow is responsive to FX-hedged borrowing cost differences rather than FX-unhedged carry incentives for these currencies. For JPY (column 9), the coefficients on both the hedged and the unhedged cost difference are significant - the coefficient for the hedged cost difference is larger in magnitude, but the coefficient for the unhedged cost difference is more statistically significant.

\footnotetext{
${ }^{39}$ Central bank swap line allows non-US banks to borrow dollar from their respective home central bank, which in turn obtains the dollar via FX swap with the US Federal Reserve.

${ }^{40}$ EEA-regulated banks include banks and foreign banking branches in the EEA and the UK

${ }^{41}$ The impact on CIP deviation is from the baseline estimates in Table 1 in Bahaj and Reis (2018), and the impact on dollar corporate bonds is from the exact match estimates in Table 4 in their paper.
} 
Columns 13 to 18 show the issuance response to CIP deviation and credit spread differential separately. The directions of the response match model predictions. The positive coefficients on CIP deviation indicate that firms issue more in USD when it is more costly to swap from other currencies to the US dollar. The positive coefficients on credit differential indicate that when credit spread is wide in the other currency relative to the dollar, firms issue more debt in the dollar.

In contrast to the statistically significant corporate basis coefficients for EUR, GBP, JPY, and CHF, the coefficients for the corporate basis for AUD and CAD are close to zero (columns 4 and 6). One possible interpretation is that issuance flow is an important source of arbitrage capital in some currency pairs, but it is not a dominant force of arbitrage capital for other currency pairs. Interestingly, the coefficients on interest rate differential (in columns 10 and 12) are highly significant for AUD and CAD. As local interest rate differential proxies unhedged carry trade returns, these coefficients indicate that issuers might be issuing unhedged foreign debt for carry trade motives, a phenomenon that Bruno and Shin (2017) show for corporate issuers in emerging markets. Related to this hypothesis, CIP deviations in AUD and CAD relative to USD are less correlated with their credit spread differentials, as presented earlier in Fig. 5 and Table 1 .

Table 3 presents the response of issuance flow sensitivity pre- and post-GFC. The dependent variable is the aggregated issuance flow between the US and the combined four currency regions (EMU, UK, Japan, and Switzerland) that have an issuance response to deviations. The pre-crisis sample displays insignificant issuance response to deviations (column 2 and 5). This is in contrast with the strong issuance flow response to deviations post-crisis (column 3 and 6 ). The result suggests that debt issuing firms started to arbitrage the deviations at the aggregate level only after the crisis, possibly because the deviations were smaller in the pre-crisis period and traditional institutions such as banks played a larger role in arbitrage activities.

\subsection{Firm-level analysis}

The aggregate results showing the response of issuance flow to the pricing anomalies can also be tested using a panel of firm-specific credit spread differentials. I examine firms' decisions on debt currency denomination with a linear probability model. This firm-level study exploits variations within firm and cross-sectionally within the time period. Therefore, it serves as validation of the aggregate result. To construct firm-specific credit spread differentials, I estimate the cross-sectional regression at each date $t, S_{i t}=\alpha_{c t}+\delta_{f t}+\alpha_{c t} \cdot \delta_{f t}+\varepsilon_{i t}$, where $S_{i t}$ is the credit spread for bond $i$ issued in currency $c$, by firm $f$. $\alpha_{c t}$ and $\delta_{f t}$ are currency and firm fixed effects. The firm-specific residualized credit spread differential is estimated as $\kappa_{f c t}=\hat{\alpha}_{c t}+\hat{\delta}_{f t}+\hat{\alpha}_{c t} \cdot \hat{\delta}_{f t}$. I also construct a firm-specific corporate basis $\Psi_{f c t}$ using the same approach but with the credit spread adjusted for CIP deviation $S_{i t}^{F \text { Xhedged }}$ as the dependent variable.

Table 4 presents the result of the firm-level currency choice analysis. Column 1 shows that a firm's debt currency choice is sensitive to both its own credit spread and the cash CIP deviation common to all market participants. Each standard deviation increase in the firmspecific credit spread differential $\kappa_{f c t}$ is associated with a $1.6 \%$ decrease in the probability of issuing that that currency. Each standard deviation increase in $x_{t}$ (the cost of swapping to 


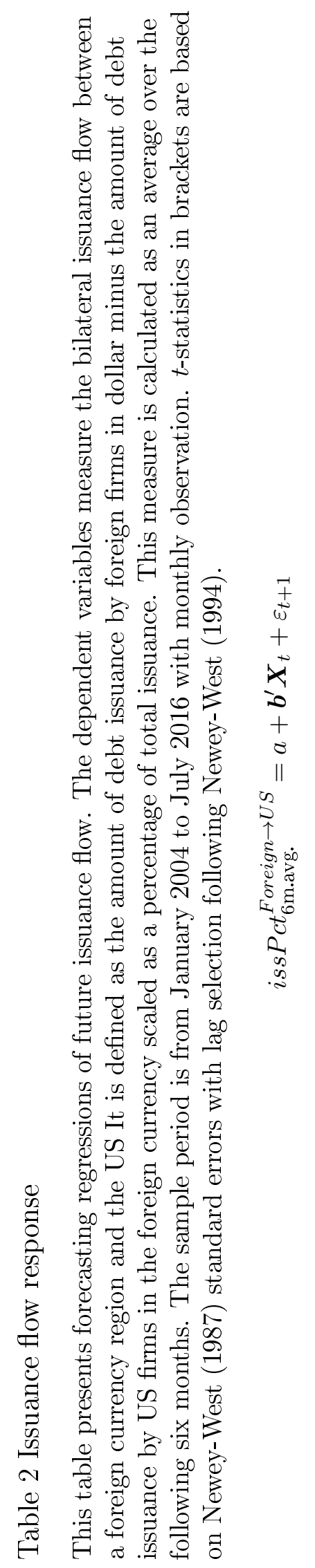

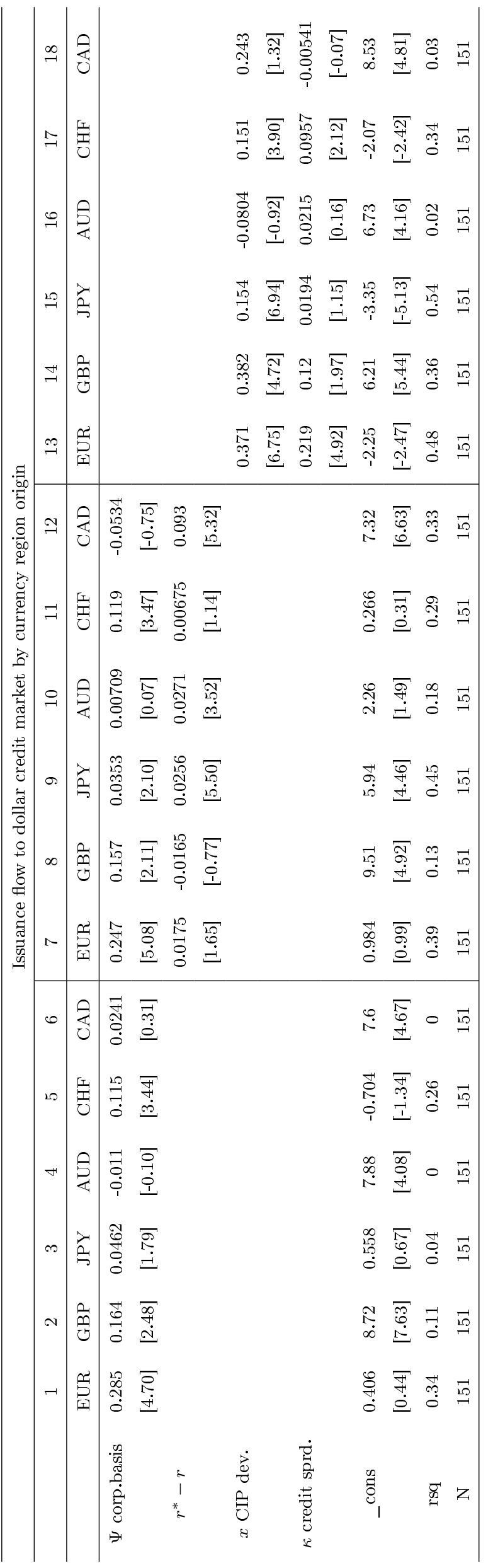


Table 3 Pre- and post-crisis issuance flow sensitivity

This table presents forecasting regressions of future issuance flow using corporate basis, CIP basis, and credit differential. $t$-statistics in brackets are based on Newey-West (1987) standard errors with lag selection following Newey-West (1994).

\begin{tabular}{cccc|ccc}
\hline \multicolumn{6}{c}{ Issuance flow to dollar credit market } \\
\hline & 1 & 2 & 3 & 4 & 5 & 6 \\
\hline & full sample & Pre-2009 & Post-2009 & full sample & Pre-2009 & Post-2009 \\
\hline$\Psi$ corp. basis & 0.155 & -0.00507 & 0.132 & & & \\
& {$[3.61]$} & {$[-0.19]$} & {$[3.09]$} & & & \\
\multirow{2}{*}{$x$ CIP dev. } & & & & 0.224 & 0.0484 & 0.171 \\
& & & {$[7.23]$} & {$[0.66]$} & {$[3.25]$} \\
$\kappa$ credit sprd. & & & 0.112 & 0.0182 & 0.12 \\
& & & & {$[4.07]$} & {$[0.43]$} & {$[2.59]$} \\
\multirow{2}{*}{ cons } & 0.757 & -2.72 & 2.3 & -1.36 & -2.6 & 0.751 \\
& {$[1.28]$} & {$[-5.52]$} & {$[3.37]$} & {$[-2.52]$} & {$[-4.88]$} & {$[0.47]$} \\
rsq & 0.29 & 0.00 & 0.31 & 0.54 & 0.01 & 0.34 \\
$\mathrm{~N}$ & 151 & 60 & 91 & 151 & 60 & 91 \\
\hline
\end{tabular}

USD) is associated with a $7.2 \%$ decrease in the probably of issuing in the non-USD currency. Column 2 shows that the impact of the firm-specific corporate basis is equally large. A one standard deviation increase in the corporate basis (more expensive FX-hedged non-USD borrow cost) reduces foreign currency debt issuance by $3.6 \%$.

\subsection{Arbitrage capital and deviation alignment}

The model shows that an exogenous increase in debt issuance amount $D$ allows firms to deploy more arbitrage capital and reduces the corporate basis. In this section, I analyze whether changes in the amount of arbitrage capital affect the corporate basis with an instrumental variable (IV) approach that uses the amount of maturing debt to instrument for the need to rollover and refinance through new debt issuance. Specifically, I run a regression with the following form:

$$
\Delta|\Psi|_{c, t}=\alpha_{c}+\beta_{1} D_{c, t}+\varepsilon_{c, t},
$$

where $\Delta|\Psi|_{c, t}$ is the monthly change in the absolute value of corporate basis and $D_{c, t}$ is the total amount of debt issued in both currency $c$ and USD in month $t$. Note that $D_{c, t}$ is the amount of debt issued at time $t$, not the level of outstanding debt.

Conceptually, the analysis relies on the assumption that firms are opportunistic regarding the relative currency allocations of their debt issuance, as opposed to engaging in market timing and adjusting their total issuance amount. While the market timing motive is important and widely documented in many studies, it does not obviate a firm's decision regarding the relative currency allocation of their debt issuance once they have decided the total amount to issue.

To address potential concerns with the endogenous debt issuance decision, I instrument $D_{c, t}$ with the maturing debt amount, $M_{c, t}$. Firms frequently issue new debt to rollover 
Table 4 Firm-level issuance choice and violations in credit and CIP

This table presents regressions of firm-level debt denomination choice on credit spread differential and CIP deviation. I estimate the probability that a firm issues debt in currency $c$ conditional on the firm issuing debt in that quarter. I estimate the following specifications in column 1:

$$
I_{f c t}=\beta_{0}+\beta_{1} \kappa_{f c t}+\beta_{2} x_{c t}+\mathbf{X}_{\mathbf{i t}}^{\prime} \beta+\varepsilon_{f c t} .
$$

$I_{f c t}$ is an indicator variable that equals one if firm $f$ issues in currency $c$ in quarter $t . \kappa_{f c t}$ is the firm-specific residualized credit spread differential defined in the text. In column 2, I estimate the regression with corporate basis as the independent variable, $I_{f c t}=\beta_{0}+\beta_{1} \Psi_{f c t}+\mathbf{X}_{\mathbf{i t}}^{\prime} \beta+\varepsilon_{f c t}$, where corporate basis $\Psi_{f c t}$ is estimated similarly to $\kappa_{f c t} . t$-statistics in brackets are based on robust standard errors clustered by firm and time.

\begin{tabular}{ccc}
\hline & \multicolumn{2}{c}{ probability of } \\
& issuing in ccy $c$ \\
& $(1)$ & $(2)$ \\
\hline credit diff $\kappa_{f c t}$ & -0.0727 & \\
& {$[-5.41]$} & \\
CIP $x$ & -0.135 & \\
& {$[-3.19]$} & \\
corp. basis $(\Psi)$ & & -0.074 \\
& & {$[-5.53]$} \\
firm FE & $\mathrm{x}$ & $\mathrm{x}$ \\
time FE & $\mathrm{x}$ & $\mathrm{x}$ \\
$\mathrm{rsq}$ & 0.18 & 0.18 \\
$\mathrm{~N}$ & 28,726 & 28,726 \\
\hline
\end{tabular}


maturing debt. When deciding to rollover old debt, firms can choose a denomination currency different from that of the maturing debt. In effect, the amount of debt that needs to be refinanced represents arbitrage capital that issuers can deploy to take advantage of profitable deviations.

Table 5 presents the result of this analysis. Column 1 shows the ordinary least squares (OLS) regression estimates, and Column 4 shows the IV result. The coefficients on the debt issuance amount are significant and economically meaningful. For each standard deviation ( $\$ 25$ billion) increase in the total issuance amount in USD and EUR debt, the corporate basis is reduced by around two basis points. This price elasticity is likely an underestimate due to the anticipatory effect of debt issuance and front-running by other market participants. Debt issuance and rollovers are pre-announced (through roadshows, dealers, and regulatory filings) and are anticipated by investors and hedge funds. The full unanticipated effects are likely larger.

Table 5 Debt issuance amount and deviation alignment

This table presents regressions of the monthly change in the absolute value of corporate basis on total debt issuance amount in the same month. The regression is specified as follows:

$$
\Delta\left|\Psi_{c, t}\right|=\alpha_{c}+\beta_{1} D_{c, t}+\varepsilon_{t},
$$

where $D_{c, t}$ is the total combined amount of debt issued in currency $c$ and USD expressed in $\$$ billions, where $c=\mathrm{AUD}, \mathrm{CAD}, \mathrm{CHF}, \mathrm{EUR}, \mathrm{GBP}$, or JPY. The amount of debt issued is instrumented by the amount of maturing debt, $M_{c, t}$. Column 1 shows the OLS result with debt issued. Column 2 shows the reduced-form regression with maturing debt. Column 3 shows the first-stage regression of issued debt on maturing debt. Column 4 shows the IV regression. $t$-statistics in brackets are based on robust standard errors clustered by time.

\begin{tabular}{ccccc}
\hline \multicolumn{5}{c}{$\Delta\left|\Psi_{c, t}\right|$} \\
& OLS & $\begin{array}{c}\text { Reduced } \\
\text { form }\end{array}$ & 1st stage & IV \\
\hline$D_{c, t}\left(\hat{D}_{c, t}\right)$ & -0.080 & & & -0.0939 \\
& {$[-3.98]$} & & & {$[-2.05]$} \\
$M_{c, t}$ & & -0.0500 & 0.525 & \\
& & {$[-2.42]$} & {$[4.94]$} & \\
$\Delta\left|\Psi_{c, t-1}\right|$ & -0.089 & -0.073 & & -0.0929 \\
& {$[-1.44]$} & {$[-1.16]$} & & {$[-1.29]$} \\
$\operatorname{ccy~fe}$ & $\mathrm{x}$ & $\mathrm{x}$ & $\mathrm{x}$ & $\mathrm{x}$ \\
$\mathrm{rsq}$ & 0.05 & 0.01 & 0.63 & 0.05 \\
$\mathrm{~N}$ & 1,180 & 1,180 & 1,198 & 1,180 \\
\hline
\end{tabular}




\section{Conclusion}

This paper documents the joint determination of cash CIP deviations and credit spread differentials for bonds of similar risk but different denomination currency. I show that these two pricing anomalies have been substantial and persistent since the financial crisis. The two anomalies are highly aligned in magnitude and direction in both the time series and the cross-section of currencies. The sum of the two pricing deviations - the corporate basis is the relative FX-hedged borrowing cost between currencies and explains up to a third of the variation in cross-currency debt issuance flow. I develop a model of market segmentation in two dimensions - in the credit market across currency denomination and the FX market between spot and forward exchange rates. This framework shows that arbitrage aimed at exploiting one type of security anomaly can give rise to an anomaly in another market. Arbitrage processes are imperfect in either market, but capital flow, such as debt issuance

and investment, ensures that the two anomalies are intimately connected. FX-hedged debt issuance exerts price pressure on both the CIP deviation and the credit spread differential, bundling the two anomalies into one. 


\section{References}

Andersen, L., Duffie, D., and Song, Y. (2019). Funding value adjustments. Journal of Finance, 74:145-192.

Anderson, A., Du, W., and Schlusche, B. (2019). Money market fund reform and arbitrage capital. Unpublished working paper. Federal Reserve Board and Chicago Booth.

Augustin, P., Chernov, M., and Song, D. (2018). Sovereign credit risk and exchange rates: evidence from CDS quanto spreads. Unpublished working paper. NBER.

Avdjiev, S., Du, W., Koch, C., and Shin, H. S. (2019). The dollar, bank leverage and the deviation from covered interest parity. American Economic Review: Insights, 1:193-208.

Baba, N., Packer, F., and Nagano, T. (2008). The spillover of money market turbulence to FX swap and cross-currency swap markets. BIS Quarterly Review.

Bahaj, S. and Reis, R. (2018). Central bank swap lines. Unpublished working paper. CEPR.

Baker, M., Foley, C. F., and Wurgler, J. (2009). Multinationals as arbitrageurs: the effect of stock market valuations on foreign direct investment. Review of Financial Studies, 22(1):337-369.

Baker, M. and Wurgler, J. (2000). The equity share in new issues and aggregate stock returns. Journal of Finance, 55(5):2219-2257.

Bordalo, P., Gennaioli, N., and Shleifer, A. (2018). Diagnostic expectations and credit cycles. Journal of Finance, 73(1):199-227.

Bräuning, F. and Ivashina, V. (2016). Monetary policy and global banking. Unpublished working paper. NBER.

Brunnermeier, M. K. and Pedersen, L. H. (2009). Market liquidity and funding liquidity. Review of Financial Studies, 22(6):2201-2238.

Bruno, V. and Shin, H. S. (2014). Cross-border banking and global liquidity. Review of Economic Studies, 82(2):535-564.

Bruno, V. and Shin, H. S. (2017). Global dollar credit and carry trades: a firm-level analysis. Review of Financial Studies, 30(3):703-749.

Buraschi, A., Menguturk, M., and Sener, E. (2015). The geography of funding markets and limits to arbitrage. Review of Financial Studies, 28(4):1103-1152.

Burger, J. D., Warnock, F. E., and Warnock, V. C. (2018). Currency matters: analyzing international bond portfolios. Journal of International Economics, 114:376-388.

Campbell, J. Y. (2017). Financial Decisions and Markets: A Course in Asset Pricing. Princeton University Press, Princeton. 
Cho, T. (2019). Turning alphas into betas: arbitrage and endogenous risk. Journal of Financial Economics, forthcoming.

Coffey, N., Hrung, W. B., and Sarkar, A. (2009). Capital constraints, counterparty risk, and deviations from covered interest rate parity. Staff Reports. Federal Reserve Bank of New York.

Collin-Dufresne, P., Goldstein, R. S., and Martin, J. S. (2001). The determinants of credit spread changes. Journal of Finance, 56(6):2177-2207.

Corradin, S. and Rodriguez-Moreno, M. (2016). Violating the law of one price: the role of non-conventional monetary policy. Unpublished working paper. ECB.

Della Corte, P., Sarno, L., Schmeling, M., and Wagner, C. (2018). Exchange rates and sovereign risk. Unpublished working paper. Imperial College Business School, City University London, Goethe University Frankfurt, and WU Vienna University of Economics and Business.

Dooley, M. P. and Isard, P. (1980). Capital controls, political risk, and deviations from interest-rate parity. Journal of Political Economy, 88(2):370-384.

Driscoll, J. C. and Kraay, A. C. (1998). Consistent covariance matrix estimation with spatially dependent panel data. Review of Economics and Statistics, 80(4):549-560.

Du, W., Im, J., and Schreger, J. (2018a). The us treasury premium. Journal of International Economics, 112:167-181.

Du, W. and Schreger, J. (2016). Local currency sovereign risk. Journal of Finance, 71(3):1027-1070.

Du, W., Tepper, A., and Verdelhan, A. (2018b). Deviations from covered interest rate parity. Journal of Finance, 73(3):915-957.

Duffie, D. (2010). Presidential address: asset price dynamics with slow-moving capital. Journal of Finance, 65(4):1237-1267.

Fletcher, D. J. and Taylor, L. W. (1996). "swap" covered interest parity in long-date capital markets. Review of Economics and Statistics, 78:530-538.

Frenkel, J. A. and Levich, R. M. (1975). Covered interest arbitrage: unexploited profits? Journal of Political Economy, 83(2):325-338.

Frenkel, J. A. and Levich, R. M. (1977). Transaction costs and interest arbitrage: tranquil versus turbulent periods. Journal of Political Economy, 85(6):1209-1226.

Gabaix, X., Krishnamurthy, A., and Vigneron, O. (2007). Limits of arbitrage: theory and evidence from the mortgage-backed securities market. Journal of Finance, 62(2):557-595.

Gabaix, X. and Maggiori, M. (2015). International liquidity and exchange rate dynamics. Quarterly Journal of Economics, 130(3):1369-1420. 
Gârleanu, N. and Pedersen, L. H. (2011). Margin-based asset pricing and deviations from the law of one price. Review of Financial Studies, 24(6):1980-2022.

Gârleanu, N., Pedersen, L. H., and Poteshman, A. M. (2009). Demand-based option pricing. Review of Financial Studies, 22(10):4259-4299.

Goldberg, L. S., Kennedy, C., and Miu, J. (2010). Central bank dollar swap lines and overseas dollar funding costs.

Gourinchas, P.-O. and Rey, H. (2007a). From world banker to world venture capitalist: Us external adjustment and the exorbitant privilege. In Clarida, R.H. (Ed.), G7 Current Account Imbalances: Sustainability and Adjustment, pages 11-66. University of Chicago Press.

Gourinchas, P.-O. and Rey, H. (2007b). International financial adjustment. Journal of Political Economy, 115(4):665-703.

Gozzi, J. C., Levine, R., Peria, M. S. M., and Schmukler, S. L. (2015). How firms use corporate bond markets under financial globalization. Journal of Banking and Finance, $58: 532-551$.

Greenwood, R., Hanson, S., and Stein, J. C. (2010). A gap-filling theory of corporate debt maturity choice. Journal of Finance, 65(3):993-1028.

Greenwood, R. and Hanson, S. G. (2013). Issuer quality and corporate bond returns. Review of Financial Studies, 26(6):1483-1525.

Greenwood, R., Hanson, S. G., and Jin, L. J. (2019). Reflexivity in credit markets. Unpublished working paper. NBER.

Greenwood, R., Hanson, S. G., and Liao, G. Y. (2018). Asset price dynamics in partially segmented markets. Review of Financial Studies, 31(9):3307-3343.

Greenwood, R. and Vayanos, D. (2010). Price pressure in the government bond market. American Economic Review, 100(2):585-590.

Greenwood, R. and Vayanos, D. (2014). Bond supply and excess bond returns. Review of Financial Studies, 27(3):663-713.

Greenwood, R. M. and Vissing-Jorgensen, A. (2018). The impact of pensions and insurance on global yield curves. Unpublished working paper. Harvard Business School and University of California Berkeley.

Griffoli, T. M. and Ranaldo, A. (2011). Limits to arbitrage during the crisis: funding liquidity constraints and covered interest rate parity. Unpublished working paper. Swiss National Bank.

Gromb, D. and Vayanos, D. (2002). Equilibrium and welfare in markets with financially constrained arbitrageurs. Journal of Financial Economics, 66(2-3):361-407. 
Gromb, D. and Vayanos, D. (2018). The dynamics of financially constrained arbitrage. Journal of Finance, 73(4):1713-1750.

Hale, G., Jones, P., and Spiegel, M. M. (2016). The rise in home currency issuance. Unpublished working paper. Federal Reserve Bank of San Francisco.

He, Z. and Krishnamurthy, A. (2013). Intermediary asset pricing. American Economic Review, 103(2):732-70.

Huang, J.-Z. and Huang, M. (2012). How much of the corporate-treasury yield spread is due to credit risk? Review of Asset Pricing Studies, 2(2):153-202.

Iida, T, T. K. and Sudo, N. (2016). An upsurge in a CIP deviation during the noncrisis period and the role of divergence in monetary policy. Unpublished working paper. Bank of Japan.

Ivashina, V., Scharfstein, D. S., and Stein, J. C. (2015). Dollar funding and the lending behavior of global banks. Quarterly Journal of Economics, 1241:1281.

Jiang, Z., Krishnamurthy, A., and Lustig, H. (2018). Foreign safe asset demand for US Treasuries and the dollar. AEA Papers and Proceedings, 108:537-41.

Jiang, Z., Krishnamurthy, A., and Lustig, H. (2019). Foreign safe asset demand and the dollar exchange rate. Unpublished working paper. Stanford University Graduate School of Business.

Kim, Y. C. and Stulz, R. (1988). The Eurobond market and corporate financial policy: a test of the clientele hypothesis. Journal of Financial Economics, 22(2):189-205.

Krishnamurthy, A. (2002). The bond/old-bond spread. Journal of Financial Economics, $66(2): 463-506$.

Kyle, A. S. and Xiong, W. (2001). Contagion as a wealth effect. Journal of Finance, 56(4):1401-1440.

Lando, D. and Bang Nielsen, A. (2018). Quanto CDS spreads. Unpublished working paper. Copenhagen Business School.

Levich, R. M. (2012). FX counterparty risk and trading activity in currency forward and futures markets. Review of Financial Economics, 21(3):102-110.

López-Salido, D., Stein, J. C., and Zakrajšek, E. (2017). Credit-market sentiment and the business cycle. Quarterly Journal of Economics, 132(3):1373-1426.

Ma, Y. (2019). Non-financial firms as cross-market arbitrageurs. Journal of Finance.

Maggiori, M., Neiman, B., and Schreger, J. (2019). International currencies and capital allocation. Journal of Political Economy, forthcoming. 
Mano, R. (2013). Exchange rates upon sovereign default. Unpublished working paper. International Monetary Fund.

McBrady, M. R. and Schill, M. J. (2007). Foreign currency-denominated borrowing in the absence of operating incentives. Journal of Financial Economics, 86(1):145-177.

McGuire, P. and von Peter, G. (2012). The dollar shortage in global banking and the international policy response. International Finance, 15(2):155-178.

Newey, W. K. and West, K. D. (1987). A simple, positive semi-definite, heteroskedasticity and autocorrelation consistent covariance matrix. Econometrica, 55:703-708.

Newey, W. K. and West, K. D. (1994). Automatic lag selection in covariance matrix estimation. Review of Economic Studies, 61(4):631-653.

Newman, Y. and Rierson, M. (2004). Illiquidity spillovers: theory and evidence from European telecom bond issuance. Unpublished working paper. Barclays.

Popper, H. (1993). Long-term covered interest parity: evidence from currency swaps. Journal of International Money and Finance, 12(4):439-448.

Rime, D., Schrimpf, A., and Syrstad, O. (2017). Segmented money markets and covered interest party arbitrage. Unpublished working paper. Bank of International Settlements.

Shleifer, A. and Vishny, R. W. (1997). The limits of arbitrage. Journal of Finance, 52(1):3555.

Sushko, V., Borio, C., Mccauley, R., and Mcguire, P. (2016). Whatever happened to covered interest parity? Unpublished working paper. Bank of International Settlements. 


\title{
Internet Appendix
}

\author{
Credit Migration and Covered Interest Rate Parity \\ Gordon Y. Liao
}

August 2019

\section{Data description}

The merged data set consists of corporate bond issuance, attributes and yields from SDC Global New Issuance database, Moody's Default \& Recovery database and Bloomberg. The data merge uses ISINs and CUSIPs when possible. If neither of the identifiers are available, the merge is performed using issuer ticker, coupon, and maturity. The merged data set contains corporate bonds that are non-floating, non-perpetual and with no-embedded options (straight, bullet bonds). Securities with remaining maturities of less than one year and of less than ten percent of the original maturity are excluded since the liquidity for these bonds are poor and pricing is often missing. This filter also rules out short-term funding instruments such as commercial paper. Loans, convertible bonds, and asset backed securities are also excluded from the data set. Since the analyses focus on cross-currency issuers in major currencies (USD, EUR, JPY, GBP, CHF, AUD, and CAD), A bond is only included in the data set if the ultimate parent of the issuer has at least one other bond denominated in a different currency outstanding. I also exclude bonds with less than $\$ 50 \mathrm{~mm}$ notional at issuance. Bond yields are obtained from Bloomberg and winsorized at $1 \%$ to remove erroneous prices. Table 1 provides a summary of the bond data.

The credit spread is calculated as yield-yield asset swap spread against the benchmark LIBOR-based swap curve. To calculate this credit spread, I subtract the individual bond yield by the maturity-matched swap yield linearly interpolated from swaps with maturities of $1,2,5,7,10,12,15,20$, and 30 years. Using spline interpolation (instead of linear interpolation) does not result in noticeable difference in the residualized credit spreads. Using OIS-based swaps also does not result in a large difference in the overlapping sample. OIS-based swaps lack pricing observations for a large part of the earlier sample and for certain currency and maturities.

\section{Additional robustness checks}

Additional controls in the measurement of credit spread differential Fig. 1 presents the comparison of the estimates from the augmented model and the main regression specification. The augmented model includes controls for amount outstanding, bond age relative to initial maturity, seniority, and governance law.

Heterogeneity for different credit ratings Fig. 2 presents the residualized credit spread differentials constructed with high-grade and low-grade bonds separately for each of the currencies. High-grade bonds are defined as bonds with a Moody's rating of single A or better. This split allows for a roughly equal number of high-grade vs. low-grade bonds. When the sample is restricted to only low-grade bonds, the credit spread differentials are larger in magnitude than those of high-grade bonds. 
Non-mechanical comovement A possible concern is that the high comovement between the two deviations is driven mechanically since the funding rate (swap rate) appears in the calculation of both the credit spread and CIP deviation. This mechanical linkage does not appear to be in the correct direction. Credit spreads generally do not mechanically narrow and widen with changes in the risk-free rate. That is, a decline in the risk-free rate does not mechanically widen credit spread. A decline in the risk-free rate over a sustained period of time can lead to credit spread compression through investors reaching-for-yield, a motive that has been studied by Becker and Ivashina (2015) and Choi and Kronlund (2017), among others. However, the reach-for-yield effect occurs gradually and is far from mechanical. I consider such an effect to be a source of credit demand shock $\varepsilon_{\kappa}$.

It would also appear that the CIP basis, defined as the actual non-dollar funding rate minus the FXimplied non-dollar funding rate, $x_{E U R} \equiv r_{E U R}^{a c t u a l}-r_{E U R}^{F X-i m p l i e d}$, is mechanically affected by changes in $r_{E U R}^{a c t u a l}$. However, event studies using intraday data around ECB policy announcements by Du, Tepper, and Verdelhan (2018) suggest that $x_{E U R}$ decreases when there is a positive shock to the two-year German bund yield. This evidence goes against a mechanical effect that would result in the correlation of $\kappa$ and $x$.

Non-USD currency bases In the main text, we analyzed both credit spread differentials and CIP violations for six major currencies against the U.S. dollar. These deviations can also be analyzed against other currencies. Fig. 3 and 4 graph the credit spread differentials and CIP violations against EUR and GBP. These graphs also show a high level of correlation and alignment in direction and magnitude for the two deviations.

The transformed graphs of the two deviations offer additional insights. For instance, Fig. 3 shows that all credit spreads against EUR have widened since 2014. With the exception of JPY, the euro credit spread is tighter than all other credit spreads. This is perhaps indicative of a euro-specific factor.

\subsection{Covariance between currency depreciation and credit default}

The main text describes the benchmark asset pricing model that showcases the default-depreciation covariance. This section relates the prices to credit spread formally, presents the full cross-sectional asset pricing test and CDS-implied levels of this covariance risk.

Let $M_{t+1}$ and $M_{t+1}^{*}$ denote the domestic (dollar) and the foreign (euro) stochastic discount factors (SDFs). I use $*$ to denote foreign association. In a complete market, the two SDFs are related by

$$
M_{t+1}^{*}=M_{t+1} \frac{Q_{t+1}}{Q_{t}},
$$

where $Q_{t}$ is the exchange rate quoted in dollar per euro (Campbell 2017). An increase in $Q_{t}$ corresponds to an appreciation of the euro. Let $L_{t+1}$ be a random variable that denotes the default loss as a fraction of the bond face value at time $t+1$ when the bond matures. The price of a risky dollar bond is $P_{t}=\mathbb{E}\left[M_{t+1}\left(1-L_{t+1}\right)\right]$, and the price of a risky foreign bond is $P_{t}^{*}=\mathbb{E}\left[M_{t+1}^{*}\left(1-L_{t+1}^{*}\right)\right]$. Substituting in Eq. 1, the foreign bond price is

$$
P_{t}^{*}=\mathbb{E}\left[M_{t+1} \frac{Q_{t+1}}{Q_{t}}\left(1-L_{t+1}^{*}\right)\right]
$$

or equivalently

$$
P_{t}^{*}=\mathbb{E}\left[M_{t+1}\left(1-L_{t+1}^{*}\right)\right] \mathbb{E}\left[\frac{Q_{t+1}}{Q_{t}}\right]+\operatorname{Cov}\left(M_{t+1}\left(1-L_{t+1}^{*}\right), \frac{Q_{t+1}}{Q_{t}}\right)
$$


Thus, a positive covariance of debt repayment (default) and foreign currency appreciation (depreciation) leads to a higher foreign bond price or lower yield.

To relate prices to credit spreads, the pricing equations above can be rewritten under risk-neutral expectation and converted to yields after taking logs. Du and Schreger (2016) derive the following proposition, which I restate below ${ }^{1}$.

Proposition 1. Let $L_{t+1}$ and $L_{t+1}^{*}$ denote default loss of dollar and non-dollar bond at time $t+1$ as a fraction of the face value in the respective currencies. Let $\mathbb{E}^{\mathbb{Q}}$ denote expectation under the dollar risk-neutral measure. In a complete market, the (non-dollar minus dollar) credit spread differential is

$$
\kappa_{t} \equiv\left(y_{t}^{*}-r_{t}^{*}\right)-\left(y_{t}-r_{t}\right) \approx \mathbb{E}_{t}^{\mathbb{Q}}\left[L_{t+1}^{*}\right]-\mathbb{E}_{t}^{\mathbb{Q}}\left[L_{t+1}\right]-q_{t}
$$

where $q_{t}=\frac{\operatorname{Cov}_{t}^{\oplus}\left(\frac{Q_{t+1}}{Q_{t}}, 1-L_{t+1}^{*}\right)}{\mathbb{E}_{t}\left[\frac{Q_{t+1}}{Q_{t}}\right] \mathbb{E}_{t}\left[1-L_{t+1}^{*}\right]}$ is the quanto adjustment.

Note that because $L_{t}$ and $L_{t}^{*}$ are both losses expressed as a fraction of face value, $L_{t+1}$ and $L_{t+1}^{*}$ are equal for debt of the same entity under pari pasu clauses that are typical of corporate debt contracts. The regression-based approach of estimating $\kappa_{t}$ is aimed precisely at residualizing for the term $\mathbb{E}_{t}^{\mathbb{Q}_{t}}\left[L_{t+1}^{*}\right]-$ $\mathbb{E}^{\mathbb{Q}}{ }_{t}\left[L_{t+1}\right]$. I proceed with empirically testing whether the relationship $\kappa_{t} \approx-q_{t}$ holds in the data.

\section{Cross-sectional test of quanto risk}

The cross-sectional test examines whether currencies with higher exposures to credit risk have lower credit spreads on average. First, betas are estimated from a time-series regression of currency returns on the excess returns of corporate bonds,

$$
r_{c, t}=\alpha+\beta_{c} r_{c o r p, t}+\varepsilon_{c, t},
$$

where $r_{c, t}$ is the return of currency $c$ relative to the dollar and $r_{c o r p, t}$ is the excess return on a benchmark credit index. Then I run a cross-sectional regression,

$$
\bar{k}_{c}=\lambda \hat{\beta}_{c}+\alpha_{c}
$$

where $\lambda$ is the cross-sectional compensation for bearing the credit-FX covariance risk. According to theory, $\lambda$ should be negative if the default-depreciation covariance is positive. In other words, high credit-beta currencies should have lower credit spread. In contrast to the theory, $\lambda$ is positive empirically. Fig. 5 shows the cross-sectional relation. The x-axis shows the betas between FX return and credit sector return. The y-axis shows the average residualized credit spread for each currency versus the dollar. AUD and CAD have the highest credit betas - they tend to depreciate the most when the credit market sells off. Under the benchmark model above, this higher credit beta should translate into lower credit spread $\kappa$. Likewise, JPY and CHF are two safe-haven currencies that, according to the model, should have the highest credit

\footnotetext{
${ }^{1}$ Taking expectation of Eq. 1 and converting to the risk-neutral measure, the SDF relation becomes $e^{-r_{t}^{*}} \mathbb{E}^{\mathbb{Q}^{*}} t_{t}[1]=$ $e^{-r_{t}} \mathbb{E}^{\mathbb{Q}_{t}}\left[\frac{Q_{t+1}}{Q_{t}}\right]$. In the risk-neutral form, the price of dollar bond is $P_{t}=e^{-r_{t}} \mathbb{E}^{\mathbb{Q}}\left[1-L_{t+1}\right]$. Taking the log of both sides, the credit spread is $y_{t}-r_{t} \approx \mathbb{E}^{\mathbb{Q}}\left[L_{t+1}\right]$, where the approximation comes from $-\ln \mathbb{E}^{\mathbb{Q}}\left[1-L_{t+1}^{*}\right] \approx \mathbb{E}^{\mathbb{Q}}\left[L_{t+1}^{*}\right]$. For the non-dollar bond, Eq. 2 in $\log$ risk-neutral form becomes $-y_{t}^{*} \approx-r_{t}+\ln \mathbb{E}_{t}^{\mathbb{Q}}\left[\frac{Q_{t+1}}{Q_{t}}\right]-\mathbb{E}^{\mathbb{Q}_{t}}\left[L_{t+1}^{*}\right]+q_{t}$, where $q_{t}=\frac{\operatorname{Cov}_{t}^{\mathbb{Q}}\left(\frac{Q_{t+1}}{Q_{t}}, 1-L_{t+1}^{*}\right)}{\mathbb{E}_{t}\left[\frac{Q_{t+1}}{Q_{t}}\right] \mathbb{E}_{t}\left[1-L_{t+1}^{*}\right]}$ . Substituting in the risk-neutral log SDF relation, we obtain $y_{t}^{*}-r_{t}^{*} \approx \mathbb{E}_{t}^{\mathbb{Q}}\left[L_{t+1}^{*}\right]-x_{t}-q_{t}$.
} 
spreads, but we observe the opposite in the data. The cross-sectional evidence directly refutes the idea that the covariance between bond repayment and local currency return is the main determinant of $\kappa$.

In addition to the cross-sectional test, time serial variations in $\kappa$ also do not match the intuition of the covariance risk. For instance, the JPY-USD residualized credit spread differential became very negative (more than the EUR-USD spread) during the 2011-2012 Eurozone crisis despite the JPY being a safe-haven currency that appreciated during this period. Furthermore, both JPY-USD and EUR-USD residualized credit spreads were larger in 2016 - a relatively calm market period. Moreover, the residualized credit spread differentials were small before 2008 but have been persistently large since, whereas the covariance risk would have been priced in before 2008 if it were the main contributor to the credit spread difference.

\section{CDS-implied quanto adjustment}

The second test follows an established method that uses CDS contracts with payout in multiple currencies. This methodology has been used by a number of recent papers ${ }^{2}$ to quantify the implied currency depreciation associated with sovereign debt defaults. Quanto CDS contracts have a payout in a different currency than the underlying debt obligation. A credit event on an entity triggers all CDS contracts of the same doc clause regardless of the currency of the payout. ${ }^{3}$ The differences in the CDS premiums of the same reference entity but with payout in different currencies measure the quanto adjustment.

This analysis is applied to entities based in the European Monetary Union (EMU) and Japan with at least three dealer quotes in both the dollar and the nondollar contract on $95 \%$ of the observation days. The dealer quotes are from Markit, a pricing service provider that aggregates contributed quotes from dealers. This selection criteria results in 147 European firms, which are quoted by 7.1 dealers, on average, and 82 Japanese firms, which are quoted by 5.9 dealers, on average. The number of quotes is large given that CDS market-marking activities are concentrated among a handful of dealers (Giglio, 2014, Siriwardane, 2019).

With CDS contracts matched for the same firm and contractual terms (doc clause and tier) but different denomination currencies, the euro depreciation-upon-default for each matched pair is calculated as $(C D S(\$)-C D S(€)) / C D S(\$)$ (similarly for the yen). The intuition is the following: suppose Italy's default is associated with a $40 \%$ depreciation in the euro; then Italy's euro CDS premium has to be priced at a $40 \%$ discount to its dollar CDS in order for the euro CDS buyer to purchase additional contracts and achieve equivalent payout as the dollar CDS. The same logic applies to a corporate entity, although corporate defaults are more idiosyncratic and are less associated with currency movement. A formal treatment and discussion of this measure is provided in Mano (2013) and Du and Schreger (2016). ${ }^{4}$

Table 2 shows the summary statistics of the implied depreciation of the local currency calculated from quanto CDS spreads. The sample period starts in August 2010, when data on the euro quanto CDS contracts became available on Markit. ${ }^{5}$ In the first two rows, the median implied depreciations of EUR and JPY are close to zero. The mean for the eurozone firms is also close to zero, while the mean for the Japanese firms

\footnotetext{
${ }^{2}$ Mano (2013), Buraschi, Sener, and Menguturk (2015), Della Corte et al. (2018), Du and Schreger (2016), Augustin, Chernov, and Song (2018), and Lando and Nielsen (2018).

${ }^{3} \mathrm{CDS}$ contracts are written on standardized contract terms categorized by doc clauses that the International Swaps and Derivatives Association (ISDA) periodically updates. The most recent update implemented in 2014, for instance, resulted in possible redenomination risk of the euro (Kremens, 2018). I match CDS contracts of the same doc clause for the same entity in calculating quanto spreads.

${ }^{4}$ Recent studies by Augustin, Chernov, and Song (2018) and Lando and Nielsen (2018) suggest that this simplified oneperiod measure overestimates depreciation upon default since the quanto CDS spread reflects both a jump risk and covariance between exchange rate and default risk absent of credit event realization. I set aside this distinction since an overestimation of depreciation upon default is the conservative approach for ruling out the covariance effect.

${ }^{5}$ Markit data before August 2010 have identical prices for euro and dollar contracts.
} 
is around $7 \%$. In contrast, the last two rows show that the European sovereign (average of 12 eurozone countries) and Japanese government CDS contracts price a substantial amount of depreciation-upon-default. The implied depreciation of the euro is around one-third, on average, in the event of a sovereign default, and it is around two-thirds for the yen. These sharply contrasting results between firms and sovereigns suggest that individual firm defaults mostly reflect idiosyncratic risk, while sovereign defaults are reflective of systematic economic risk linked with local currency depreciation.

\section{Cross-currency basis as CIP deviation}

The cross-currency basis $B$ is defined as the fair exchange of $\$$ LIBOR for foreign LIBOR $+B$. Alternatively, the OIS rate can be used instead of LIBOR. The following derivation establishes the relation between crosscurrency basis swaps and CIP deviation. Fig. 6 illustrates the cash flow of a cross-currency basis swap.

Variable definitions:

- $Z_{T}$ : Domestic zero rate

- $Z_{T}^{*}$ : Foreign zero rate

- $R$ : Dollar par swap rate

- $R^{*}$ : Foreign par swap rate

- $S$ : Spot currency exchange rate at time 0. Dollar per 1 unit of foreign currency. e.g. EURUSD

- $F_{T}$ : Forward currency exchange rate at time 0

- T: Maturity

- $B$ : A swap of 3-month dollar LIBOR is fair against 3-month foreign LIBOR $+B$

Without CIP deviation, the forward exchange rate can be expressed as

$$
F=S \frac{(1+Z)^{T}}{\left(1+Z^{*}\right)^{T}} .
$$

A simplified definition of CIP deviation can be expressed as $x$ in the following equation

$$
F=S \frac{1+r}{1+r^{*}-x} .
$$

Using a replication portfolio similar in methodology to Tuckman and Porfirio (2003), I show that

$$
F .=\frac{S_{0}(1+Z)^{T}}{\left(1+Z^{*}\right)^{T}}\left(1+B \frac{\left[\left(1+Z^{*}\right)^{T}-1\right]}{R^{*}\left(1+Z^{*}\right)^{T}}\right)^{-1}
$$

Consider the following replicating portfolio for a cross-currency basis swap

Positive $=$ Receive, Negative $=$ Pay 


\begin{tabular}{|c|c|c|c|c|c|c|}
\hline Transaction & to $(\$)$ & Interim $(\$)$ & $\mathrm{T}(\$)$ & t0 $(\mathrm{F})$ & Interim $(\mathrm{F})$ & $\mathrm{T}(\mathrm{F})$ \\
\hline $\begin{array}{c}\text { Rec. Euribor }+B \text { vs } \\
\text { pay } \$ \text { LIBOR } \\
\text { cross-currency swap }\end{array}$ & $+S_{0}$ & $-S_{0} L_{t}$ & $-S_{0}$ & -1 & $L_{t}^{*}+B$ & +1 \\
\hline Spot FX & $-S_{0}$ & & & +1 & & \\
\hline $\begin{array}{c}\text { Foreign: Pay } \\
\text { fixed/rec. floating par } \\
\text { swap in amount } \frac{B}{R^{*}}\end{array}$ & & & & & $B / R^{*}\left[L_{t}^{*}-R^{*}\right]$ & \\
\hline $\begin{array}{c}\text { Foreign: Pay floating } \\
\text { zero coupon swap } \\
\text { (ZCS) in amount } \\
\left(1+\frac{B}{R^{*}}\right)\end{array}$ & & & & & $-L_{t}^{*}\left(1+\frac{B}{R^{*}}\right)$ & $\left(1+\frac{B}{R^{*}}\right)\left[\left(1+Z^{*}\right)^{T}-1\right]$ \\
\hline $\begin{array}{l}\text { Dollar: Rec. floating } \\
\text { ZCS in amount } S_{0}\end{array}$ & & $S_{0} L_{t}$ & $-S_{0}\left[(1+Z)^{T}-1\right]$ & & & \\
\hline \multirow[t]{2}{*}{$\begin{array}{l}\text { Sell foreign fwd. of in } \\
\text { amount } \frac{S_{0}(1+Z)^{T}}{F}\end{array}$} & & & $\frac{S_{0}(1+Z)^{T}}{F} F$ & & & $-\frac{S_{0}(1+Z)^{T}}{F}$ \\
\hline & 0 & 0 & 0 & 0 & 0 & \\
\hline
\end{tabular}

Setting the foreign cash flow of time $T$ equal to 0 , we get

$$
\begin{aligned}
\left(1+\frac{B}{R^{*}}\right)\left[\left(1+Z^{*}\right)^{T}-1\right]+1 & =\frac{S_{0}(1+Z)^{T}}{F} \\
\left(1+Z^{*}\right)^{T}+\frac{B\left[\left(1+Z^{*}\right)^{T}-1\right]}{R^{*}} & =\frac{S_{0}(1+Z)^{T}}{F} \\
1+\frac{B\left[\left(1+Z^{*}\right)^{T}-1\right]}{R^{*}\left(1+Z^{*}\right)^{T}} & =\frac{S_{0}(1+Z)^{T}}{F\left(1+Z^{*}\right)^{T}} \\
F & =\frac{S_{0}(1+Z)^{T}}{\left(1+Z^{*}\right)^{T}}\left(1+B \frac{\left[\left(1+Z^{*}\right)^{T}-1\right]}{R^{*}\left(1+Z^{*}\right)^{T}}\right)^{-1} \\
F_{d / f} & =S_{d / f} \frac{(1+Z)^{T}}{\left(1+Z^{*}\right)^{T}}\left(1+P V^{*}[B]\right)^{-1}
\end{aligned}
$$

Now relating this to the simplified definition

$$
F=S \frac{(1+Z)^{T}}{\left(1+Z^{*}-x\right)^{T}}
$$

We set the two relations equal to each other and obtain

$$
\begin{aligned}
& \frac{1}{\left(1+Z^{*}-x\right)^{T}}=\frac{1}{\left(1+Z^{*}\right)^{T}}\left[1+B \frac{\left(1+Z^{*}\right)^{T}-1}{R^{*}\left(1+Z^{*}\right)^{T}}\right]^{-1} \\
& \left(1+Z^{*}-x\right)^{T}=\left[1+B \frac{\left(1+Z^{*}\right)^{T}-1}{R^{*}\left(1+Z^{*}\right)^{T}}\right]\left(1+Z^{*}\right)^{T}
\end{aligned}
$$


The left hand side can be Taylor approximated around $B=0$ as $\left(1+Z^{*}\right)^{T}+T\left(1+Z^{*}\right)^{T-1} B$, therefore

$$
\begin{aligned}
\left(1+Z^{*}\right)^{T}+T\left(1+Z^{*}\right)^{T-1} x & \approx\left[1+X \frac{\left(1+Z^{*}\right)^{T}-1}{R^{*}\left(1+Z^{*}\right)^{T}}\right]\left(1+Z^{*}\right)^{T} \\
\frac{T x}{1+Z^{*}} & \approx-B \frac{\left(1+Z^{*}\right)^{T}-1}{R^{*}\left(1+Z^{*}\right)^{T}} \\
x & \approx-B\left[\frac{\left(1+Z^{*}\right)^{T}-1}{R^{*}\left(1+Z^{*}\right)^{T}}\right] \frac{1+Z^{*}}{T}
\end{aligned}
$$

With the definition of a swap $R^{*}=\frac{1-\left(1+Z^{*}\right)^{-T}}{\sum_{t=1}^{T}\left(1+Z_{0, t}^{*}\right)^{t}}$, we get

$$
x \approx-B\left[\sum_{t=1}^{T}\left(1+Z_{0, t}^{*}\right)^{-t}\right] \frac{1+Z^{*}}{T}
$$

Suppose zero rates for different maturities are constant, $Z_{0, t}=Z_{0, T}=z$, i.e. the zero curve is flat (this also implies a flat swap curve). Generally, zero coupon curves are upward sloping. Assuming a flat curve biases the discount factor to be smaller, making for a more conservative estimation. Then the PV becomes

$$
\sum_{t=1}^{T}\left(1+z^{*}\right)^{-t}=-\frac{\left(z^{*}+1\right)^{-T}-1}{z^{*}}
$$

and $x$ becomes

$$
\begin{aligned}
x & \approx-P V \frac{1+z^{*}}{T} B \\
& \approx\left[\frac{\left(z^{*}+1\right)^{-T}-1}{z^{*} T}\left(1+z^{*}\right)\right] B \\
& \approx-\left[1+\frac{1}{2}(1-T) z^{*}+1 / 6\left(T^{2}-1\right)\left(z^{*}\right)^{2}\right] B
\end{aligned}
$$

where the last line applies a third-order Taylor approximation.

Cross-currency basis swap with OIS rate Most cross-currency basis swaps traded in the market are LIBOR-based. Combining the LIBOR cross-currency basis swap with other swaps such as the LIBOROIS swap or the Fixed-for-Floating LIBORswap allows the end user to customize the resultant swap to their particular needs. OIS-based cross-currency basis swaps have also been traded directly in the market, although far less frequently and only on a few currencies. The maturity of the OIS-based swaps is also incomplete for certain currencies. Fig. 7 shows the comparison of the five year LIBOR-based cross-currency basis and the five-year OIS-based cross-currency basis for EURUSD. The two time series are similar. This reflects that the five-year dollar Libor-OIS swap spread and the equivalent spread in EUR are similar.

\section{Extended model}

This section provides a model extension from the model in the main text. The key extensions are made on the global issuers. In contrast to the simple model in the main text, the extension allows firms to choose their FX hedging ratio with possible carry trade motives. In addition, the extension incorporates the possibility 
that firms have natural exchange rate hedges, e.g. cash flow or asset denominated in the currency of debt issuance. The main model predictions, along with additional implications, emerge in the extended model. Fig. 8 presents a schematic of the model.

\subsection{Credit markets}

In this static model, there are two credit markets: the euro-denominated corporate bond market and the dollar-denominated corporate bond market, and three main credit market players: specialist local investors in EUR debt, specialist local investor in USD debt and a representative firm that has access to both debt markets.

Local investors The active local investors are specialized in investments in their home currency. U.S. active investors specialize in the investment of corporate bonds denominated in dollars. They borrow at the domestic short rate, $r_{U}$, and purchase bonds with a promised net yield of $Y_{U}$. With fixed probability $\pi$, the bonds default and lose $L$ in value. The payoff of the bonds has a variance of $V_{C}$, which is treated as an exogenous constant in the model for tractability ${ }^{6}$. Investors have a mean-variance preference with risk tolerance $\tau_{i}$ and choose investment amount $X_{U}$ to solve the following

$$
\max _{X_{U}}\left[X_{U}\left((1-\pi) Y_{U}-\pi L-r_{U}\right)-\frac{1}{2 \tau_{i}} X_{U}^{2} V_{C}\right]
$$

which has the solution

$$
X_{U}=\tau_{i} \frac{(1-\pi) Y_{U}-\pi L-r_{U}}{V_{C}} .
$$

Similarly, the European credit investors are constrained to invest in euro-denominated bonds. For simplicity, assume that the default probability, loss given default and payoff variance are the same for bonds in both markets ${ }^{7}$. European credit investors have a demand of

$$
X_{E}=\tau_{i} \frac{(1-\pi) Y_{E}-\pi L-r_{E}}{V_{C}} .
$$

Exogenous credit demand shocks In addition, I introduce idiosyncratic demand shocks of $\varepsilon_{U}$ in dollar bonds and $\varepsilon_{E}$ in euro bonds. These shocks are exogenous to the model and perhaps represent demand shocks that originate from Quantitative Easing or preferred-habitat investors with inelastic demands such as pension funds, insurance companies and endowments. The sources of exogenous shocks are discussed in Section 5 .

Firm The representative global firm needs to issue a fixed debt amount $D$. The firm chooses a share $\mu$ of the debt to be issued in dollars at a cost of $Y_{U}$. The remainder $1-\mu$ of the debt is issued in euros, promising a coupon of $Y_{E}$. The firm is a price taker, and its decision is analyzed in Section 4.3.

\footnotetext{
${ }^{6}$ A Bernoulli default distribution with probability $\pi$, loss-given-default $L$ and promised yield $Y_{U}$ implies that $V_{C}=\pi(1-\pi)\left(Y_{U}+L\right)^{2}$. The solution to the investors' problem would contain a quadratic root. To keep the model tractable, $V_{C}$ is assumed to be an exogenous constant.

${ }^{7}$ Given common default probability $\pi$ and loss-given-default $L$, payoff variance $V_{C}$ of euro-denominated and dollardenominated bonds can only be the same if the promised yields $Y_{U}$ and $Y_{E}$ are also identical. With a small difference in $Y_{U}$ and $Y_{E}$ in comparison to $L, V_{C}$ is assumed to be the same for both markets.
} 
Market-clearing conditions in the dollar and euro credit market are

$$
\begin{aligned}
X_{U}+\varepsilon_{U} & =\mu D \\
X_{E}+\varepsilon_{E} & =(1-\mu) D .
\end{aligned}
$$

Combining the demand equations with the market-clearing conditions and applying first-order Taylor approximation for $\pi$ around 0 , we can write the difference in promised yield between euro and dollar bonds as a credit spread difference, $\kappa$, and a risk-free rate difference, $\rho$.

$$
\begin{aligned}
Y_{E}-Y_{U} & =\underbrace{\frac{V_{C}}{\tau_{i}}\left((1-2 \mu) D-\varepsilon_{\kappa}\right)}_{\kappa}+\underbrace{\left(r_{E}-r_{U}\right)}_{\rho} \\
& \equiv \kappa+\rho
\end{aligned}
$$

where $\varepsilon_{\kappa} \equiv \varepsilon_{E}-\varepsilon_{U}$ is the relative idiosyncratic euro credit demand. The credit spread differential, $\kappa$, is a function of dollar issuance share $\mu$, local investor risk preference $\tau_{i}$, payoff variance $V_{C}$ and relative credit demand shock. $\kappa$ represents the price discrepancy of credit risk since the default probability and loss given default are identical across the two markets.

The cross-currency issuer has limited ability to influence the relative credit spread. If it chooses all of its debt to be issued in euros instead of dollars, i.e. $\mu=0$, then the relative credit spread in euros would widen as a result of the additional debt supply. The issuer's impact is limited, however, by the size of its total debt issuance $D$ given the restriction that $\mu \in[0,1]$.

\subsection{Currency swap market}

Next, I describe the dynamics of the currency swap market. There are two main players in this market: currency swap traders and issuers.

Currency swap traders Currency swap traders choose an amount of capital to devote to either CIP deviations, denoted as $x$, or to an alternate investment opportunity with a profit of $f(I)$, where $I$ is the amount of investment.

To arbitrage CIP violations, the trader must set aside a haircut $H$ when it enters the swap transaction. Following Garleanu and Pedersen (2011), the haircut amount is assumed to be proportional to the size $s$ of the swap position, $H=\gamma|s|$. Therefore, the capital devoted to alternative investment is $I=W-\gamma|s|$. The swap trader has total wealth $W$ and solves $\max _{s} x s+f(W-\gamma|s|)$. The solution, $x=\operatorname{sign}[s] \gamma f^{\prime}(W-\gamma|s|)$, provides the intuition that the expected gain from conducting an additional unit of CIP arbitrage is equal to the marginal profitability of the alternative investment. A simple case is when the alternative investment activity is quadratic, $f(I)=\phi_{0} I-\frac{1}{2} \phi I^{2}$. In this case, $x=\operatorname{sign}[s] \gamma\left(\phi_{0}-\phi W+\gamma \phi|s|\right)$.

I make an additional simplifying assumption that while CIP deviation $x$ disappears when there is no net demand for swaps, as soon as there is net demand for swaps, $x$ becomes nonzero. This assumption is equivalent to stating that $\frac{\phi_{0}}{\phi}=W$, which means that the arbitrageur has just enough wealth $W$ to take advantage of all positive-NPV investment opportunities in the alternative project $f(I)$. Simplifying with this assumption and omitting the constant intercept term in the equation for $x$, we obtain that CIP deviation is proportional to the trader's position, $x=\phi \gamma^{2} s$. I further normalize $\phi$ to one for simplicity. This swap trader model is analogous to that of Ivashina, Scharfstein, and Stein (2015) which models the outside alternative 
activity of the trader with a log functional form instead of the quadratic form.

Firm The same representative firm from the credit market also engages in FX swap transactions as a price taker. The issuer has a desired dollar funding ratio of $m$ and a euro funding ratio of $1-m$. This target could represent the firm's operational exposures in different currencies. For instance, AT\&T would have $m=1$ since its operations are entirely in the U.S. The issuer thus has an exchange rate exposure of $(m-\mu)$ given its choice of dollar issuance share $\mu$. It chooses a hedging ratio $h \in[0,1]$ for a total amount of hedged foreign issuance $(m-\mu) h D$. From the perspective of a U.S.-based issuer with $m=1$, e.g. AT\&T, the hedging amount $(1-\mu) h D$ is positive and represents the issuer's dollar borrowing via the FX market. AT\&T buys dollars in the spot market for conversion of euro issuance proceeds into dollars and sells dollars in the forward market for future repayment of debt. The currency swap trader must hold the opposite position, that is, lending dollars to AT\&T by selling dollars in the spot market and buying dollars in the forward market.

Exogenous FX swap demand In addition, there is a source of exogenous shock $\varepsilon_{x}$ that represents other non-issuance-related use of FX-swaps. The sources of exogenous shocks are discussed in Section 5.

Equilibrium The market-clearing condition of the FX swap market implies that the equilibrium level of CIP deviation satisfies

$$
x=\gamma^{2} \phi\left(D(m-\mu) h+\varepsilon_{x}\right)
$$

Equation 12 provides several intuitive comparative statics. First, the CIP deviation $x$ is proportional to the total amount of hedging demand $D(m-\mu) h+\varepsilon_{F} . x$ is positive when there is a net hedging demand for borrowing dollars/lending euros, that is when $D(m-\mu) h+\varepsilon_{x}>0$. This can occur if the issuer has a dollar funding shortfall, $m>\mu$, e.g. if AT\&T issues a fraction of its bonds in euros but has its entire funding needs in U.S. dollars and therefore needs to borrow dollars/lend euros via the FX market. On the other hand, $x$ is negative when the net hedging demand is for borrowing euros/lending dollars. Second, more stringent haircut requirements $\gamma$ intensify the impact of hedging demand for either positive or negative deviations.

One additional insight on the role of the issuer in the above setup is that debt issuer hedging demand $D(m-\mu) h$ does not have to have the same sign as other exogenous hedging demand, $\varepsilon_{x}$. In the case $\operatorname{sign}\left[\varepsilon_{x}\right] \neq \operatorname{sign}[D(m-\mu)]$ and $\left|\varepsilon_{x}\right|>|D(m-\mu)|$, the issuer provides (rather than demands) liquidity in the FX swap market and incurs an additional benefit (instead of cost) through hedging. In this case, the firm would contribute to the elimination of CIP deviation and act as a provider of liquidity in the currency forward market.

\subsection{The Firm's Problem}

Putting it all together, I describe the firm's optimization problem and first-order conditions. The representative firm has a mean-variance preference and wants to minimize the total cost of issuance while avoiding exchange rate volatility. It chooses a fraction $\mu$ of the debt to be issued in dollars and a hedging ratio $h$ to minimize the total financing cost. Dollar debt carries a promised yield of $Y_{U}$, and the remaining debt is issued in euros at a yield of $Y_{E} \equiv Y_{U}+\kappa+\rho$. The unhedged cost difference is $\kappa+\rho$, where $\rho$ the interest rate differential is the gain from FX carry trade. FX-unhedged issuance that deviates from the firm's desired currency mix $m$ exposes the firm to exchange rate variance $V_{F}$ and incurs a cost reflecting distaste 
for volatility ${ }^{8}$. Since $D(m-\mu)$ is the currency mismatch and $1-h$ fraction of this mismatch is unhedged, the cost due to FX volatility is $\frac{1}{2 \tau_{F}} D^{2}(m-\mu)^{2}(1-h)^{2} V_{F}$. FX hedging imposes an adjustment to debt servicing cost equal to the amount of hedging need $(m-\mu) h$ multiplied by the per-unit price of hedging $x$, which is the deviation from CIP.

Given the above setup, the firm solves

$$
\min _{\mu, h} D[\underbrace{\mu Y_{U}}_{\text {USD funding cost }}+\underbrace{(1-\mu)\left(Y_{U}+\kappa\right)}_{\text {EUR funding cost }}+\underbrace{(m-\mu) h x}_{\text {hedging cost }}+\underbrace{\frac{1}{2 \tau_{F}} D(m-\mu)^{2}(1-h)^{2} V_{F}}_{\text {distaste for FX volatility }}] .
$$

Cross-currency issuers are taken to be a representative firm that is a price taker in the credit and FX swap markets. That is, there can be many other identical firms of total measure one solving the same optimization problem. Their debt issuance in each market determines the bond yields and currency swap levels but they take the equilibrium prices as given when solving their optimization problem.

We first analyze the partial equilibrium solution in the firm's problem before considering the general equilibrium in section (4.4). The firm's first-order conditions are

$$
\mu^{*}=m+\frac{\tau_{F}\left(\kappa+x h^{*}\right)}{D\left(h^{*}-1\right)^{2} V_{F}}
$$

and

$$
h^{*}=1+\frac{\tau_{F} x}{\left(m-\mu^{*}\right) D V_{F}} .
$$

Equation 14 says that the issuer has a natural inclination to issue a fraction $m$ of the total debt in dollars to obtain the optimal capital structure. With credit market frictions, dollar issuance share increases in the relative euro credit spread $\kappa$. That is, if AT\&T's euro credit spread were wide relative to that of the dollar, it is more incentivized to issue in dollars. Similarly, segmentation in the FX market also affects the equilibrium share of issuance in dollar. When the cost of borrowing dollars in the FX market is large, AT\&T is reluctant to issue in euros and engage in the swapping of proceeds to dollars-therefore the dollar issuance ratio $\mu^{*}$ is high.

Equation 15 expresses the optimal hedging ratio in terms of the optimal share of dollar issuance. I impose the assumption that the issuer cannot make a pure exchange rate bet, thus $h \in[0,1]$. When there is a dollar financing shortfall $\left(m>\mu^{*}\right)$, hedging is incomplete $(h<1)$ if there is a costly CIP deviation for borrowing dollars via the FX market $(x>0)$. Similarly, when there is a euro financing shortfall $m<\mu^{*}$, hedging is incomplete if it is costly to borrow euros via the FX market $(x<0)$. Furthermore, hedging ratio approaches unity when the firm has zero risk tolerance $\tau_{F}$, a large amount of issuance-driven FX exposure $\left(m-\mu^{*}\right) D$, or when FX volatility is high. In sum, hedging is incomplete when it is costly and more complete when the firm is averse to large risks.

\footnotetext{
${ }^{8}$ The incentive to hedge volatile cash flows can be rationalized in the framework of costly external finance and a firm's incentive to keep sufficient internal funds available to take advantage of attractive investment opportunities (Froot, Scharfstein, and Stein 1992).
} 


\subsection{Perfect alignment of deviation}

Rewriting equations (10), (12), (14), and (15), we have four equilibrium conditions and four endogenous variables $(x, \kappa, \mu, h)$ summarized again below:

- Credit spread difference (euro minus dollar credit spreads)

$$
\kappa=\frac{V_{C}}{\tau_{i}}\left((1-2 \mu) D+\varepsilon_{\kappa}\right)
$$

- CIP violation (FX-implied minus actual euro funding rate)

$$
x=\gamma^{2} \phi\left(D(m-\mu) h+\varepsilon_{x}\right)
$$

- Issuance share in dollar

$$
\mu=m+\frac{\tau_{F}(\kappa+x h)}{D(h-1)^{2} V_{F}}
$$

- Hedging ratio

$$
h=1+\frac{\tau_{F} x}{(m-\mu) D V_{F}}
$$

The first two equations represent equilibrium conditions that determine the price deviations in the FX and credit markets. The last two equations are FOCs from the firm's issuance and hedging decisions. Two types of shocks are exogenous to the system: credit demand shock $\varepsilon_{\kappa}$ (positive indicates relative demand for euro credit) and FX swap demand shock $\varepsilon_{x}$ (positive indicates dollar-borrowing demand).

We can solve the model and obtain the general equilibrium solutions for $\kappa, x, \mu$, and $h$. We analyze the solution for $\kappa$ and $x$, and especially focus on the shock terms.

The solutions can be written in matrix form as

$$
\left[\begin{array}{c}
\kappa \\
x \\
\mu
\end{array}\right]=\Lambda\left(\left[\begin{array}{cc}
-\left(\tau_{F} V_{C}+\tau_{s} V_{C} V_{F}\right)-\tau_{\chi} V_{C} V_{F} D & -2 \tau_{\chi} V_{C} V_{F} D \\
\tau_{\chi} V_{C} V_{F} D & \tau_{i} V_{F}+2 \tau_{\chi} V_{C} V_{F} D \\
-\tau_{\chi}\left(\tau_{F} V_{C}+\tau_{s} V_{C} V_{F}\right) & \tau_{\chi} \tau_{i} V_{F}
\end{array}\right]\left[\begin{array}{ll}
\varepsilon_{\kappa} & \varepsilon_{x}
\end{array}\right]^{T}+\text { const. }\right)
$$

where

$$
\Lambda=\left[D \tau_{\chi}\left(2 V_{C}\left(\tau_{F}+V_{F} \tau_{s}\right)+V_{F} \tau_{i}\right)+\tau_{i}\left(\tau_{F}+V_{F} \tau_{s}\right)\right]^{-1} .
$$

$\Lambda$ decreases with risk tolerance and debt amount. Intuitively, the absolute level of deviations is reduced when there is more capital devoted to cross-market arbitrage or agents are more risk tolerant.

While comparative statics with respect to the terms that appear in $\Lambda$ cannot be seen easily in the above expression, it is informative to examine the direction and relative magnitude of the impact of $\varepsilon_{\kappa}$ and $\varepsilon_{x}$ shocks on $\kappa, x$ and $\mu$. A positive $\varepsilon_{\kappa}$ shock (more demand for euro credit) compresses the relative euro credit spread $\kappa$ as well as increases the hedging cost $x$. The credit shock's effect on CIP deviation $x$, indicated by the term $\tau_{\chi} V_{C} V_{F} D \Lambda$, is from the issuer's conversion of its euro bond issuance proceeds into dollar. Given limited FX swap arbitrageur capital, the demand to borrow dollars and lend euros exerts a price pressure on FX forwards relative to spot exchange rates, creating the deviation in CIP as a result. The credit shock's impact on the corporate basis $\kappa+x$ is $-\left(\tau_{F} V_{C}+\tau_{s} V_{C} V_{F}\right) \Lambda$. This impact motivates the firm to shift the 
currency of issuance to lean against the shock. Therefore, $\mu$, the share of issuance denominated in dollars, declines proportionally to this impact.

Similarly, a $\varepsilon_{x}$ shock to the FX swap market also has multitudinous effects on the two LOOP violations and issuance currency choice. A positive $\varepsilon_{x}$ shock represents demand for borrowing dollars/lending euros (buy dollar spot/sell dollar forward) via the FX market. Therefore, the $\varepsilon_{x}$ shock raises $x$, making it more costly to swap euros into dollars. Facing this higher cost of conversion, the firm has less incentives to issue in euros, and its share of dollar issuance increases by $\tau_{\chi} \tau_{i} V_{F} \Lambda$. With an inward shift in the supply of euro credit, the price of euro credit increases as well, or equivalently $\kappa$ falls. Similar to the impact of $\varepsilon_{k}$ shocks, the impact of $\varepsilon_{x}$ shocks on the equilibrium issuance share in dollars is $\tau_{\chi} \tau_{i} V_{F} \Lambda$; this is directly proportional to the shock's impact on the corporate basis $\kappa+x$.

In equilibrium, issuance share in dollar $\mu$ co-moves with the corporate basis $\kappa+x$. This comovement is robust to the presence of either type of shocks. Suppose $\tau_{\chi} \gg 0$ that the firm is very tolerant of concentration risk, then any small corporate basis would motivate the firm to change its currency mix substantially to take advantage of the corporate basis. In the limiting case in which the firm is unrestricted in FX-hedged crosscurrency issuance, the corporate basis would disappear entirely, i.e. $\lim _{\tau_{\chi} \rightarrow \infty} \kappa+x=0$. The preference for a diverse currency mix and limited issuance amount prevents the firm from completely arbitraging away $\kappa+x$.

\subsection{Imperfect alignment of deviations}

In the previous section, I introduced the model to show a simple case of perfect alignment between the two deviations. Next, I explore more realistic case in which there is imperfect alignment. Since the firm integrates the two deviations, there must be some frictions that prevent the firms from completely aligning the two deviations.

$$
\min _{\mu, h}[\underbrace{-\mu \kappa}_{\text {credit spread diff. }}+\underbrace{\frac{1}{\tau_{\chi}}(m-\mu)^{2}}_{\text {optimal capital structure deviation }}+\underbrace{(m-\mu) h x}_{\text {hedging cost }}+\underbrace{\frac{1}{2 \tau_{F}} D(m-\mu)^{2}(1-h)^{2} V_{F}}_{\text {distaste for FX volatility }}] .
$$

The term $\frac{1}{\tau_{\chi}}(m-\mu)^{2}$ comes from refinancing risk due to the concentration of bond ownership (Boermans, Frost, and Bisschop, 2016), or collateral constraints for hedging (Rampini and Viswanathan, 2010). Loosely speaking, $\tau_{\chi}$ represents balance sheet strength.

Partial equilibrium; FOC condition for $\mu^{*}$

$$
\mu^{*}=m+\tau_{\chi}(\kappa+x)
$$

$h^{*}$ is the same as before.

The solution can be written in matrix form,

$$
\left[\begin{array}{c}
\kappa \\
x \\
\kappa+x \\
\mu
\end{array}\right]=\Lambda\left(\left[\begin{array}{cc}
-\left(\tau_{\chi} \gamma^{2} \phi V_{F} D+\gamma^{2} \phi \tau_{F}+V_{F}\right) V_{C} & -2 \gamma^{2} \phi \tau_{\chi} V_{C} V_{F} D \\
\tau_{\chi} \gamma^{2} \phi V_{F} D V_{C} & \gamma^{2} \phi\left(2 \tau_{\chi} V_{C} D+\tau_{i}\right) V_{F} \\
-\left(\gamma^{2} \phi \tau_{F}+V_{F}\right) V_{C} & \gamma^{2} \phi \tau_{i} V_{F} \\
-\tau_{\chi}\left(\gamma^{2} \phi \tau_{F}+V_{F}\right) V_{C} & \tau_{\chi} \gamma^{2} \phi \tau_{i} V_{F}
\end{array}\right]\left[\begin{array}{ll}
\varepsilon_{\kappa} & \varepsilon_{x}
\end{array}\right]^{T}+\right.\text { const. }
$$


where

$$
\Lambda=\left[\gamma^{2} \phi\left(\tau_{F}\left(2 D V_{C} \tau_{\chi}+\tau_{i}\right)+D V_{F} \tau_{i} \tau_{\chi}\right)+V_{F}\left(2 D V_{C} \tau_{\chi}+\tau_{i}\right)\right]^{-1}
$$

The solution model yields the following propositions.

Proposition 2. (The alignment of deviations) When firms are relatively unconstrained by capital structure considerations, $\tau_{X} \gg 0$, the credit spread differential and CIP deviations respond to shocks to either credit or FX swap demand directly opposite of each other, $\frac{\partial \kappa}{\partial \varepsilon_{\kappa}} \approx-\frac{\partial x}{\partial \varepsilon_{\kappa}}$ and $\frac{\partial \kappa}{\partial \varepsilon_{x}} \approx-\frac{\partial x}{\partial \varepsilon_{x}}$. The two deviations also have similar magnitude, $|\kappa| \approx|x|$. When firms are completely unconstrained in capital structure, $\lim _{\tau_{\chi} \rightarrow \infty} \kappa=-\lim _{\tau_{\chi} \rightarrow \infty} x$.

As we have already seen in Equation 19, the two violations share common loadings on $\varepsilon_{x}$ and $\varepsilon_{\kappa}$ shocks. Rewriting the comparative statics of the violations with respect to the shocks, we have

$$
\frac{1}{\tau_{\chi}} \frac{\partial \mu}{\partial \varepsilon_{\kappa}}=\frac{\partial x}{\partial \varepsilon_{\kappa}}+\frac{\partial \kappa}{\partial \varepsilon_{\kappa}}
$$

and

$$
\frac{1}{\tau_{\chi}} \frac{\partial \mu}{\partial \varepsilon_{x}}=\frac{\partial x}{\partial \varepsilon_{x}}+\frac{\partial \kappa}{\partial \varepsilon_{x}} .
$$

When the issuer is completely unrestricted in the choice of issuance currency, the two deviations are perfectly offseting in response to shocks, i.e. $\lim _{\tau_{\chi} \rightarrow \infty} \frac{\partial \kappa}{\partial \varepsilon_{\kappa}}=-\lim _{\tau_{\chi} \rightarrow \infty} \frac{\partial x}{\partial \varepsilon_{\kappa}}$ and $\lim _{\tau_{\chi} \rightarrow \infty} \frac{\partial \kappa}{\partial \varepsilon_{x}}=-\lim _{\tau_{\chi} \rightarrow \infty} \frac{\partial x}{\partial \varepsilon_{x}}$. Empirically, the two time series have a high level of negative correlation but are not perfectly negatively correlated. This indicates that issuers have a $\tau_{\chi}$ that is high but not infinite.

Proposition 3. (The comovement of cross-currency issuance with the corporate basis) Sign $\left[\frac{\partial \mu}{\partial \varepsilon}\right]=\operatorname{Sign}\left[\frac{\partial(\kappa+x)}{\partial \varepsilon}\right]$ and Sign $\left[\frac{\partial \mu}{\partial m}\right]=-\operatorname{Sign}\left[\frac{\partial(\kappa+x)}{\partial m}\right]$. Dollar issuance ratio $\mu$ is positively correlated to the corporate basis $\kappa+x$ when shocks originate from the demand for credit or FX forwards. $\mu$ is negatively correlated to $\kappa+x$ when shocks originate from exogenous changes in the desired issuance currency mix $m$ (supply shocks) ${ }^{9}$.

Proposition 4. (The cross-section of issuance-based arbitrage) $\frac{\partial^{2} \mu}{\partial \varepsilon_{\kappa} \partial \tau_{X}}<0, \frac{\partial^{2} \mu}{\partial \varepsilon_{x} \partial \tau_{X}}>0, \frac{\partial^{2}(\kappa+x)}{\partial \varepsilon_{\kappa} \partial \tau_{X}}>0$, and $\frac{\partial^{2}(\kappa+x)}{\partial \varepsilon_{x} \partial \tau_{X}}<0$. Firms with stronger balance sheets (higher $\tau_{\chi}$ ) respond more aggressively to demand shocks in credit and FX, and their firm-specific corporate basis is less responsive to shocks.

Proposition 5. (The balance sheet of financial intermediary) $\frac{\partial \kappa}{\partial \varepsilon \partial \gamma}<0, \frac{\partial x}{\partial \varepsilon \partial \gamma}<0$. When the haircut for swap traders $\gamma$ is high, both deviations are more responsive to demand shocks. The effect on the corporate basis is ambiguous, depending on the source of the shock.

Proposition 6. (The amount of capital available for arbitrage use) $\frac{\partial(\kappa+x)}{\partial \varepsilon_{\kappa} \partial D}>0, \frac{\partial(\kappa+x)}{\partial \varepsilon_{x} \partial D}<0$. The impact of shocks on the corporate basis is smaller when total amount of debt issuance is high.

9

$$
\begin{aligned}
\frac{\partial(\kappa+x)}{\partial m} & =-2 \gamma^{2} \phi \tau_{F} B V_{C}-2 B V_{C} V_{F} \\
\frac{\partial \mu}{\partial m} & =\gamma^{2} \phi \tau_{\chi} \tau_{i} V_{F} B+\tau_{i} V_{F}+\tau_{i} \gamma^{2} \phi \tau_{F}
\end{aligned}
$$


This follows the intuition that when issuers are able to provide enough cross-market arbitrage capital, the FX funding and credit markets become more integrated.

Proposition 7. (Risk and risk tolerance) $\frac{\partial \kappa}{\partial \varepsilon \partial V}<0, \frac{\partial x}{\partial \varepsilon \partial V}>0, \frac{\partial \kappa}{\partial \varepsilon \partial \tau}>0$, and $\frac{\partial x}{\partial \varepsilon \partial \tau}<0$. With higher payoff variance $V_{C}$, exchange rate variance $V_{F}$ or lower risk tolerances $\tau_{F}$ and $\tau_{i}$, the impact of demand shocks on credit spread differential and CIP violations is amplified.

This is because when the credit markets have perfectly elastic supply curves, credit demand shocks have smaller impacts on the relative price of credit; therefore, the corporate basis is also impacted. Similarly, the FX shock term $\frac{1}{\tau_{\chi}} \frac{\partial \mu}{\partial \varepsilon_{x}}$ converges to zero as either the FX arbitrageur's risk tolerance or the issuer's tolerance for exchange rate volatility approaches infinity. That is, when the FX arbitrageur or issuer provides a perfectly elastic supply of FX swaps, $\varepsilon_{x}$ shocks would not have an impact on the CIP deviation and the corporate basis.

Lastly, the model demonstrates how frictions in one market can constrain the other market with the following comparative statics.

Proposition 8. (Limits to arbitrage spillover) Comparative statics with respect to parameters reflecting prices of risk:

\begin{tabular}{cccc} 
& FX haircut $\gamma \uparrow$ & Credit investor risk tol. $\tau \uparrow$ & bond risk $V \uparrow$ \\
\hline$|\kappa|$ & $\uparrow$ & $\downarrow$ & $\uparrow$ \\
$|x|$ & $\uparrow$ & $\downarrow$ & $\uparrow$
\end{tabular}

The comparative statics suggest that limits of arbitrage are carried over from one market to the other. For instance, the FX swap haircut $\gamma$ directly affects not only the CIP deviation $x$, but also indirectly affects the credit spread differential $\kappa$ through the action of the cross-market arbitrageur. Similarly, the risk tolerance of bond investors $\tau$ and bond risk $V$ also affect CIP deviation. Thus, limits of arbitrage from one market can spill over to a completely different market.

\section{$5 \quad$ Source of $\varepsilon_{\kappa}$ and $\varepsilon_{x}$ shocks}

In this section, I discuss the possible sources of shocks to the credit spread and FX basis in detail. For a graphical illustration of the frictions in the two markets, see Fig. 9.

\section{$5.1 \varepsilon_{\kappa}$ shocks}

- Central bank QE Large asset purchasing programs by central banks have contributed to the displacement of traditional government debt investors in search of high-yielding assets such as corporate bonds. The differential timing and sizes of ECB and Fed QE programs likely changed the relative demand for credit in Europe and the U.S., resulting in changes in $\varepsilon_{\kappa}$.

- Passive investor portfolio changes Shifts in passive institutional investor's benchmarks and portfolios can bring large changes to the demand for assets. For instance, Japan's Government Pension Investment Fund, which holds US $\$ 1.2$ trillion in assets and serves as the most frequently used portfolio benchmark for other Japanese-based asset managers, reduced its domestic bond holdings in October 2014 from 60 percent to 35 percent and increased its allocations to stocks and foreign assets. This large, 
one-time portfolio shift differs from that of active credit specialists who decide on bond investments based on credit risks at higher frequencies.

- Regulatory-driven demand shocks Portfolio shifts can also be driven by regulatory reforms. One such regulatory change occurred in the United Kingdom, when the 2005 Pension Reform Act forced pension funds to mark their liabilities to market by discounting them at the yield on long-term bonds. This reform significantly increased the demand for long-term securities (Greenwood and Vayanos 2010).

- Credit-market sentiments Many papers have analyzed the role of credit sentiment on asset prices and the real economy (Lopez-Salido, Zakrajsek and Stein, 2017; Bordalo, Gennaioli, and Shleifer, 2018; Greenwood, Hanson, and Jin, 2019; Greenwood and Hanson, 2013). A shock to the relative credit demand between bond markets can arise if credit sentiments differentially impact different markets. One such episode occurred around the time of the Bear Stearns collapse, when the residualized USD credit spread widened relative to the EUR credit spread as fears of US credit market meltdown heightened.

\section{$5.2 \varepsilon_{x}$ shocks}

- Dollar liquidity shortage Since the crisis, non-U.S. banks, in need of short-term USD funding for their U.S. operations, have become active borrowers of USD through FX swaps ${ }^{10}$. A particularly striking episode of demand shock for FX swaps into USD is the 2011-12 Eurozone Sovereign Crisis. Dollar money market funds stopped lending to European banks out of fear of fallouts from the sovereign crisis. This episode is detailed in Ivashina, Scharfstein, and Stein (2015). Acute $\varepsilon_{x}$ shocks typically affect short-term CIP more than long-term CIP.

- Money market reform in the U.S. that took effect in October 2016 has reduced the availability of wholesale USD funding to foreign banks and increased their reliance on funding via currency swaps (Pozsar, 2016).

- Structured note issuers also utilize currency swaps in the hedging of ultra long-dated structured products whose payoff depends on the exchange rate at a future date. The hedging of Power Reverse Dual Currency Notes by issuers had been an important driver of currency basis in the AUD, JPY, and other Asian currencies.

- Regulatory-driven hedging demands New regulatory requirements for the hedging of previously under-hedged exposures have also driven the CIP basis. Solvency II Directives on EU and U.K. insurance companies demanded greater usage of longer-dated cross-currency basis swaps to reduce the foreign currency exposure of insurance firm asset holdings ${ }^{11}$. The Solvency II rules started with initial discussions in 2009 and finally took effect in 2016.

- Central bank policies European banks with excess EUR liquidity have been able to take advantage of the higher interest on excess reserve (IOER) rate offered by the Fed through conversion via FX

\footnotetext{
${ }^{10}$ Banks do not all have dollar liquidity shortage. For instance, in Australia, banks need to fund their long term needs abroad as the base of investors lending long-term is small. They borrow in USD or EUR and swap it back in AUD. CIP deviations in AUD indicates that it is more expensive to swap into AUD instead of the other way around. This demand is partially captured in the data on corporate debt issuance since the Australian banks fund through both the long-term debt market and short-term money market.

${ }^{11}$ Previously, insurance firms partially hedged using rolling short-dated FX forwards
} 
swaps. As of September 2016, foreign bank offices in the U.S. have $\$ 377$ billion in currency-swapped deposits at the Fed ${ }^{12}$.

The policies at other central banks also affected CIP violations. For example, the termination of the ECB's sterilization programs reduced the amount of High Quality Liquid Assets (HQLA) for European banks and was a contributing factor to the widening of the CIP violation in $2014^{13}$.

- Hedging demand from investors I do not consider this an $\varepsilon_{x}$ shock since the issuers in my model can be broadly interpreted as both sellers and buyers of bonds. Another reason why investors are not a major contributor to long-term CIP violations is that they often hedge FX risk using rolling short-dated forwards ${ }^{14}$.

\section{Additional analyses}

\subsection{Structural VAR}

I test the spillover of deviations through the channel of debt issuance by analyzing the impulse responses of credit spread differential $\kappa$, CIP violation $x$, and issuance flow $\mu$ to $\varepsilon_{\kappa}$ and $\varepsilon_{x}$ shocks. Additionally, I show that large issuances have a price impact on the FX basis.

Structural vector auto-regression (SVAR) analysis is informative in this context since the simultaneity of $\varepsilon_{k}$ and $\varepsilon_{x}$ shocks and slow issuance responses pose particular challenge to identification. As discussed in the earlier section, there are many potential sources of $\varepsilon_{\kappa}$ and $\varepsilon_{x}$ shocks. These shocks can occur concurrently, and they can be protracted and anticipated (e.g., gradual regulatory changes). Moreover, arbitrage capital provided by non-specialized agents are often slow to react to market distortions due to inattention and institutional impediments to immediate trade (Duffie, 2010; Mitchell, Pedersen and Pulvino, 2007). In this setting, cross-currency issuance responds to shocks gradually only when firms have issuance needs.

Fig. 10 presents the orthogonalized impulse response functions with shocks to the credit and CIP deviations. I apply Cholesky Decomposition following a partial identification approach that restricts $\mu$ to respond with a lag to $\kappa$ and $x$ but allows $\kappa$ and $x$ to have contemporaneous effects on each other. This specification is the following:

$$
\left[\begin{array}{ccc}
1 & & \\
a_{\kappa \mu} & 1 & a_{\kappa x} \\
a_{x \mu} & a_{x \kappa} & 1
\end{array}\right]\left[\begin{array}{c}
\mu_{t} \\
\kappa_{t} \\
x_{t}
\end{array}\right]=B\left[\begin{array}{c}
\mu_{t-1} \\
\kappa_{t-1} \\
x_{t-1}
\end{array}\right]+\left[\begin{array}{c}
\varepsilon_{\mu, t} \\
\varepsilon_{\kappa, t} \\
\varepsilon_{x, t}
\end{array}\right]
$$

The first row of the figure confirms model prediction 1. A $\varepsilon_{\kappa}$ shock that increases the euro credit spread relative to the dollar also increases dollar issuance fraction $\mu$ (top middle) and reduces dollar hedging cost $x$

\footnotetext{
${ }^{12}$ Foreign banks have a total excess reserve at the Fed totaling $\$ 766$ billion as of September 2016, of which $\$ 429$ billion are funded through fed fund and repo agreements as a part of the IOER-fed fund arbitrage (Flow of Funds Table L.112).

${ }^{13}$ ECB's Security Market Program that started in 2010 and the Outright Monetary Transaction program that started in 2012 both were initially sterilized purchasing programs. Sterilization encouraged the use of ECB excess reserves and provided a way for banks to obtain HQLAs needed to fulfill liquidity coverage ratio requirements. The end of ECB sterilization in 2014 meant that European banks needed to look for other HQLA to replace around $\$ 200$ billion of ECB excess reserves. Therefore, these banks had to either invest in EUR assets or swap into other currencies and park their cash at the Fed or other central banks.

${ }^{14}$ Most benchmark indices calculate total returns on foreign sovereign and corporate bonds either as unhedged returns or hedged returns using one-month rolling FX forwards. Bank of America Merrill Lynch, Barclays, and Citi each state in their index methodology that one-month rolling forwards are used in the calculation of total returns for currency hedged indices. Longer horizon FX hedges are sometimes used but generate tracking errors from benchmark for investors. Of course, the longand short- dated CIP basis are integrated to a certain extent as discussed below.
} 
(top right). Credit spread differential then gradually normalizes over the next few months after the initial shock, as do $\mu$ and $x$. The bottom row shows the impulse responses with an exogenous shock in $\varepsilon_{x}$ that signals an increase in the cost of swapping to USD from the other currencies. As predicted by Proposition 1, a higher cost of swapping from EUR to USD increases dollar issuance share $\mu$ (bottom middle). Euro credit spread relative to USD credit spread also decreases as EUR issuance supply shifts inward (bottom right). The persistence of response in issuance flow $\mu$ to $\varepsilon_{\kappa}$ and $\varepsilon_{x}$ shocks suggests that corporate financing decisions are slow-moving. The price under-reactions in the market not directly impacted by the shocks conforms with model predictions for slow-moving, partially segmented markets (Greenwood, Hanson, and Liao, 2018).

\subsection{Limits to arbitrage spillover}

I discuss evidence suggestive of limits to arbitrage spillover. The model shows that frictions that are constraining in one market can also be constraining for the other market. These limits to arbitrage frictions can be either quantifiable costs, such as transaction costs, or difficult-to-observe frictions, such as agency frictions. In the model, these constraints are represented by the FX swap collateral haircut $\gamma$ and the ratio of bond risk to risk tolerance $\frac{V}{\gamma}$. The FX haircut is a direct cost while the latter might proxy for indirect agency frictions associated with holding an arbitrage position that could become more dislocated before converging.

The empirical measures of these two types of limits to arbitrage are difficult to assess. The FX collateral haircut for a derivative transaction is specific to the trade and depends on the currency, maturity, and counterparty. The indirect costs of holding arbitrage positions to maturity are also challenging to quantify. As a suggestive test, I analyze the impact of broker-dealer leverage, proxying for $\gamma$, and the VIX index, proxying for $\frac{V}{\tau}$, on the absolute level of credit spread differential and CIP deviation. The results, presented in Table 3, are suggestive of the models on the spillover of constraints. Column 1 and 3 shows that a positive innovation to broker-dealer leverage factor is associated with reductions in the absolute level of the CIP basis and credit spread differential. Column 2 and 4 shows that a positive increase in the VIX index is associated with increases in the absolute level of the two deviations.

\section{References}

Augustin, P., Chernov, M., and Song, D. (2018). Sovereign credit risk and exchange rates: evidence from CDS quanto spreads. Unpublished working paper. NBER.

Becker, B. and Ivashina, V. (2015). Reaching for yield in the bond market. The Journal of Finance, $70(5): 1863-1902$.

Boermans, M. A., Frost, J., and Bisschop, S. S. (2016). European bond markets: Do illiquidity and concentration aggravate price shocks? Economics Letters, 141:143-146.

Bordalo, P., Gennaioli, N., and Shleifer, A. (2018). Diagnostic expectations and credit cycles. The Journal of Finance, 73(1):199-227.

Buraschi, A., Menguturk, M., and Sener, E. (2015). The geography of funding markets and limits to arbitrage. Review of Financial Studies, 28(4):1103-1152.

Choi, J. and Kronlund, M. (2017). Reaching for yield in corporate bond mutual funds. The Review of Financial Studies, 31(5):1930-1965. 
Della Corte, P., Sarno, L., Schmeling, M., and Wagner, C. (2018). Exchange rates and sovereign risk. Unpublished working paper. Imperial College Business School, City University London, Goethe University Frankfurt, and WU Vienna University of Economics and Business.

Du, W. and Schreger, J. (2016). Local currency sovereign risk. Journal of Finance, 71(3):1027-1070.

Du, W., Tepper, A., and Verdelhan, A. (2018). Deviations from covered interest rate parity. The Journal of Finance, 73(3):915-957.

Duffie, D. (2010). Presidential address: Asset price dynamics with slow-moving capital. The Journal of finance, 65(4):1237-1267.

Froot, K. A., Scharfstein, D. S., and Stein, J. C. (1993). Risk management: Coordinating corporate investment and financing policies. the Journal of Finance, 48(5):1629-1658.

Giglio, S. (2016). Credit default swap spreads and systemic financial risk. Unpublished working paper. ESRB.

Greenwood, R. and Hanson, S. G. (2013). Issuer quality and corporate bond returns. Review of Financial Studies, 26(6):1483-1525.

Greenwood, R., Hanson, S. G., and Jin, L. J. (2019). Reflexivity in credit markets. National Bureau of Economic Research.

Greenwood, R. and Vayanos, D. (2010). Price pressure in the government bond market. The American Economic Review, 100(2):585-590.

Ivashina, V., Scharfstein, D. S., and Stein, J. C. (2015). Dollar funding and the lending behavior of global banks. The Quarterly Journal of Economics, 1241:1281.

Kremens, L. (2018). Leaving a mark on the euro. Unpublished working paper. London School of Economics.

Lando, D. and Bang Nielsen, A. (2018). Quanto CDS spreads. Unpublished working paper. Copenhagen Business School.

López-Salido, D., Stein, J. C., and Zakrajšek, E. (2017). Credit-market sentiment and the business cycle. The Quarterly Journal of Economics, 132(3):1373-1426.

Mano, R. (2013). Exchange rates upon sovereign default. Unpublished working paper. International Monetary Fund.

Mitchell, M., Pedersen, L. H., and Pulvino, T. (2007). Slow moving capital. American Economic Review, $97(2): 215-220$.

Pozsar, Z. (2016). Global money notes. Credit Suisse.

Rampini, A. A. and Viswanathan, S. (2010). Collateral, risk management, and the distribution of debt capacity. The Journal of Finance, 65(6):2293-2322.

Siriwardane, E. N. (2019). Limited investment capital and credit spreads. Journal of Finance, 74:2303-2347.

Tuckman, B. and Porfirio, P. (2003). Interest rate parity, money market basis swaps, and cross-currency basis swaps. Fixed income liquid markets research, Lehman Brothers. 


\section{Appendix Tables}

Table 1 Bond data summary

\begin{tabular}{cccccc}
\hline & & \multicolumn{2}{c}{ All bonds } & \multicolumn{2}{c}{ June 2016 outstanding } \\
& & Number & Notional $\$$ bil & Number & Notional $\$$ bil \\
\hline currency & all & 34,945 & 23,217 & 18,746 & 11,970 \\
& USD & 12,530 & 9,732 & 6,273 & 5,053 \\
& EUR & 8,608 & 9,257 & 4,776 & 4,572 \\
JPY & 8,152 & 1,969 & 4,814 & 1,049 \\
& GBP & 1,492 & 945 & 848 & 637 \\
rating & CAD & 1,124 & 516 & 542 & 246 \\
& CHF & 2,017 & 478 & 1,015 & 241 \\
& AUD & 1,022 & 319 & 478 & 171 \\
& AA- or higher & 11,937 & 10,780 & 5,561 & 4,614 \\
& A+ to BBB- & 13,633 & 9,367 & 7,736 & 5,564 \\
HY $($ BB + or lower $)$ & 1,898 & 1,119 & 975 & 676 \\
& NA & 7,477 & 1,951 & 4,474 & 1,117 \\
& $1-3 y r s$ & 1,259 & 967 & 131 & 86 \\
& $3-7$ yrs & 14,704 & 10,480 & 4,898 & 3,146 \\
& $7-10$ yrs & 4,736 & 2,941 & 3,030 & 1,909 \\
& $10 y r+$ & 14,246 & 8,829 & 10,687 & 6,828 \\
\hline
\end{tabular}

This table presents the summary of the merged data set for all bonds (including matured bonds) and outstanding bonds in June 2016. For the first two columns which summarize all bonds, maturity and rating are categorized based on the first occurrence of each bond in the data set (typically at issuance). For the last two columns which summarize debt outstanding on June 2016, maturity is categorized based on the remaining maturity of each bond.

Table 2 Quanto CDS-implied currency depreciation

\begin{tabular}{ccccccc}
\hline Entity type & $\mathrm{N}$ & $\begin{array}{c}\text { \# dealers } \\
\text { mean }\end{array}$ & $\begin{array}{c}\text { \# dealers } \\
\text { s.d. }\end{array}$ & $\begin{array}{c}\text { \% depre. } \\
\text { median }\end{array}$ & $\begin{array}{c}\text { \% depre. } \\
\text { mean }\end{array}$ & $\begin{array}{c}\text { \% depre. } \\
\text { s.d. }\end{array}$ \\
\hline \hline Eurozone firms & 147 & 7.13 & 2.53 & 0.00 & -0.02 & 0.53 \\
\hline Japan firms & 82 & 5.91 & 1.76 & 1.6 & 7.3 & 15.2 \\
\hline Eurozone gov. & 12 & 4.95 & 1.93 & 31.4 & 35.4 & 25.1 \\
\hline Japan gov. & 1 & 5.74 & 1.78 & 65.2 & 67.8 & 14.0 \\
\hline
\end{tabular}

This table shows the implied local currency (LC) depreciation upon default using CDS contracts that are matched for the same entity, doc clause, and tier. The implied depreciation is calculated as $(C D S(\$)-C D S(L C)) / C D S(\$)$ and is expressed as a percentage. The sample period is from August 2010 to July 2017. The statistics are calculated pooling across time and entities in each category. 


\section{Table 3 Broker-dealer leverage and risk tolerance}

This table presents the regression of the absolute level of deviations on broker-dealer leverage and the VIX index. Broker-dealer leverage factor is constructed following Adrian, Etula and Muir (2014) using the Flow of Funds data.

\begin{tabular}{ccccc}
\hline & \multicolumn{2}{c}{ CIP basis $|x|$} & \multicolumn{2}{c|}{ credit diff. $|\kappa|$} \\
\hline levfac $\gamma^{-1}$ & -1.755 & & -4.916 \\
& {$[-2.26]$} & & {$[-3.40]$} & \\
vix $\tau^{-1} V$ & & 0.499 & & 0.932 \\
& & {$[3.25]$} & & {$[4.15]$} \\
\multirow{2}{*}{ cons } & 18.37 & 9.589 & 17.83 & 0.947 \\
& {$[8.09]$} & {$[2.40]$} & {$[8.70]$} & {$[0.21]$} \\
$\mathrm{N}$ & 288 & 906 & 288 & 906 \\
\hline
\end{tabular}

\section{Appendix Figures}

\section{Figure 1 Additional Controls}

This figure presents the credit spread differential between bonds denominated in different currencies relative to US dollar. The solid red line is the residualized credit spread differential constructed based on the specification in the main text. The dotted blue line is estimated with cross-sectional regressions that control for the amount outstanding, the age of the bond relative to maturity, governance law and the seniority of the bond in addition to maturity bucket, rating, and firm.

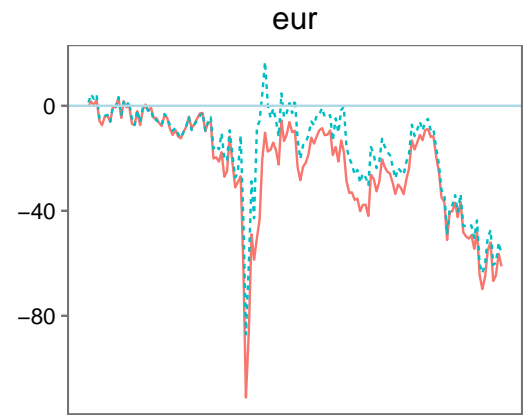

2004200620082010201220142016

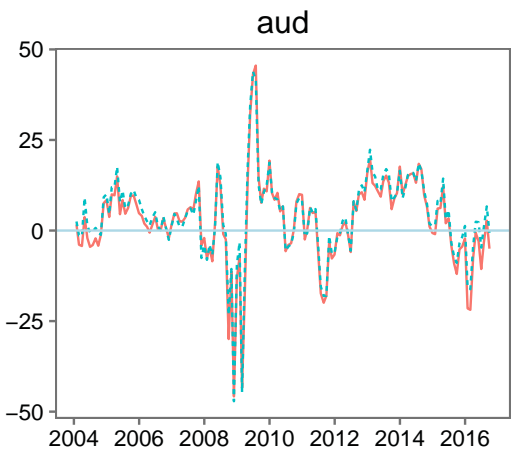

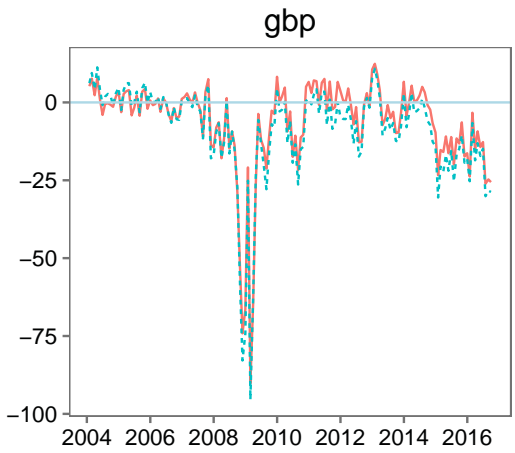
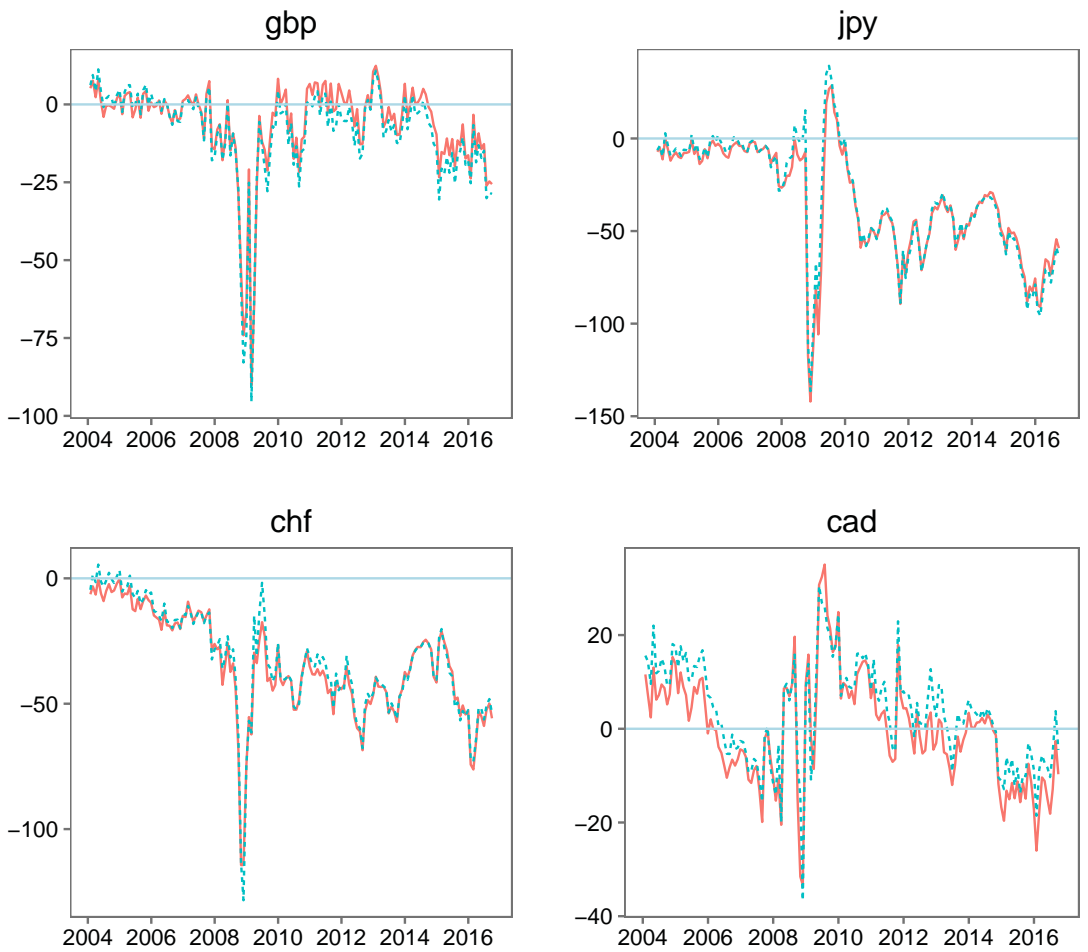

— residualized credit spread diff. - - - with additional controls 
Figure 2 Low-grade vs high-grade credit spread differential in other currencies

This figure presents the credit spread differential between bonds denominated in different currencies relative to US dollar for low-grade and high-grade bonds. High grade bonds are defined as bonds with single-A or higher rating by Moody. I estimate the following cross-sectional regression at each date $t$ for low-grade and high-grade bonds separately

$$
S_{i t}=\alpha_{c t}+\beta_{f t}+\gamma_{m t}+\varepsilon_{i t}
$$

where $S_{i t}$ is the yield spread over the swap curve for bond $i$ that is issued in currency $\kappa$, by firm $f$, and with maturity $m$. The residualized credit spread of currency $\kappa$ relative to dollar is defined as $\hat{\alpha}_{c, t}-\hat{\alpha}_{u s d, t}$.
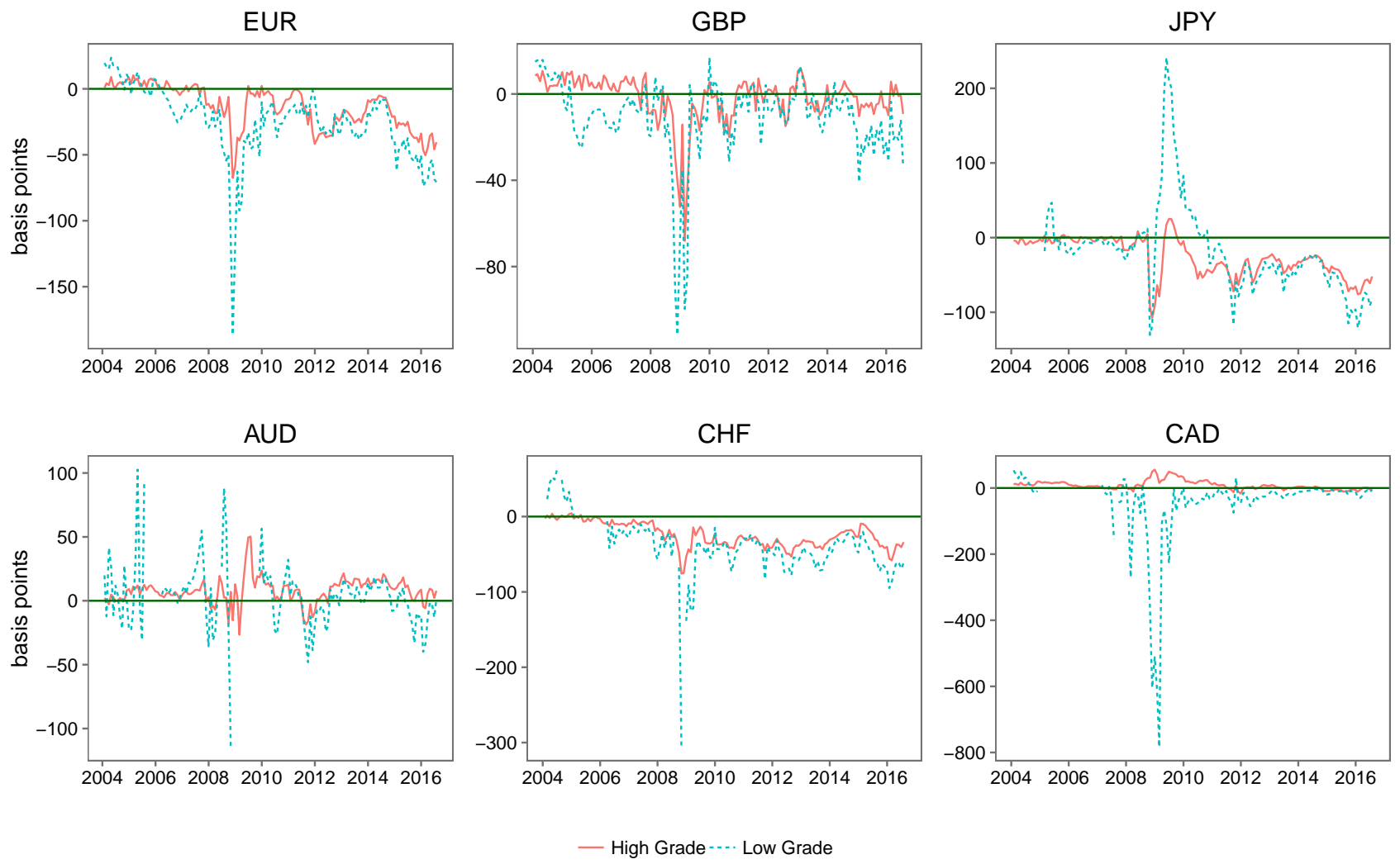


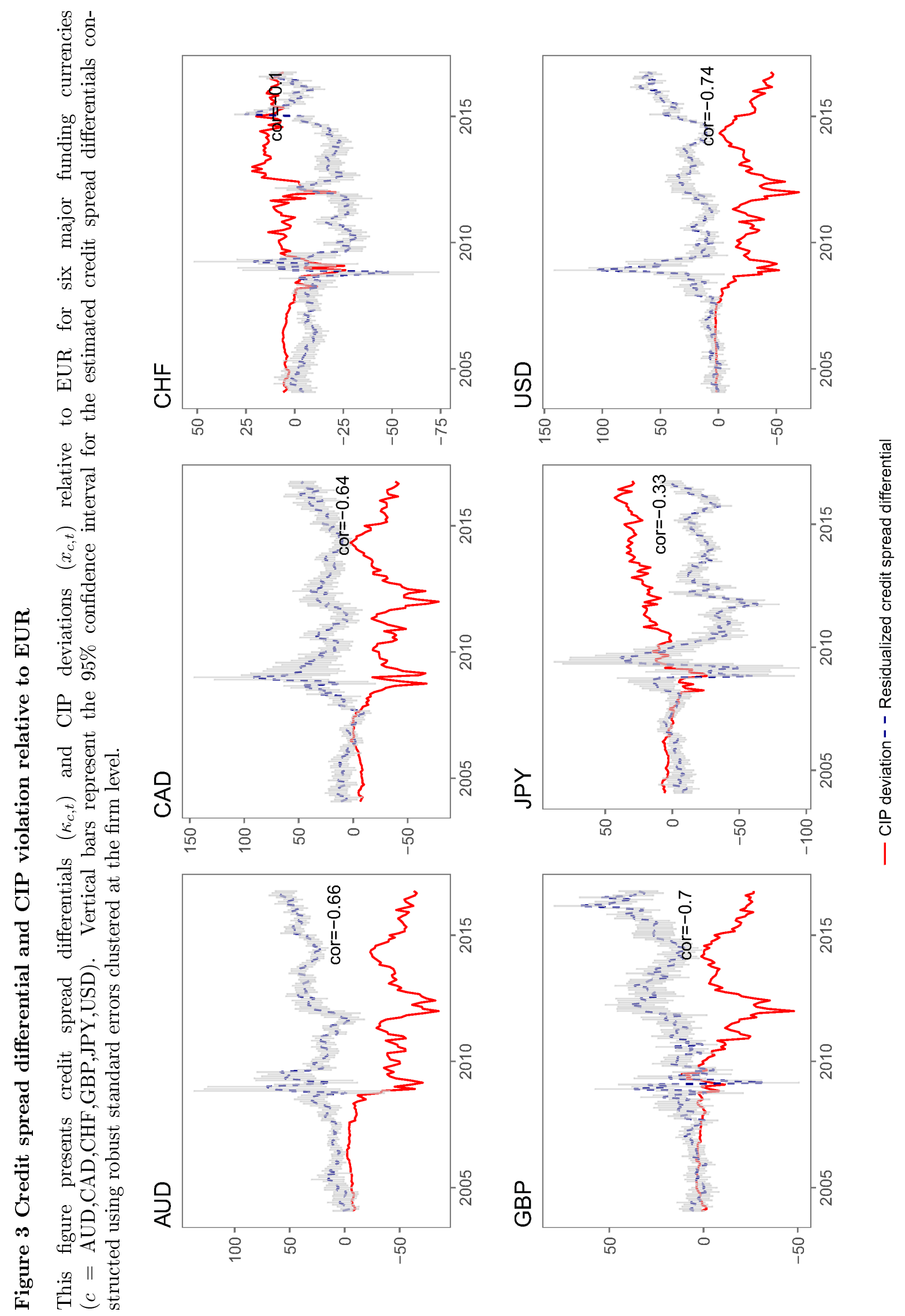




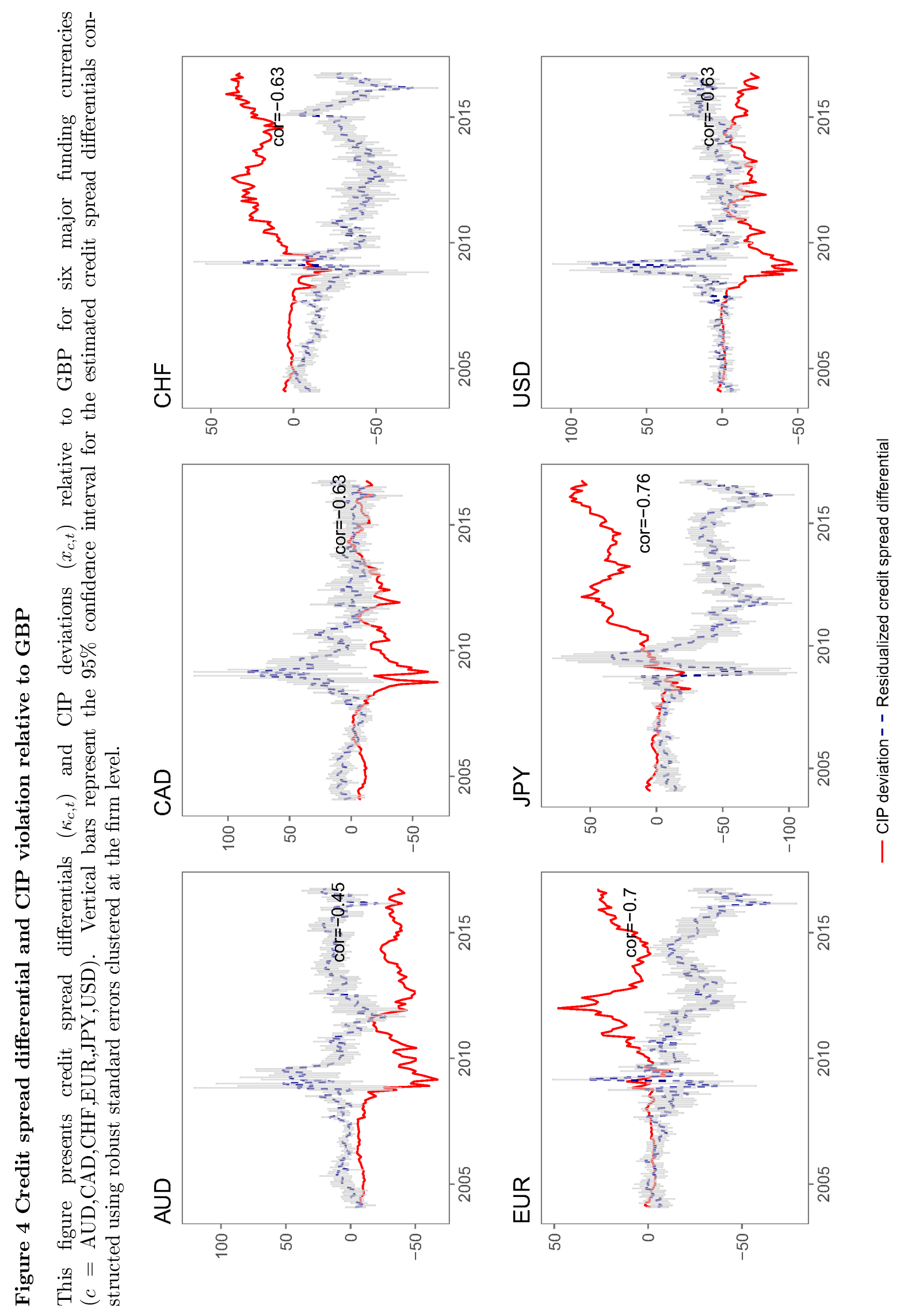




\section{Figure 5 Cross-sectional test for default-depreciation covariance}

This figure shows the cross-sectional relationship between the residualized credit spread differential and credit betas for each currency. $\bar{\kappa}$ is the time averaged residualized credit spread differential for each currency. $\hat{\beta}_{c}$ is estimated from the time series regression $r_{c, t}=\alpha+\beta_{c} r_{c o r p, t}+\varepsilon_{t}$, where $r_{c, t}$ is the monthly (log) return of currency $c$ against the dollar, and $r_{c o r p, t}$ is the monthly $(\log )$ return of the ICE Bank of America Merrill Lynch Corporate Bond Master Index in excess of the five-year treasuries return. The sample period for the betas estimate is from 1999:01 (when the EUR was introduced) to 2016:12.

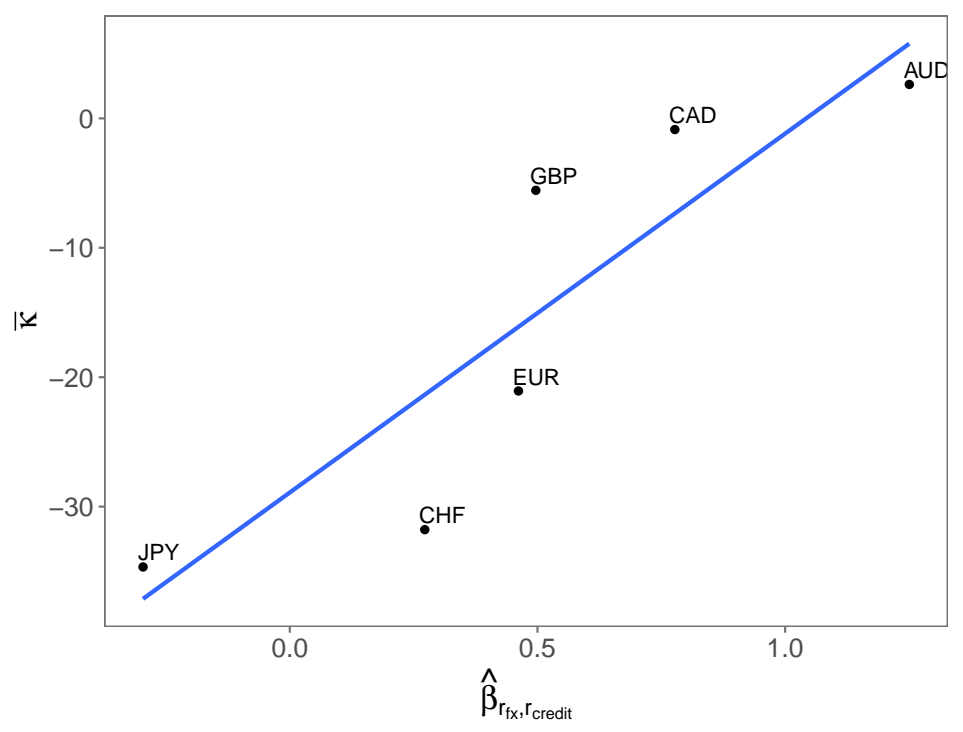




\section{Figure 6 Cross-currency basis swap cash flows}

This figure decomposes the cash flows of a lend EUR/borrow USD (receive Euribor + basis versus pay $\$$ Libor) cross-currency basis swap into two floating-rate notes (FRNs) in EUR and USD. The euro lending cash flows are shown in blue and the dollar borrowing cash flows are shown in red. Upward arrows represent payments and downward arrows represent receivables. An initial exchange of $\hat{A} € 1$ for $\$ 1.1$ (at the spot FX rate) is made at the swap initiation date. Floating rate coupons based on the Euribor and \$Libor reference rates are exchanged every quarter in the interim. A final exchange of the original principal amount (at the initial FX rate) is made at the maturity date. The other counterparty of this swap holds a borrow EUR/lend USD position and the reverse of the cash flows shown below.
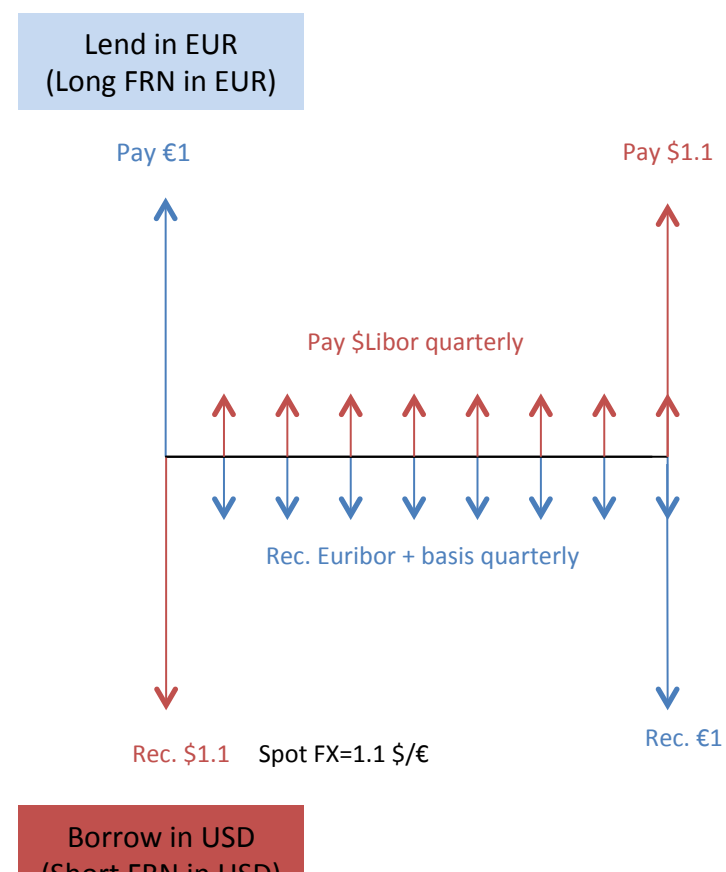

(Short FRN in USD) 


\section{Figure 7 Cross-currency basis swap with OIS rates}

This figure presents a comparison of cross-currency basis swaps $\left(-x_{t}\right)$ with short-term reference rates as LIBOR (Red) and OIS rate (Blue) for EUR, GBP, and JPY at the five year maturity. The OIS-based cross-currency bases swap rates are from ICAP.

Panel A: EUR

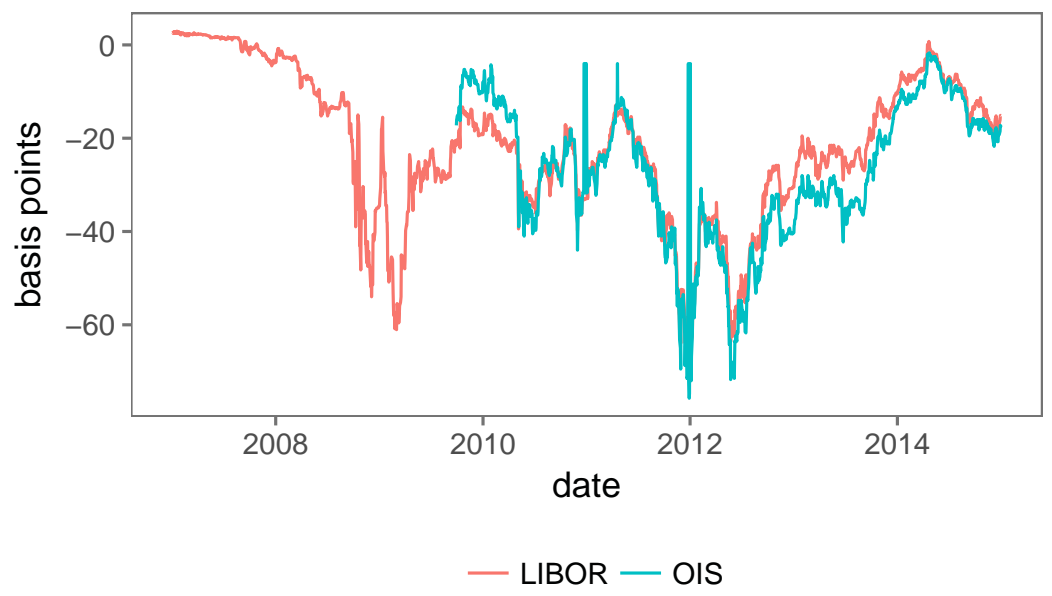

Panel B: GBP

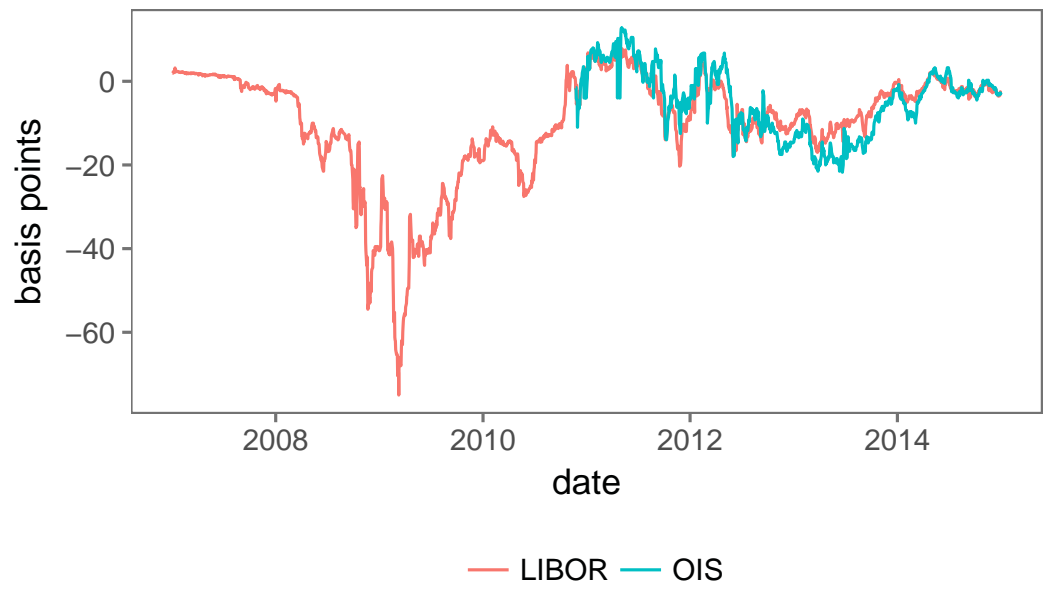

Panel C: JPY

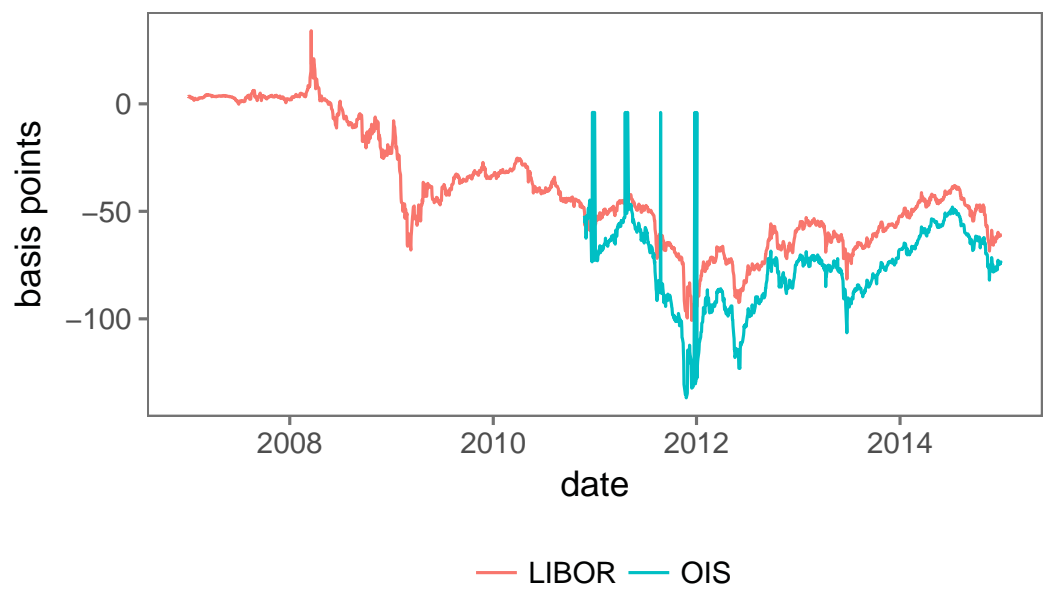




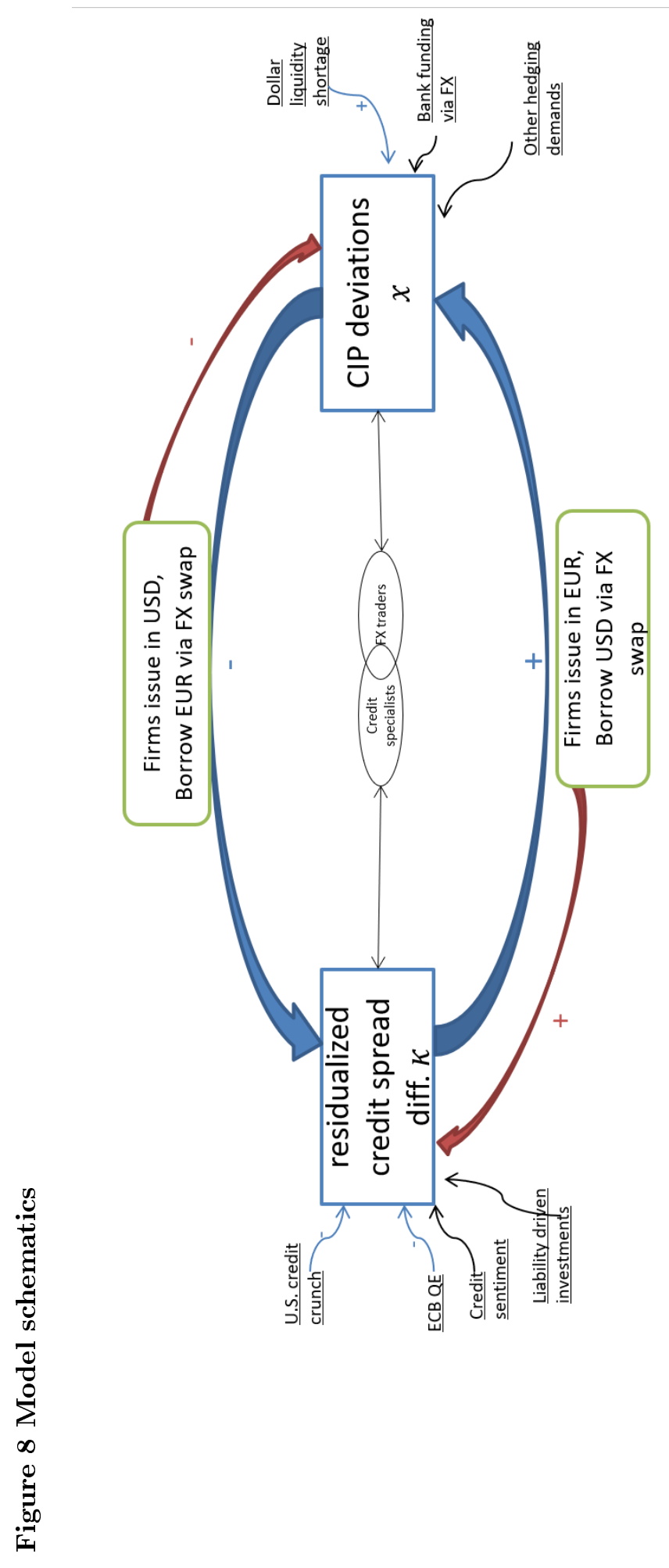




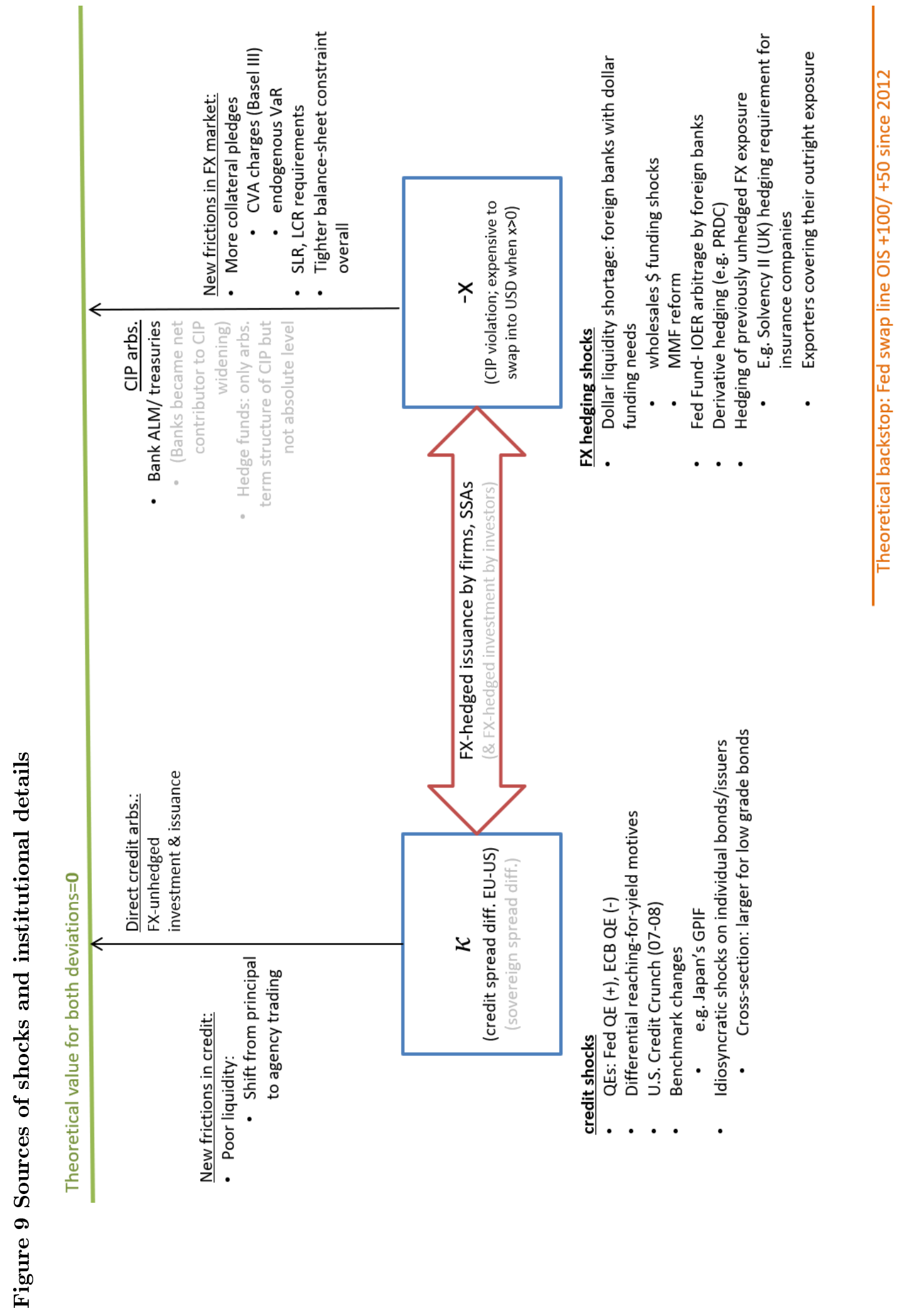


Figure 10 Spillover of deviations: partially identified impulse responses of deviations and issuance flow for EURUSD

I estimate a first order vector autoregression (VAR) of the form

$$
\left[\begin{array}{ccc}
1 & & \\
a_{\kappa \mu} & 1 & a_{\kappa x} \\
a_{x \mu} & a_{x \kappa} & 1
\end{array}\right]\left[\begin{array}{l}
\mu_{t} \\
\kappa_{t} \\
x_{t}
\end{array}\right]=B\left[\begin{array}{c}
\mu_{t-1} \\
\kappa_{t-1} \\
x_{t-1}
\end{array}\right]+\left[\begin{array}{l}
\varepsilon_{\mu, t} \\
\varepsilon_{\kappa, t} \\
\varepsilon_{x, t}
\end{array}\right]
$$

I apply a partial identification method by assuming that issuance flow responds with a lag to both $\varepsilon_{\kappa}$ and $\varepsilon_{x}$ shocks, but $x$ and $\kappa$ has no ordering with respect to each other. The orthogonalized impulse responses to $\varepsilon_{\kappa}$ and $\varepsilon_{x}$ shocks are graphed below. The choice of lag 1 is selected by Bayesian Information Criteria. Confidence intervals at the $95 \%$ level using bootstrapped standard errors are shown in gray.

Foreign credit demand shock: $\varepsilon_{\kappa} \uparrow$
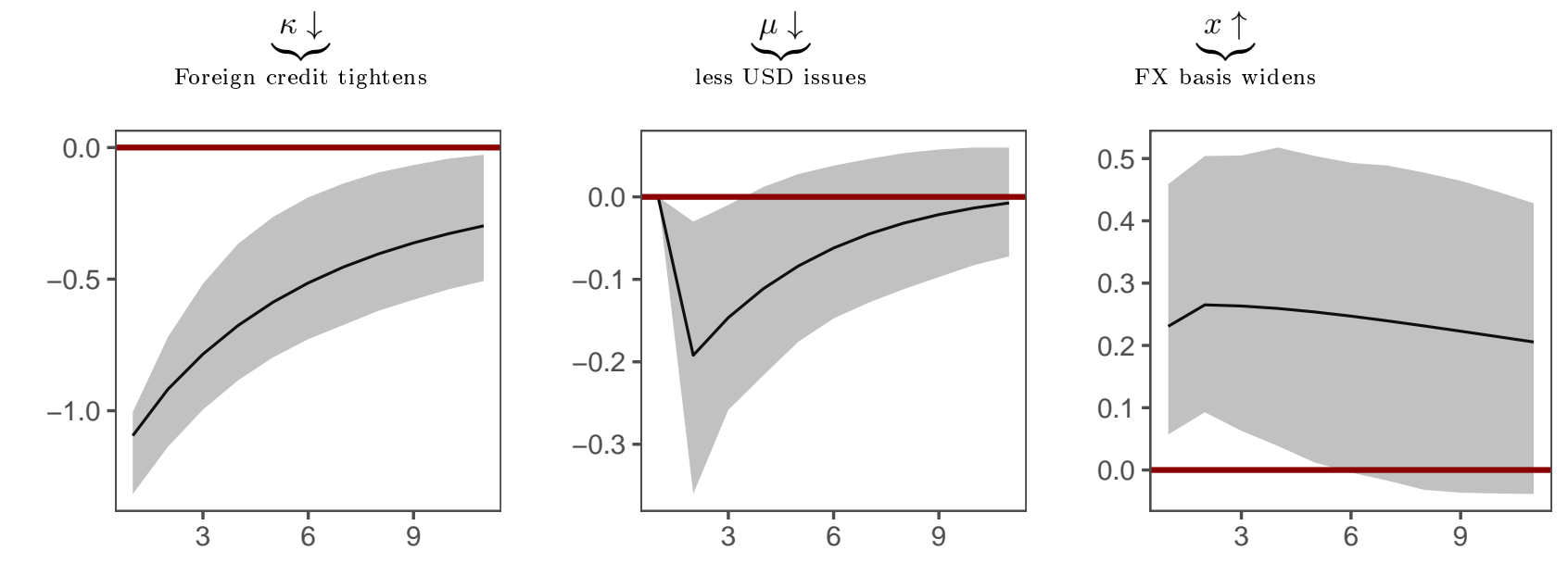

Dollar liquidity shock: $\varepsilon_{x} \uparrow$
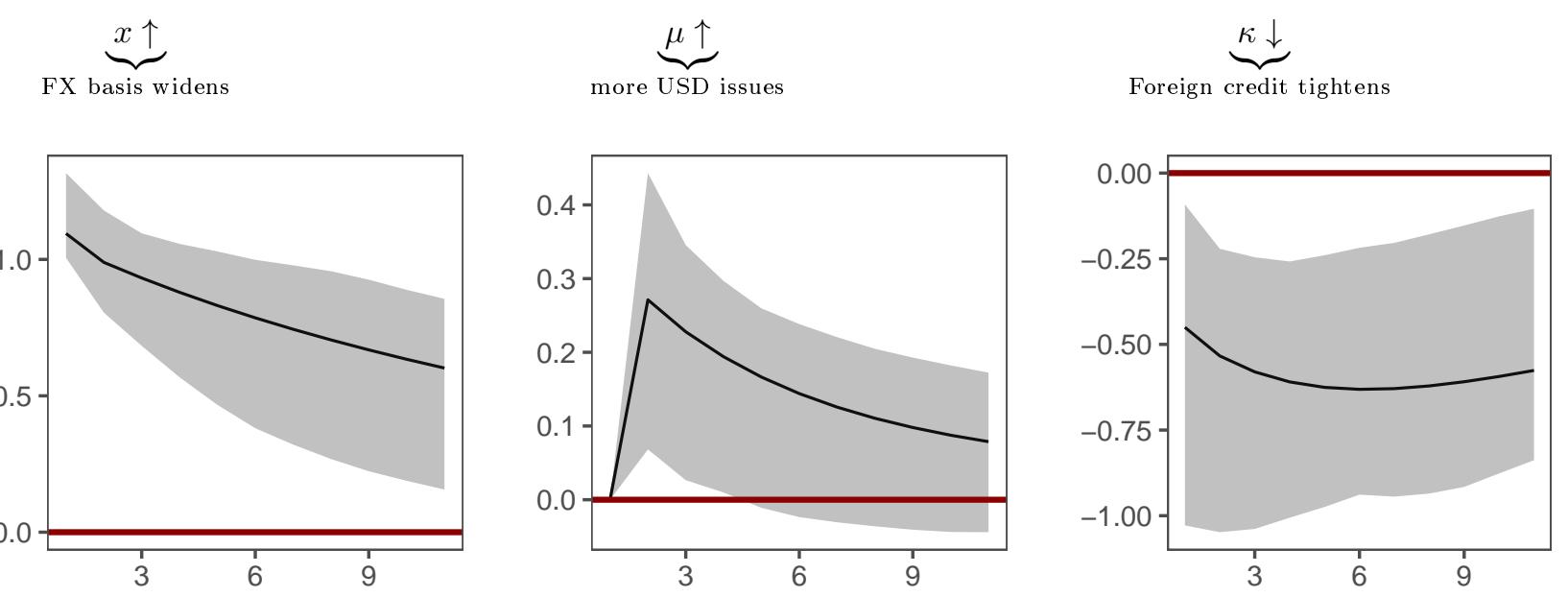